\title{
USDA
}

\section{Assessment of Forest Sector Carbon Stocks and Mitigation Potential for the State Forests of Pennsylvania}

A report for the Pennsylvania Department of Conservation and Natural Resources

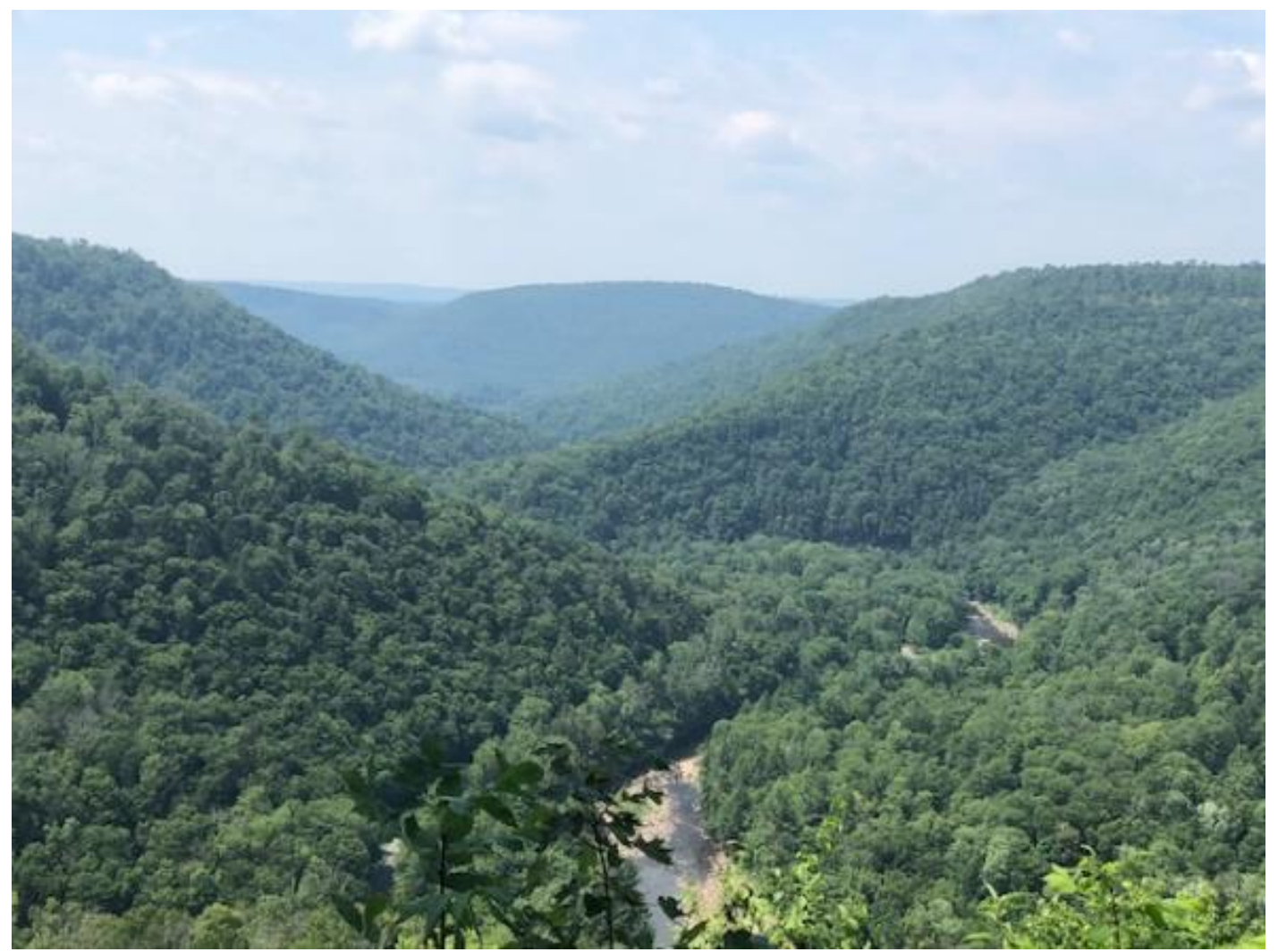




\title{
Assessment of Forest Sector Carbon Stocks and Mitigation Potential for the State Forests of Pennsylvania
}

\section{A report for the Pennsylvania Department of Conservation \& Natural Resources}

\author{
Alexa J. Dugan \\ Al Steele \\ David Hollinger \\ Richard Birdsey \\ Jeremy Lichstein
}

\section{The Authors}

ALEXA DUGAN is a Natural Resource Specialist with the U.S. Forest Service, Northern Research Station, 11 Campus Blvd, Ste 200, Newtown Square, PA 19125, adugan@fs.fed.us

AL STEELE is a Physical Scientist with the U.S. Forest Service, Northeastern Area, 180 Canfield St, Morgantown, WV 26505, asteele@fs.fed.us

DAVID HOLLINGER is the Project Leader of the Climate, Fire, and Carbon Cycle Sciences Unit and the Director of the USDA Northeast Regional Climate Hub at the U.S. Forest Service Northern Research station, 271 Mast Rd, Durham, NH 03824, dholling@fs.fed.us

RICHARD BIRDSEY is a U.S. Forest Service volunteer and Senior Scientist with the Woods Hole Research Center, 149 Woods Hole Road, Falmouth, MA 02540, rbirdsey@whrc.org

JEREMY LICHSTEIN is a Forest Ecologist in the Biology Department, University of Florida, Gainesville, FL 32611, jlichstein@ufl.edu 


\section{Contents}

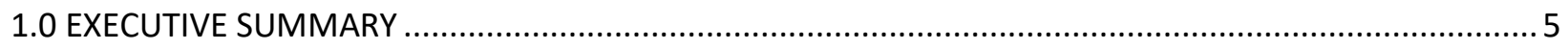

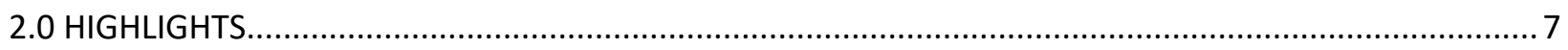

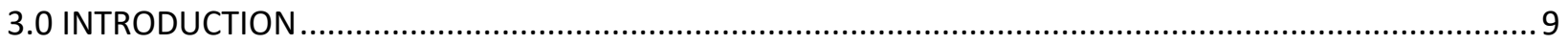

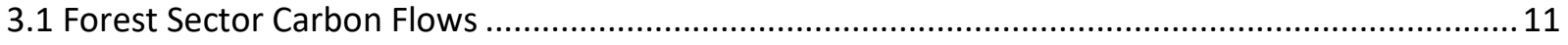

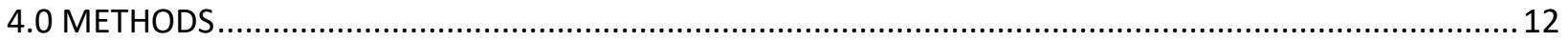

4.1 Study Area

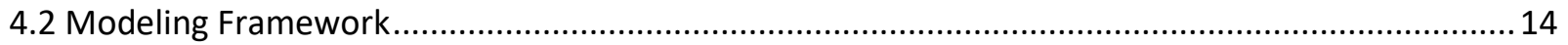

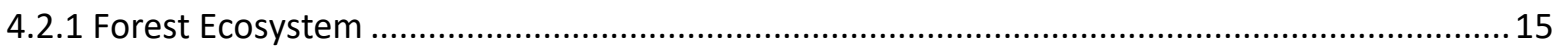

4.2.2 Harvest Wood Products and Substitution Benefits ................................................................19

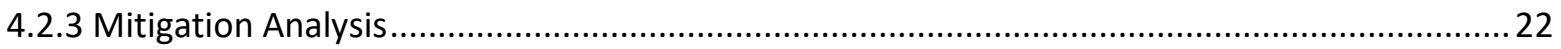

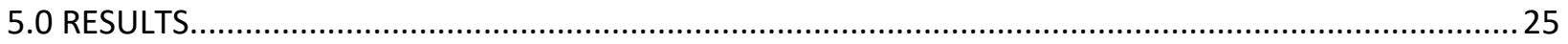

5.1 Past and Prospective Carbon Stocks and Emissions in Forests and Wood Products.......................25

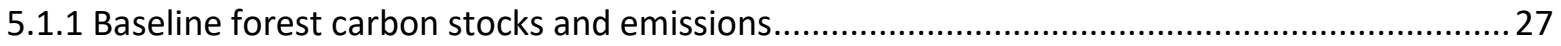

5.1.2 Baseline harvested wood products carbon stocks and emissions ..........................................30

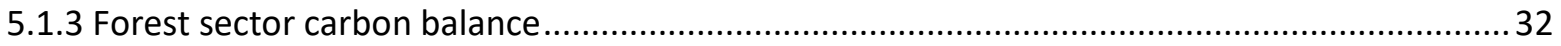

5.1.4 Factors influencing forest ecosystem carbon trends .......................................................... 33

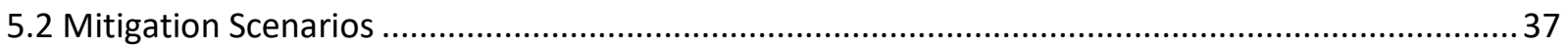

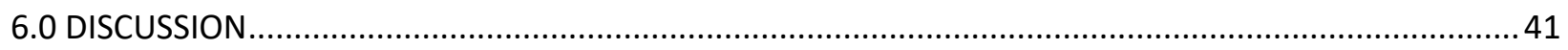

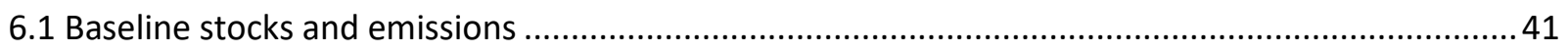

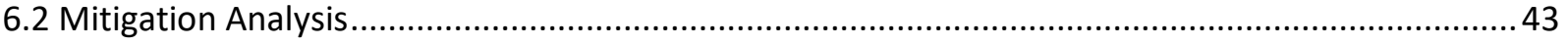

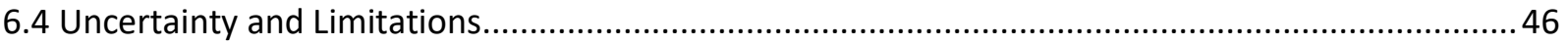

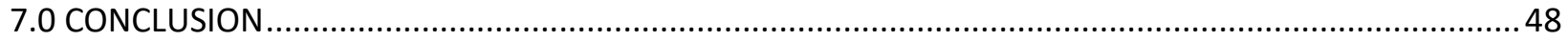

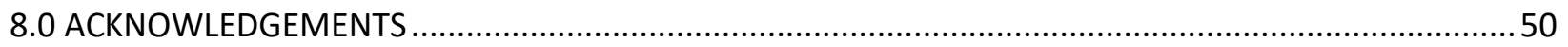

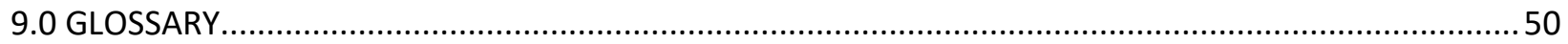

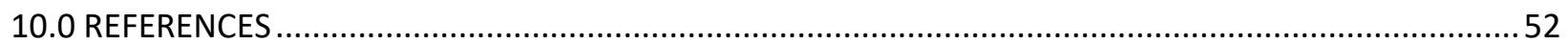

11.0 APPENDIX

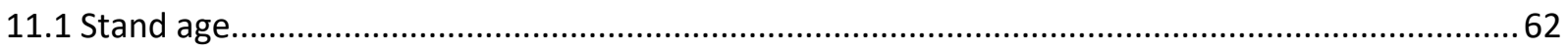

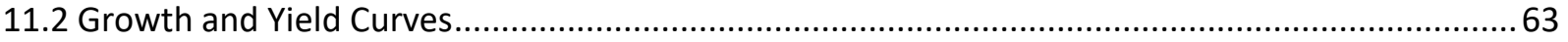

11.3 Forest ecosystem emissions with instantaneous oxidation of harvested wood ...........................64

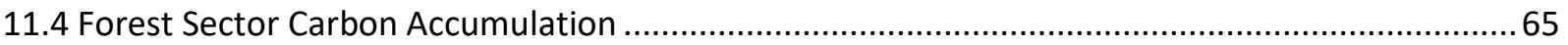




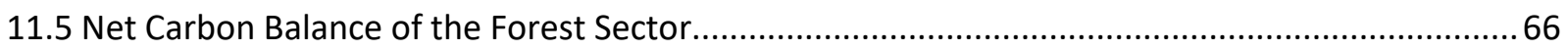

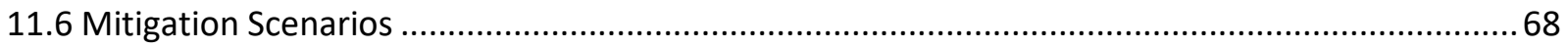

11.7 Model Comparison: Forest Carbon Stocks.............................................................................. 73

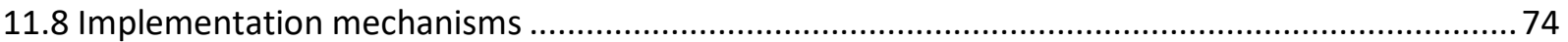




\subsection{EXECUTIVE SUMMARY}

Forests and their products provide many benefits including clean water, recreation, wildlife habitat, wood products, energy, as well as carbon sequestration and climate change mitigation. This project assesses past and future carbon sequestration and mitigation potential across the forest sector of Pennsylvania with a focus on State Forest lands. This research resulted from a collaboration between the U.S. Forest Service and the Pennsylvania Department of Conservation and Natural Resources (PA DCNR). The objectives were to: 1 ) develop a baseline assessment of carbon stocks and sequestration rates on State Forests, 2) compare State Forest carbon stocks and carbon uptake (sequestration) rates to the other land ownerships in PA, and 3) evaluate the impacts of various forest management and product sector climate change mitigation scenarios on forest sector carbon sequestration through 2050.

A complete analysis of forest sector carbon trends and climate change mitigation potential requires a systems-based approach, which examines net emissions from all forest sector components. These components include the forest ecosystem, harvested wood products, and the avoided emissions from substituting wood-based products for emission-intensive construction materials and fossil fuel-based energy. To conduct this research, we applied such a systems-based approach within a carbon modeling framework which includes: 1) a growth and yield based ecosystem model-the Carbon Budget Model of the Canadian Forest Sector, 2) a lifecycle harvested wood products model-the Carbon Budget Modelling Framework for Harvested Wood Products, and 3) published displacement factors to evaluate substitution benefits.

The results presented here are to be viewed as estimates of carbon stocks, emissions, and mitigation potential. These estimates are contingent on the models and datasets used, which all contain some levels of uncertainty. Results of this analysis indicate that between 1990 and 2017 the forest ecosystem of State Forests stored on average an estimated 243.2 tonnes (metric tons) of carbon per hectare. This was greater than carbon storage on Private and Other Public lands, but less than National Forest lands. State Forests sequestered approximately 9.3 tonnes (metric tons) carbon per hectare from 1990 to 2017. Carbon stocks are expected to continue to increase on public lands in the state, including State Forests causing forests to maintain a carbon sink through 2050. However, as forests age, the strength of this carbon sink is projected to decline due to increased mortality and lower growth rates. Of all ownerships, State Forests have relatively older stand ages which has led to the slower rates of carbon uptake over the past few decades. A loss of forestland on Private lands, combined with aging effects may cause Private lands to shift to a carbon source. However, when accounting for carbon stored in harvested wood products along with forest ecosystem, all ownerships in the state will maintain carbon sinks through 2050.

Results of the mitigation analysis indicate that extending harvest rotations and increasing the proportion of wood commodities used for long-lived products have the highest mitigation potential between 2020 and 2050. Combining multiple management actions that target rotations, residue use and productivity or other combinations of forest management and product strategies may also be effective. Scenarios aimed at increasing bioenergy production resulted in both reductions and increases in emissions depending on the feedstock used and the shift in the proportion of other wood products. While this study provides an evidence-based quantitative evaluation of the biophysical forest sector mitigation potential, it is critical to also consider the socio-economic effects as well as cost effectiveness and 
feasibility of applying forest sector mitigation strategies. Carbon uptake and storage is just one of the many benefits that these diverse, multi-use forests provide. If enhancing carbon sequestration is a

management goal, it is important to consider it along with other management objectives as well as its impacts on other critical forest benefits.

\section{Key Words}

Carbon storage and sequestration, climate change mitigation, bioenergy, wood products, Pennsylvania forests 


\subsection{HIGHLIGHTS}

The results presented here are estimates and projections that are based on models and datasets containing a range of uncertainties.

Forest Ecosystem

- From 1990 through 2017, average carbon stock density was highest on the Allegheny National Forest, followed by State Forest lands, while stock density was lowest on Private lands.

- The Allegheny National Forest experienced the greatest increase in forest ecosystem carbon stocks from 1990 to 2017, while Private lands and State Forest lands had the lowest.

- From 1990 through 2017, total ecosystem carbon stocks on State Forests have increased by an estimated 7.7 million tonnes $\left(9.3 \mathrm{t} \mathrm{Cha}^{-1}\right)$ for a rate of about 0.29 million tonnes per year.

- The rate of carbon sequestration has been declining across all ownerships and if current conditions and disturbance rates persist into the future, sequestration is expected to continue to decline through 2050.

- The decline in the strength of the carbon sink is largely the result of forest stands aging. State Forests have generally older age classes, with over $70 \%$ of stands 80 years and older. While older forests typically store more carbon, their productivity (growth rate) is lower and emissions are higher due to greater morality and respiration from decay of dead organic matter.

- Results here indicate that forest ecosystem emissions on Private lands would have been roughly $20 \%$ lower in 2017 if there had not been forest cover loss from 1990 through 2017.

\section{Harvested Wood Products}

- From 1990 to 2017, HWP from State Forests sequestered roughly 2.8 million tonnes of carbon (3.4 t C ha-1) for a rate of about 0.10 million tonnes per year, which accounts for roughly $11 \%$ of all carbon sequestered in wood products in the state.

- HWP accounted for approximately $30 \%$ of this increase in carbon storage for State Forests, while the forest ecosystem which mostly experienced increases in aboveground live biomass, accounted for the other $70 \%$.

- Private forests followed by State Forests have accumulated the most carbon in HWP per hectare since 1990.

- Across ownerships most of the harvested wood carbon has been stored in sawlogs followed by pulpwood. The majority of HWP emissions are from short-lived products including the use of mill residues for bioenergy and pulpwood. Products with longer retention times store carbon for longer and thus have lower annual emissions.

\section{Forest Sector Mitigation}

- Of the 10 mitigation scenarios we evaluated on State Forests, extending harvest rotations to 130 years, which results in a decrease in annual harvest removals, is projected to have the greatest cumulative mitigation benefit from 2020 through 2050, reducing emissions by an estimated $6 \%$. 
- A portfolio of management scenarios that were applied simultaneously including a more modest extended rotation (100 years), increasing productivity, and collecting additional harvest residues for bioenergy ranked second, reducing cumulative emissions by roughly $3.7 \%$ by 2050 .

- Increasing the proportion of commodities used for long-lived wood products also had a mitigation potential ( $2.7 \%$ emission reduction) because it reduced HWP emissions and displaced emissions from alternative fossil fuel intensive materials.

- Of the bioenergy scenarios evaluated here, increasing the use of logging residues for bioenergy had a mitigation benefit (1.4\% emission reduction) as well as shifting harvested wood from pulpwood production to bioenergy (1.7\% emission reduction).

- Shortening harvest rotations and using the additional roundwood for bioenergy is projected to increase cumulative emissions by an estimated $3.2 \%$ by 2050. However, it may take several decades and multiple rotations for the forest system to accrue the carbon removed from additional harvesting and emitted from biomass burning.

- Shifting materials from long-lived products to bioenergy is also projected to cause a small net increase in emissions of approximately $0.96 \%$ by 2050.

- If forest loss due to natural gas expansion or urban development were to continue to expand across State Forests, the impacts of deforestation $(4,700$ ha by 2050$)$ may cause a cumulative $1.6 \%$ increase in emissions by 2050 . The impacts of deforestation would continue to accrue overtime as each year the carbon that would have been sequestered in growing trees is foregone. 


\subsection{INTRODUCTION}

Since the industrial era, human activities including fossil fuel burning, land use change and agriculture have led to the dramatic rise of greenhouse gas (GHG) emissions altering the planet's climate (IPCC 2007). The increase the Earth's surface and ocean temperatures have contributed to numerous changes such as increased rate and severity of tropical storms and wildfires, sea-level rise, droughts, and species declines (NCA 2014). The Intergovernmental Panel on Climate Change suggests that significant reductions in GHG emissions will be needed to avoid the most harmful effects of climate change, recommends that this be achieved across all economic sectors (IPCC 2013).

Forests provide a variety of benefits including recreation, wood products, clean water, and carbon uptake (sequestration) and storage (Janowiak et al. 2017). The potential of forests to play a vital role in mitigating climate change has long been recognized, but also remains uncertain (Canadell and Raupach 2008, Lundmark et al. 2014, Wieder et al. 2015). As forests grow, they sequester carbon dioxide $\left(\mathrm{CO}_{2}\right)$ from the atmosphere, which offsets some fraction of human-caused GHG emissions. In the United States, forests make up the largest terrestrial carbon sink, offsetting roughly $12 \%$ to $19 \%$ of the GHG emissions from fossil fuel burning (Ryan et al. 2010, US EPA 2015). Assessing forest carbon trends and the factors that influence carbon sequestration and emissions in the forest sector can help to improve our understanding of the opportunities for forests and their products to play an enhanced role in the mitigation of climate change.

Forest sector mitigation strategies may be diverse and target land use change, forest ecosystems, and/or the wood products sector. For instance, strategies may aim to increase or maintain the area of forestland by reducing deforestation or implementing reforestation activities. Another option is to apply silvicultural treatments or to modify management practices to increase forest carbon density. On the other hand, reducing stand density in some forests may be necessary to enhance resistance to more frequent and severe disturbances that can have more damaging effects on carbon storage (Hurteau and North 2009). Also harvested wood products could be utilized in place of products that require more fossil-fuel energy to produce (e.g., steel, concrete, and plastic) Wood-based fuels (bioenergy) could be

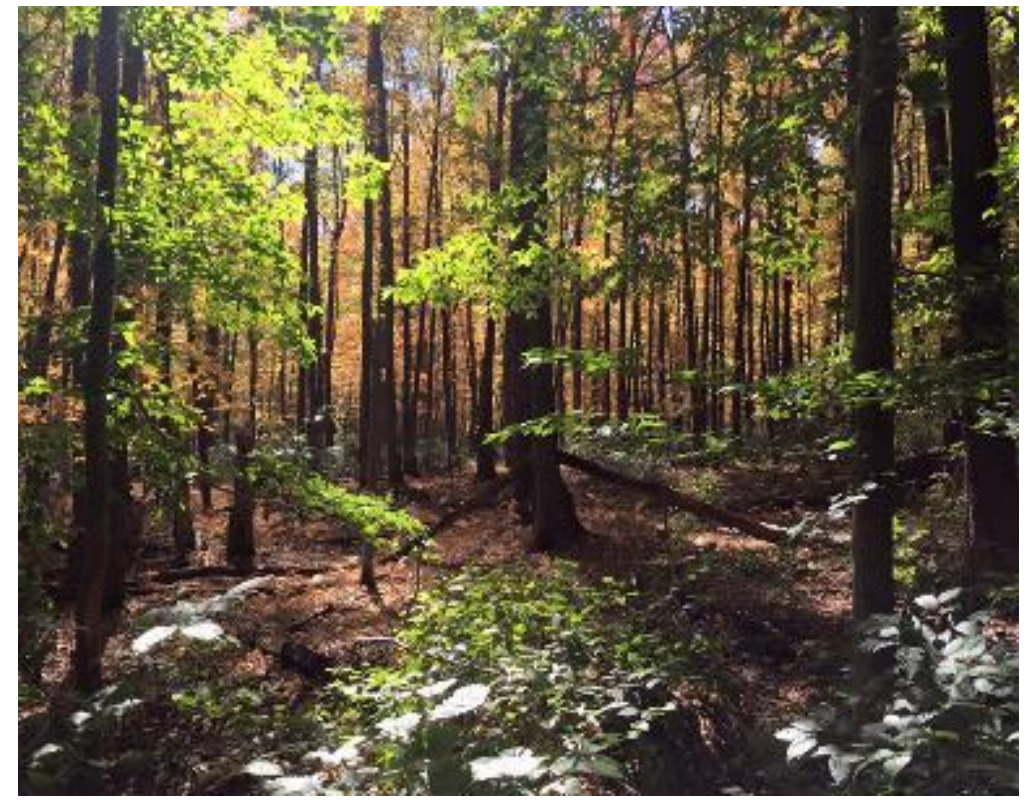

Elk State Forest, Photo by Alexa Dugan, U.S. Forest Service used directly in place of fossilfuel energy under some circumstances (Canadell and Raupauch 2008, Malmsheimer et al. 2008, McKinley et al. 2011, Birdsey et al. 2018).

Accurately quantifying how biophysical processes and management have impacted forest carbon dynamics historically is a necessary first step if the goal is to implement effective mitigation strategies now and in the future. The exchange of carbon between the forest and the atmosphere is driven by complex and interacting processes including 
growth and mortality, decay of dead organic matter, climate variability, the amount of $\mathrm{CO}_{z}$ in the, and natural and human-caused disturbances (Ryan et al. 2010). Ecosystem carbon models that integrate forest inventory datasets (e.g. Forest Inventory and Analysis; https://www.fia.fs.fed.us/), and remotelysensed disturbance and land use change products (e.g., Hansen et al. 2013, Homer et al. 2015, Goward et al. 2016) make it feasible to estimate forest carbon stocks and emissions. These tools and datasets also enable an assessment of the impacts of different factors on past and future carbon dynamics (Zhang et al. 2015, Raymond et al. 2015).

Carbon that is removed from the atmosphere by forests can be stored in the forest ecosystem in living biomass, coarse and fine litter (both above and belowground), and soil organic matter. Carbon is also stored outside the ecosystem in harvested wood commodities such as building materials and furniture. To fully evaluate forest carbon trends and management strategies that reduce forest sector emissions, it is necessary to use a systems approach that looks beyond the forest ecosystem. Carbon storage and emissions also need to be evaluated in the product sector, as well as the substitution benefits of using wood products in place of emission intensive materials and fuels (Nabuurs et al. 2007, Lemprière et al. 2013, Smyth et al. 2014).

We applied a systems-based approach to evaluate forest sector carbon sequestration and mitigation potential across the forests of Pennsylvania. Increasingly, state governments have pledged their support for reducing carbon emissions to mitigate the most harmful effects of climate change (Ray and Grannis 2015). State Forest lands comprise approximately $17 \%$ of the total forestland in the U.S. (Dilling et al. 2013) making them an important component of the U.S. carbon cycle. Although most of the 6.9 million hectares of Pennsylvania's forestland are privately owned, State Forests account for roughly 890,000 hectares (13\%) which are managed by the Pennsylvania Department of Conservation and Natural Resources (PA DCNR). As a land steward and the state's leading conservation agency, the PA DCNR has identified climate change as a principal forest stressor in Pennsylvania (DCNR 2015) and has outlined a strategic framework to address climate change through mitigation and adaptation (DCNR 2018). The latest PA DCNR Climate Change Adaptation and Mitigation Plan (DCNR 2018) has identified specific actions to enhance carbon sequestration on State Forest lands including adjusting timber rotations and avoiding conversion of forest to non-forest. We collaborated with the PA DCNR to evaluate past and prospective forest carbon trends and the biophysical impacts of a range of forest management and harvested wood products mitigation scenarios for State Forests and other ownerships in the state.

This study builds on past work that demonstrated the data, modeling tools, and analytical framework needed to evaluate forest sector climate change mitigation using case studies for selected sites in North American (Olguin et al. 2018, Smyth et al. in press, Dugan et al. in review). In this study, we worked in partnership with a land management institution to move from case study to the application of a carbon modeling framework to support land managers in their $t$ decision-making. However, we only assess the biophysical impacts of forest sector scenarios. An analysis of the socioeconomic implications and the costs, feasibility, or impacts on other ecosystem services associated with implementation of management strategies was outside the scope of this work.

Estimates of forest sector carbon stocks and emissions as well as mitigation potential were derived from forest inventory data and remotely sensed land-use change and disturbance datasets within a carbon modeling framework that includes: 1) a growth and yield based ecosystem model-the Carbon Budget Model of the Canadian Forest Sector, 2) a lifecycle harvested wood products model-the Carbon Budget Modelling Framework for Harvested Wood Products, and 3) published displacement factors for substituting wood fiber for fossil fuel-based energy or products. 


\subsection{Forest Sector Carbon Flows}

Forests interact with the atmosphere by both absorbing and emitting carbon. Live vegetation absorbs carbon from the atmosphere and stores it in the roots, wood, leaves, and bark of trees. As trees continue to grow, they periodically shed leaves and dead branches while some trees die. Microbes in the soil work to break down and decompose this dead organic matter, which releases $\mathrm{CO}_{2}$ back into the atmospheric (decomposition) (Fig. 1).

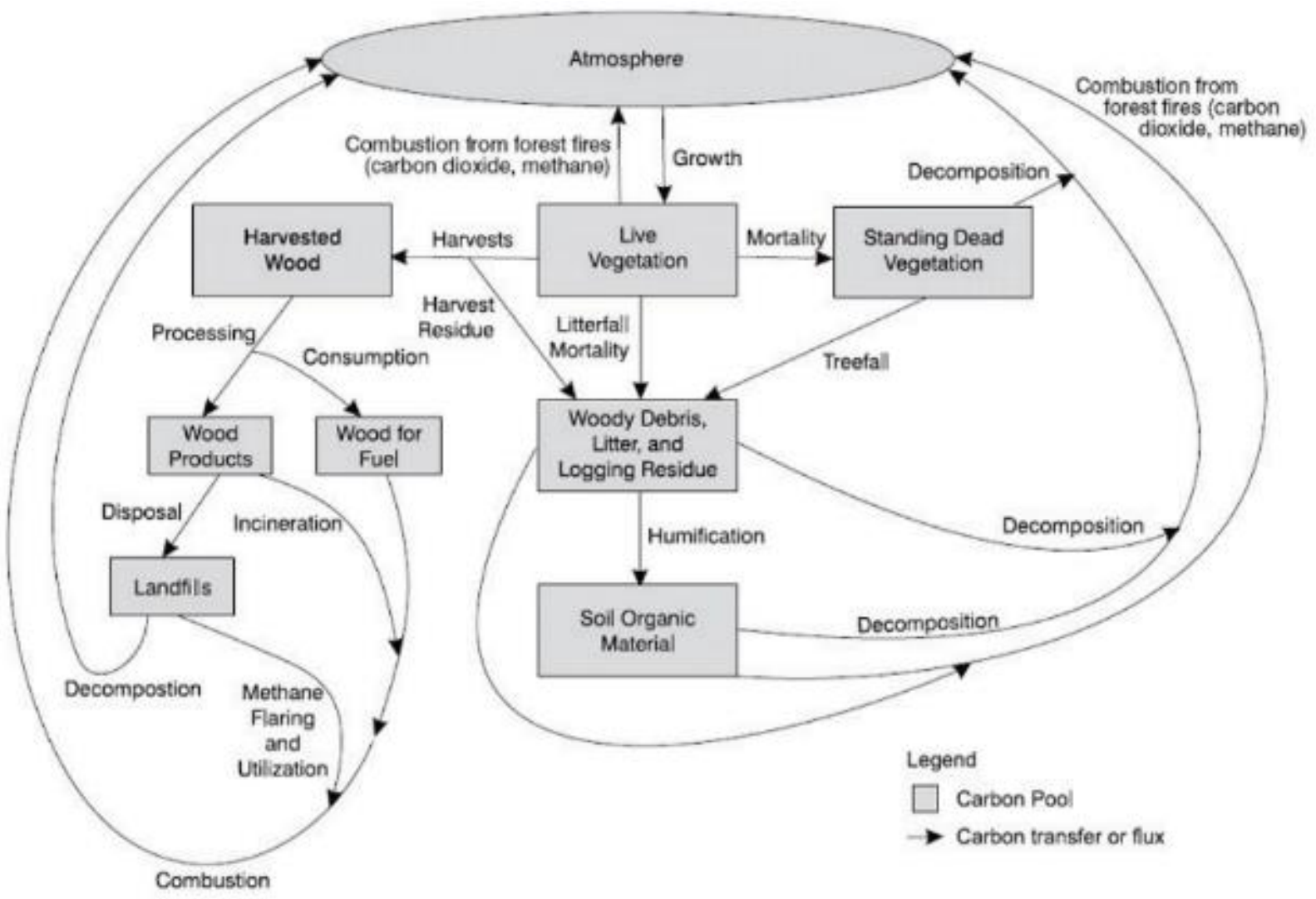

Figure 1. Forest sector carbon pools and flows (Heath et al. 2003, Birdsey et al. 2014).

Disturbances such as insects, fires, and abiotic events (wind, tornado) emit carbon into back to the atmosphere either via combustion (fires) or by increasing the amount of dead wood which then decomposes. Harvesting also removes carbon from the forest. During harvests, some logging residues may be left onsite to decompose. However, most harvested wood is transferred to the product sector to be used for products or fuel. Wood products can store carbon for years to centuries depending on the type of commodity (e.g., saw logs, pulpwood, panels). Durable wood products can then be used in place of other higher carbon emitting products such as steel, concrete, or plastics or wood-based fuels (bioenergy) can be used in place of fossil fuel energy. When products a retired they may be disposed of in landfills where they may slowly emit $\mathrm{CO}_{2}$ and methane $\left(\mathrm{CH}_{4}\right)$, a very potent greenhouse gas, back into the atmosphere as they decompose. Retired products may also be burned which releases carbon back into the atmosphere, or the energy may be captured, replacing fossil fuel energy. After disturbance events or harvests forests will re-establish and over time recover all (or more) of the carbon that had been released, thus completing the carbon cycle (Ryan et al. 2010, McKinley et al. 2010). 
Box 1 - The six forest sector carbon pools used in this report.

Aboveground live - The above-ground portions of all live woody and herbaceous vegetation, including branches, stems, and foliage.

Belowground live - All live woody vegetation stored below-ground including living coarse and fine roots.

Dead wood - Standing dead trees including coarse nonliving roots. Down dead wood, also known as coarse woody debris, includes all nonliving woody biomass lying on the ground (branches, tops, stumps)

Forest floor - Includes the litter, fumic, and humic layers and all nonliving foliage and fine root biomass lying on the ground above the mineral soil.

Soil carbon - Includes all organic material in the mineral soil below the forest floor to a depth of $1 \mathrm{~m}$ but excluding coarse roots of the pools mentioned earlier.

Harvested wood - All products in use and in landfills. Products in use include end-use products that have not been discarded. Products in landfills where most carbon is stored long-term and only a small portion of the material is assumed to degrade at a slow rate.
Environmental factors

including atmospheric $\mathrm{CO}_{2}$ concentration and climate can impact the rate of tree growth and decomposition thus impacting the flow of carbon between the atmosphere and the forest. Human activities such as burning of fossil fuels, widespread use of organic fertilizers, and changes in land use have been known to increase atmospheric $\mathrm{CO}_{2}$ and nitrogen deposition.

Generally, increases in atmospheric $\mathrm{CO}_{2}$ or nitrogen deposition act as forest fertilizers, enhancing growth and the rate of carbon uptake (Pan et al. 2009, Keenan et al. 2013).

Elevated concentrations of $\mathrm{CO}_{2}$ and other GHGs due to human activities have led to climatic changes including

warmer temperatures and regional shifts in precipitation (Walsh et al. 2014). In some regions, warmer temperatures can cause moisture stress and more rapid decomposition of surface and soil C (Ju et al. 2007), thus increasing $C$ emissions. In high latitude or altitude locations, warmer temperatures can enhance tree growth (Way and Oren 2010). Drought conditions can reduce tree growth both during the drought and up to several years after, in turn making forests less able to absorb $\mathrm{CO}_{2}$ (Anderegg et al. 2015). On the other hand, increased precipitation and humidity can enhance tree growth and $C$ uptake (Nemani et al. 2002).

\subsection{METHODS}

\subsection{Study Area}

Pennsylvania contains roughly 17 million acres (6.9 million hectares) of forested land consisting of mostly mixed-oak and northern hardwood species. It includes some of the largest contiguous blocks of forestland east of the Mississippi River. Pennsylvania forests are predominately privately owned (70\%). Private ownership is made up of family forest owners (52\%), corporations (13\%), conservation organizations and hunting clubs (5\%). Although family forest owners hold over half of PA forestlands, 
only $14 \%$ is under management plans (Albright et al. 2014). The other $30 \%$ of PA forestland is under public ownership. PA State Forests comprise $13 \%$ of the forested area in the state, making it one of the largest areas of publicly owned forestland in the Eastern U.S. Other local or state owned forests comprise $14 \%$ and include PA State Parks and other city and municipal forests. The federal Allegheny National Forest occupies roughly $3 \%$ of the state's forested area (Fig. 2).

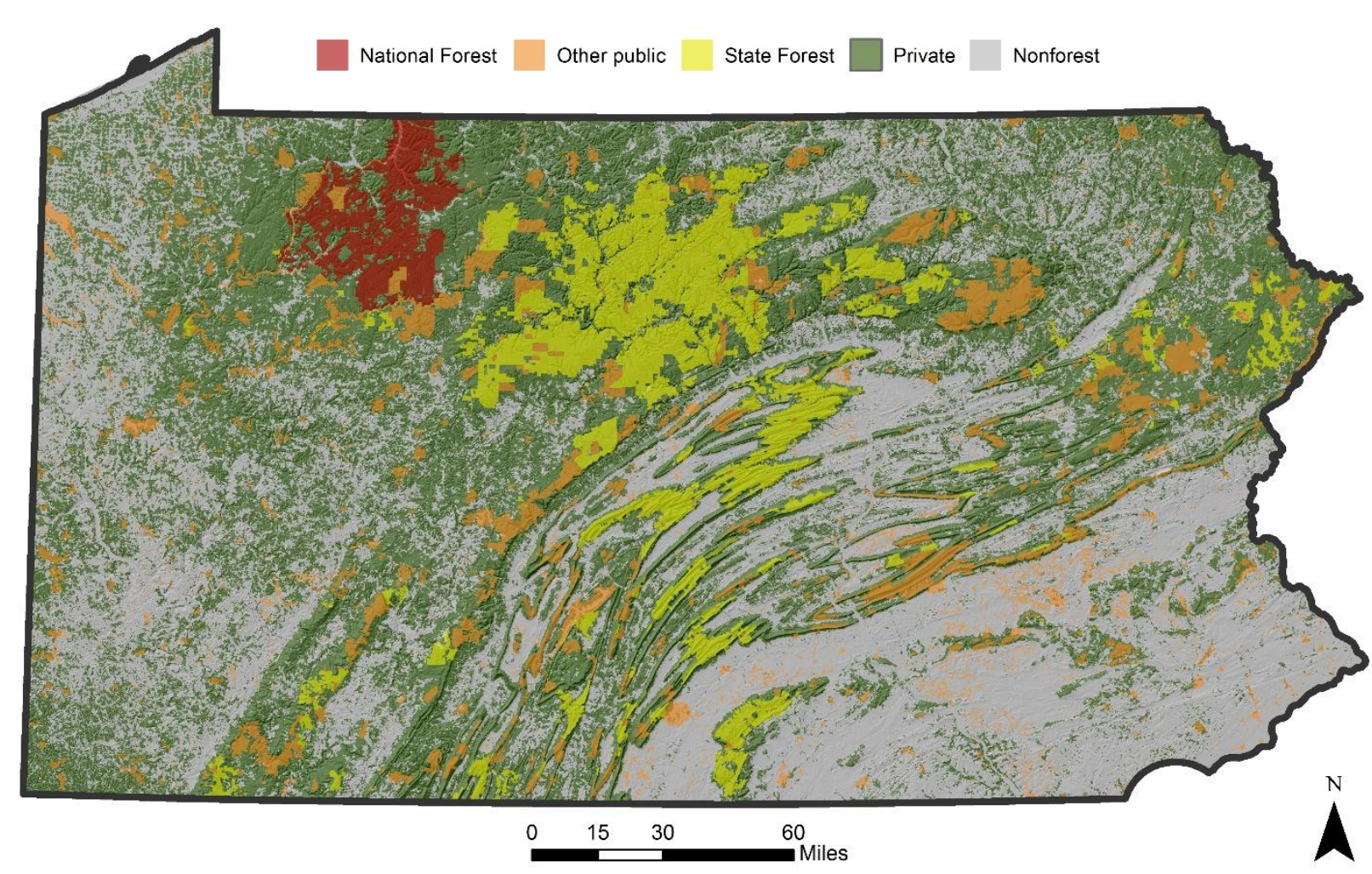

Figure 2. Land ownership map of Pennsylvania. Ownership data is provided by the USGS Protected Areas Database and the Pennsylvania Department of Conservation and Natural Resources. Elevation base data are provided by the USGS National Atlas of the USA.

The state is dominated by hardwood forests occupying $97 \%$ of forested stands. Of the U.S. Forest Service Forest Inventory and Analysis (FIA) forest type groups, Oak/Hickory (54\%) and Maple/Beech/Birch (33\%) are the dominant forest types groups in the state (Albright et al. 2014). Pennsylvania produces more hardwood lumber than any other state making the timber industry an important component of the state's economy.

Like many forests in the northeastern U.S., recent forest structure and associated carbon trends are strongly linked to the history of unregulated timber harvests and the conversion of forestland to agriculture, followed by a period of recovery and restoration beginning in the early to mid-20 ${ }^{\text {th }}$ century (Birdsey et al. 2006). For much of the $19^{\text {th }}$ century, the U.S. timber industry was centered in the Northeast. However, the depletion of merchantable timber and the settlement of the western U.S. caused the logging industry to move westward. By 1900, some 300 years after Euro-Americans first settled the region, the need for forest restoration and protection became evident (Conrad et al. 1997). 
In the 1940s, the timber industry in the northeastern U.S. started to accelerate again. Timber production increased throughout much of the mid-1900s, peaked in the late 1980s and then declined rapidly in the 1990s and 2000s (Loeffler et al. 2014). This history of timber harvesting and forest restoration in the northeast played an important role in shaping forest carbon dynamics over time. These effects of historic land use and management are evident in the stand age structure (Fig. 2a) which shows a peak in
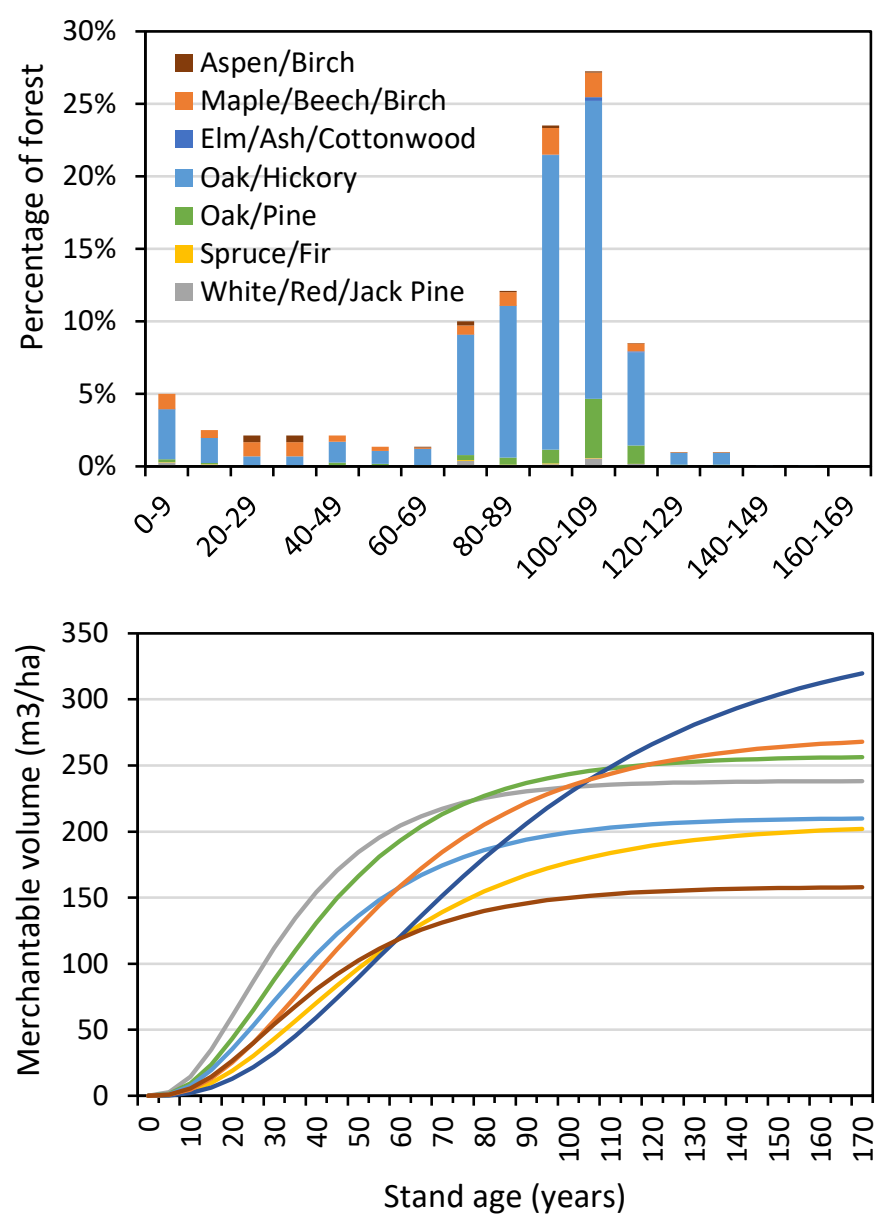

Figure 2. (a) Stand age distribution and (b) growth and yield curves, which represent annual carbon accumulation, by forest type for State Forest lands in Pennsylvania. stand establishment in the early to mid$20^{\text {th }}$ century and contains generally older stands which store more carbon but are less productive than younger forests (Fig. 2b).

In addition to timber harvesting, natural disturbances including windstorms and insects can also impact forest carbon dynamics in Pennsylvania. One of the most pervasive and damaging pests has been the Emerald Ash Borer (EAB). By 2017, all 67 counties in PA were infested with EAB (PA DCNR). After a tree has been infested, it may take up to 3 years for the damage to become apparent and up to 5 years for the tree to die. However. ash trees only make up about 3.6 percent of Pennsylvania's forests (Liu 2013). The spread and severity of insect outbreaks, pathogens, and invasive plant species are projected to intensify with continued warming trends associated with climate change (Dukes et al. 2009).

The principal scope of this analysis is the State Forest lands (SFL) within Pennsylvania. The PA DCNR is responsible for the management of the 890,000 ha (2.2 million acres) of SFL. While this study primarily focuses on the carbon dynamics on SFL, we provide similar analyses across all ownerships in the Commonwealth (see Appendix) as well as compare carbon trends between SFL and other ownerships.

\subsection{Modeling Framework}

To fully evaluate baseline carbon stocks and emissions as well as forest sector mitigation scenarios we implemented a systems approach by utilizing an integrated modeling framework. A systems approach encompasses carbon accounting in the three interconnected components that make up the forest sector: (1) the forest ecosystem, (2) harvested wood products, and (3) the substitution of bioenergy for 
fossil fuels and wood products for more fossil-fuel intensive building materials (Fig. 3) (IPCC 2007, Nabuurs et al. 2007, Lempriere et al. 2013, Smyth et al. 2014).

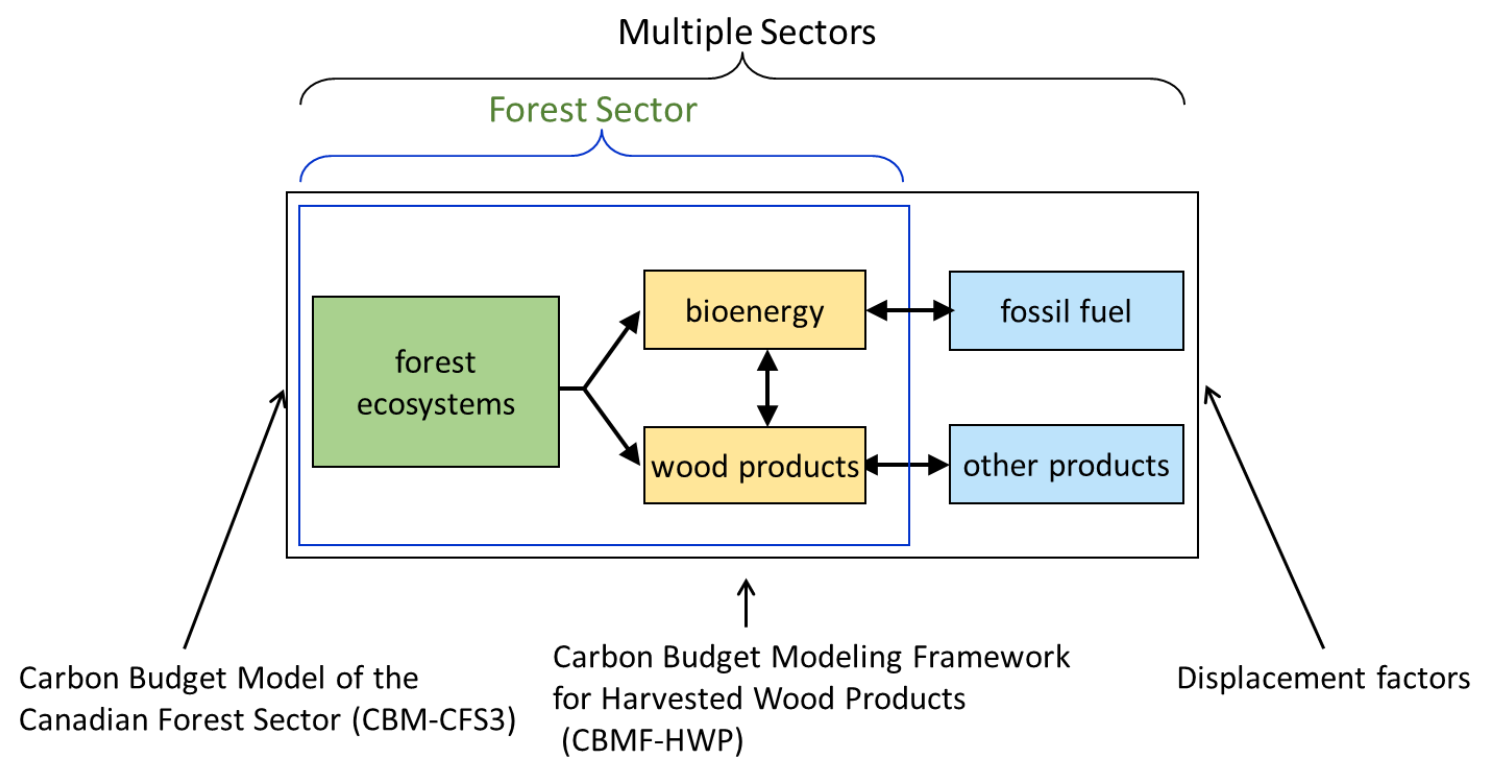

Figure 3. Systems based approach encompassing the forest ecosystem (which includes land-use change), harvested wood products, and the substitution of wood for fossil fuels and emission-intensive building materials, and the modeling tools utilized for each component.

\subsubsection{Forest Ecosystem}

We first modeled forest ecosystem carbon dynamics with the Carbon Budget Model for the Canadian Forest Sector (CBM-CFS3) (Kurz et al. 2009), which we configured for Pennsylvania forest types. CBMCFS3 is a spatially referenced, landscape scale, growth and yield based, carbon accounting model compliant with United Nations Framework Convention on Climate Change (UNFCCC) and the Intergovernmental Panel on Climate Change reporting guidelines (IPCC 2003). CBM-CFS3 has been used extensively to evaluate forest carbon budgets and mitigation potential both in Canada (Stinson et al. 2011; Smyth et al. 2014, 2018; Xu et al. 2018) and abroad (Pilli et al. 2013, Olguin et al. 2018). The model tracks carbon stocks and transfers through 10 biomass pools and 11 dead organic matter pools. Although forests absorb $\mathrm{CO}_{2}$ from the atmosphere via photosynthesis, disturbances such as fires also emit $\mathrm{CO}$ and $\mathrm{CH}_{4}$. Thus, we used 100-year global warming potentials (GWP) to convert all gases to $\mathrm{CO}_{2}$ equivalents $\left(\mathrm{CO}_{2} \mathrm{e}\right)$. Within the CBM-CFS3 model, atmospheric $\mathrm{CO}_{2}$ enters the forest ecosystem via photosynthesis and is stored as carbon in living biomass. Disturbances and biomass turnover (mortality and litterfall) transfer carbon from living biomass pools to the dead organic matter (DOM) and soil carbon pools and back to the atmosphere (Fig. 4). Harvesting transfers carbon from the ecosystem to the products sector (timber and biomass production and consumption systems). 


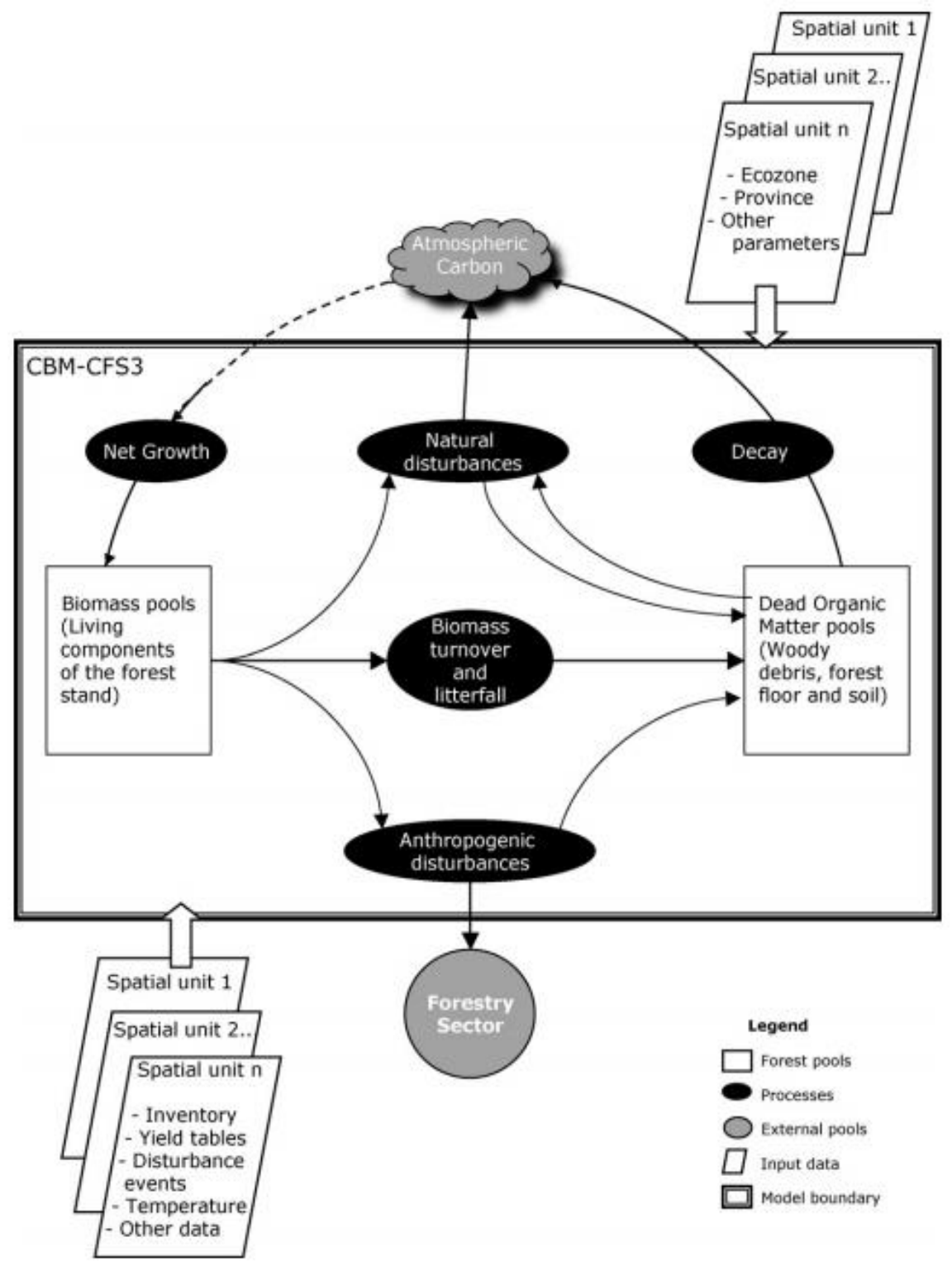

Figure 4. A schematic of the CBM-CFS3 model (Figure 1 in Kurz et al. 2009). Atmospheric carbon enters the forest ecosystem via photosynthesis and is stored in living biomass. Disturbances, biomass turnover (mortality and litterfall), and decomposition transfer carbon from biomass to the dead organic matter (DOM) and soil pools and back to the atmosphere. Harvesting transfers carbon from the ecosystem to the products sector.

The CBM-CFS3 model uses a gain-loss approach to carbon accounting. This requires data on stand attributes from a single inventory year plus information on carbon gains (growth and afforestation/reforestation) and carbon losses (deforestation, disturbances, harvests, and mortality). This method of carbon accounting makes it possible to isolate the effects of individual factors on carbon dynamics, which is critical for mitigation analysis. We compared ecosystem carbon stocks during the 
historical period (1990-2017) modeled using CBM-CFS3 to results of the Carbon Calculation Tool (CCT). The CCT model uses a stock-change approach to summarize the available Forest Inventory and Analysis (FIA) data using allometric equations (Smith et al. 2010; Woodall et al. 2011).

We employed a spatially referenced approach in which each record in the model represents a stand within the landscape with similar attributes but where the location of the stands within the unit is not specified. Stands are stratified by a set of classifiers, which are then used to target specific stands for disturbance and management activities and to apply specific growth and yield curves. For Pennsylvania, we defined seven classifiers: (1) Ownership (Private, State Forest, Other Public, Forest Service), (2) Forest Type Group based on the FIA classification, (3) Unit (east versus west) based on groupings of FIA sampling units and counties, (4) stand origin (planted versus natural), (5) protected status (eligible for harvest or not), and (6) wood type (softwood versus hardwood) in order to target harvests when the harvested forest type is unknown

We utilized CBM-CFS3 default model parameters for volume-tobiomass conversions, dead organic matter turnover rates, and merchantable tree proportions. We then replaced select default parameters to capture the biophysical conditions in Pennsylvania. For instance, we replaced the mean temperature with the 30-year mean annual temperature for the state of Pennsylvania (PRISM Climate Group). We also updated the nonforest soil carbon values used for stand initialization to reflect average cropland soil carbon in Pennsylvania (Potter et al. 2006).

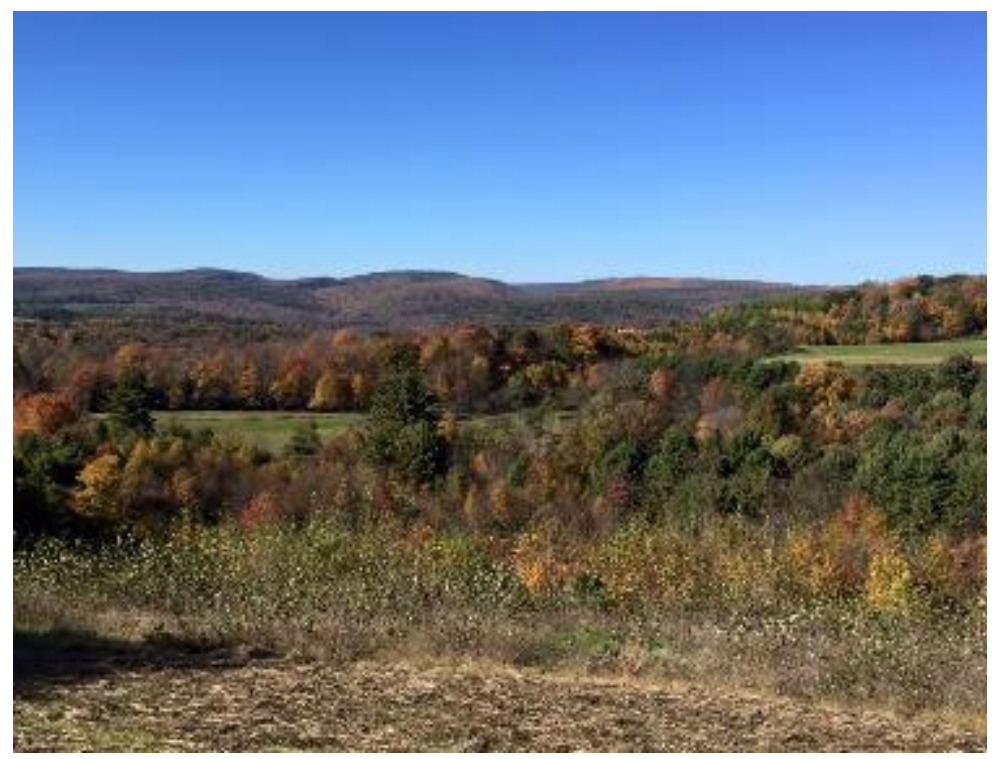

Elk County, Pennsylvania. Photo by Alexa Dugan, U.S. Forest Service

CBM-CFS3 requires several key data inputs including a detailed forest inventory for the starting year, data on historical disturbances and land use change, and growth and yield curves. For forest inventory data, we used the 2017 PA DCNR vegetation typing spatial database for State Forest lands and the USFS Forest Inventory and Analysis (FIA) database for the 2015 inventory (USDA Forest Service 2017) for all other ownerships. In addition to the classifiers described above, stands were also grouped by stand age and assigned an area from the inventory data. We rolled-back the forest inventory stand ages to the start of the simulation (1990) to estimate the stand ages for the starting year. For any stand that established between 1990 and the year of the inventory (2017 for SFL and 2015 for FIA), a statistical rule based algorithm was applied to assign stand age (Kurz et al. 2016). We converted the PA DCNR vegetation typing forest types to FIA forest type groups. Growth and yield curves describing the merchantable volume as a function of stand age (ex. Fig. $2 b)$ were derived for each ownership and forest type combination from the Carbon On-Line Estimator (COLE) (Van Deuson and Heath 2010) which is based on FIA plot data.

We used land cover change (LCC) from the National Land Cover Database (NLCD) 1992/2001 retrofit product (Fry et al. 2009) and the 2001 and 2011 products (Homer et al. 2007; 2015) as a proxy for land use change (LUC; deforestation and afforestation) (Table 1). We constrained the NLCD product by 
excluding any changes between forest and grassland/herbaceous, to reduce the likelihood of harvests/regrowth being classified as LUC. Mean annual rates of afforestation/reforestation and deforestation from 2002-2011 were applied to the remainder of the simulation period (2012-2050). LUC was minimal as any new development (roads, structures, rights of way) have mostly been limited to non-forest lands within the State Forest system (Shawn Lehman, PA DCNR, pers. communication), thus we did not include LUC for State Forest lands. In addition, LUC was minimal on the Allegheny National Forest, thus was also excluded from the simulation.

The historical annual area disturbed was derived from the North American Forest Dynamics-NASA Earth Exchange (NAFD-NEX) product which was derived from 30-m resolution Landsat imagery from 19862010. Following Mascorro et al.

(2014), we attributed the causes of disturbances to fires using Monitoring Trends in Burn Severity (MTBS) database (Eidelshink et al. 2007) and the Fire Information for Resource Management System (FIRMS) database (ESDIS 2015), and insect, defoliators, and abiotic factors using the Forest Service National Insect and Disease Survey (Johnson and Wittwer 2008) (Fig. 5). For the Allegheny National Forest we utilized spatially-explicit manually verified disturbance and harvest maps which includes disturbance type, year, and magnitude (Healey et al. 2014, Raymond et al. 2015, Dugan et al. 2017). Although insects are the

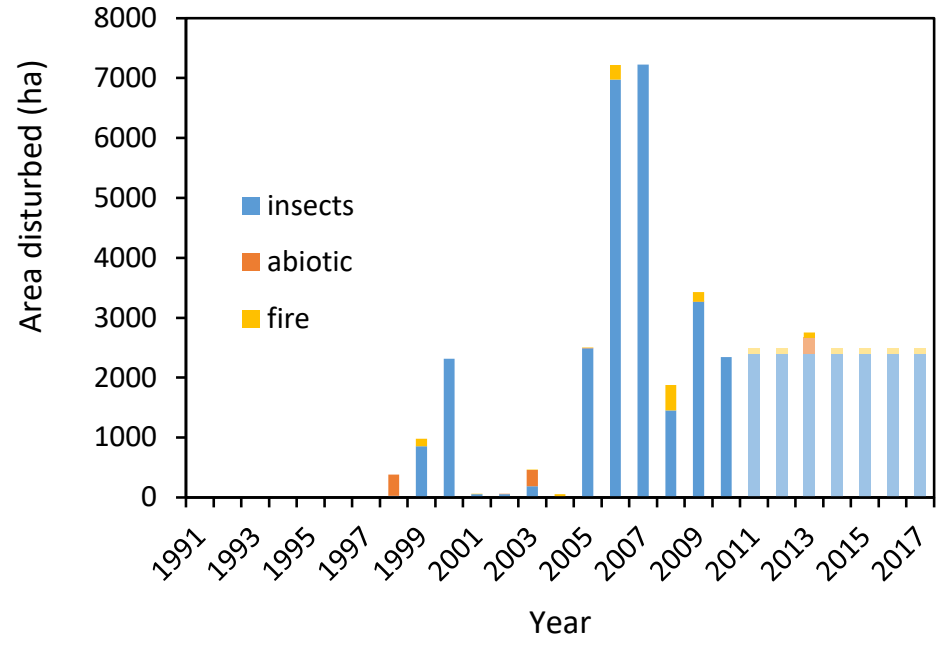

Figure 5. Area disturbed by type from 1991-2017 for Pennsylvania forests. Lighter bars represent historical 10year average disturbance rates. dominant disturbance type, the annual area impacted by any disturbance is small relative to the total area of forestland (Fig. 5). We applied 10-year average rate of historical disturbances from 2001-2010 to the rest of the simulation period (2011-2050).

We used the FIA Timber Product Output (TPO) data retrieval system (https://www.fs.usda.gov/srsfia/php/tpo_2009/tpo_rpa_int1.php) to determine the volume of softwood and hardwood roundwood removed from 1991-2012 on Private, State, and Other Public forests. For Private and Other Public lands, the removals were then divided into clearcut (85\% merchantable stemwood removal) and partial cut ( $45 \%$ merchantable stemwood removal) based on data from Oswalt and Smith (2014) and were used throughout the simulation. For State Forests, we used data from the PA DCNR annual timber reports to breakdown volume removals on State Forest lands into the following treatment categories: clearcut ( $85 \%$ merchantable stemwood removal), clearcut with salvage ( $85 \%$ merchantable stemwood and $50 \%$ standing dead wood removal) partial cut ( $45 \%$ merchantable stemwood removal), partial cut with salvage (45\% merchantable stemwood and standing dead removal), and salvage only (50\% standing dead removal). For use in the CBM-CFS3 model we converted volumetric roundwood removals to biomass using specific gravities from the FIA database (USDA Forest Service 2017) and equations for calculating biomass from Woodall et al. (2011) and then to carbon by multiplying biomass by 0.5 based on the assumption that biomass is 50 percent carbon (Fig. 
6). We applied 10-year average rate of removals from 2003-2012 to the rest of the simulation period (2013-2050).

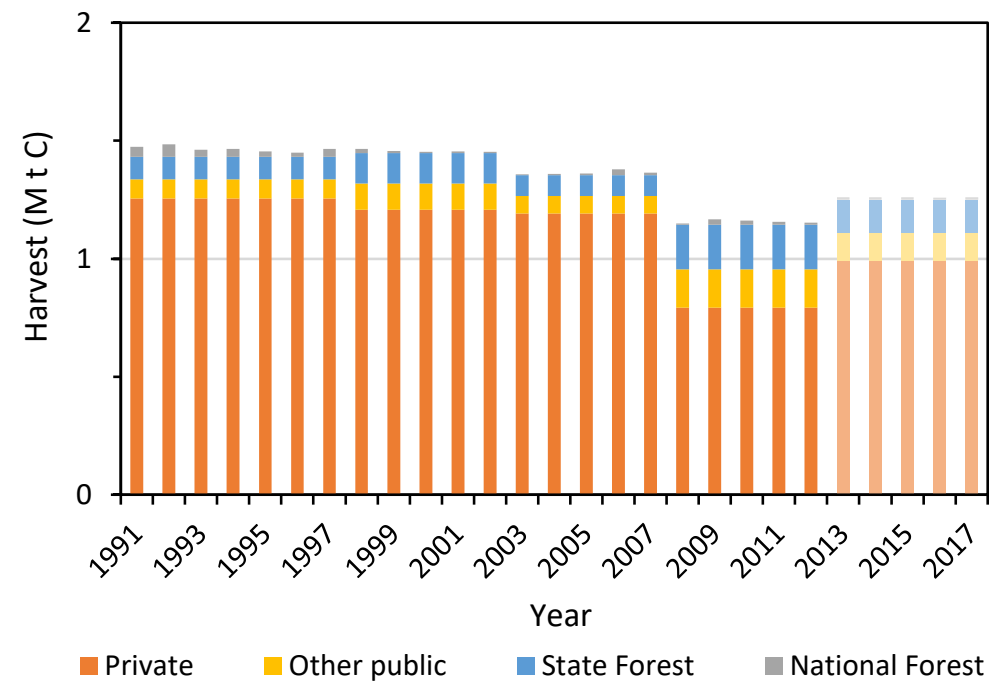

Figure 6. Merchantable carbon removals for by ownership from 1991-2017. Lighter bars (2013-2017) represent historical 10-year average removals.

\subsubsection{Harvest Wood Products and Substitution Benefits}

Carbon in wood harvested from the CBM-CFS3 simulations was then transferred to the Carbon Budget Modelling Framework for Harvest Wood Products (CBM-FHWP) which quantifies emissions through the harvested wood product (HWP) sector. CBM-FHWP accounts for emissions from manufacturing of commodities, bioenergy, mill residues, domestic use and export, and post-consumer treatment of retired products (Fig. 7). In taking a system's approach, rather than assuming that harvested wood was instantaneously oxidized in the forest ecosystem, causing harvest emissions to be counted in the forest ecosystem, all emissions from wood harvested from the forest ecosystem are tracked in the HWP sector using the CBM-FHWP model.

Harvested roundwood, salvaged wood, and residues (tops, stumps, limbs) enter the product sector to be processed into various commodities. We used the FIA TPO data to determine the proportion of harvested roundwood manufactured for the commodity classes including saw logs, veneer logs, pulpwood, composite panels, fuelwood (bioenergy), posts/poles/pilings, and other industrial products (Fig. 8), as well as the disposition of mill residues to commodities, bioenergy, or disposal. National statistics on the proportion of commodities exported outside of the U.S. versus consumed domestically were obtained from the U.S. Timber Production, Trade, Consumption, and Price Statistics, 1965-2013 Report (Howard and Jones 2016, their Table 5a). The half-life of each commodity defines the decay rate at which carbon in the product-in-use category is spent and is transferred to the discarded category. 


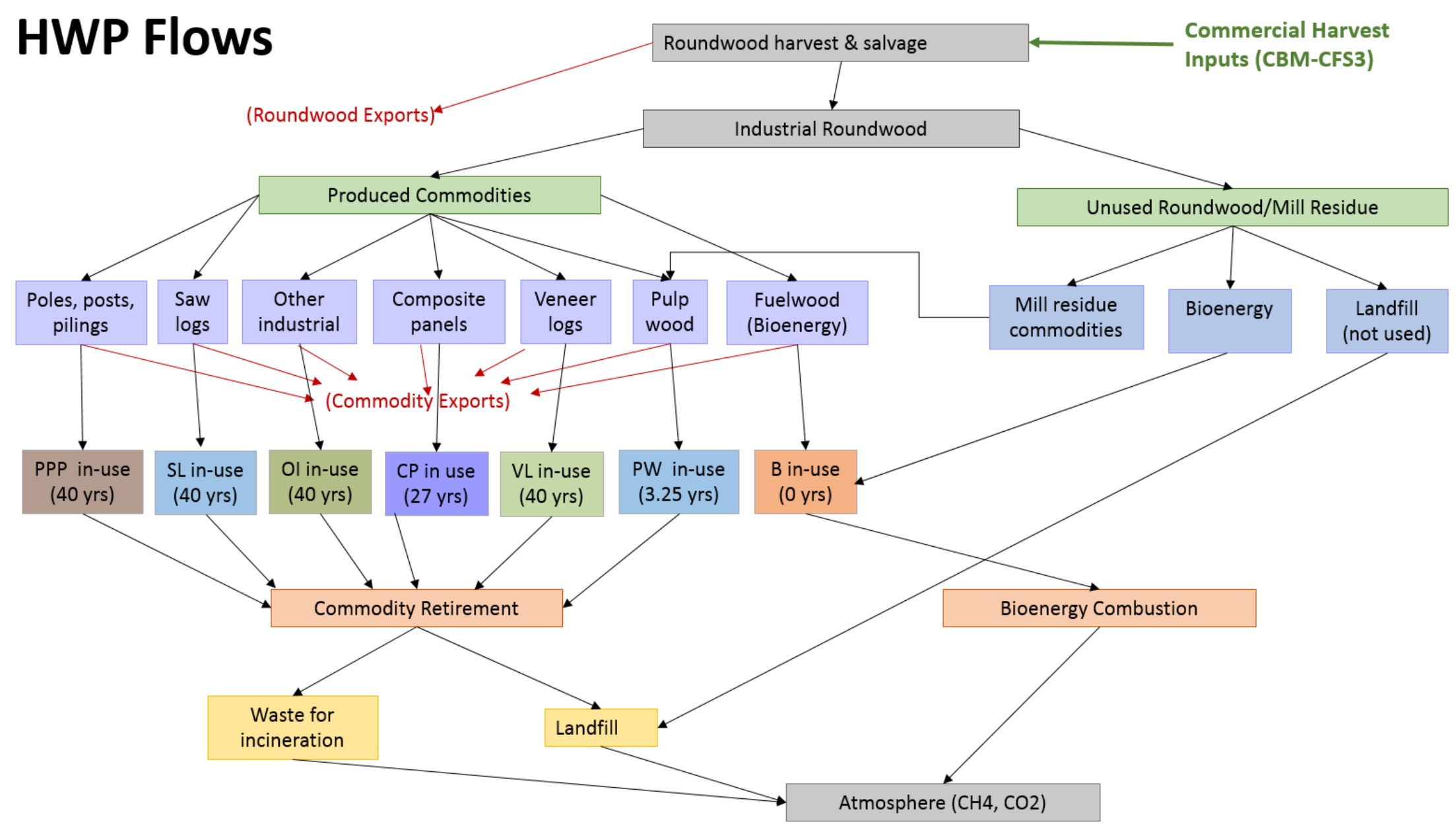

Figure 7. The fate of carbon in harvested wood products (HWP). The CBM-FHWP tracks stocks and emission through the lifecycle of manufactured commodities, exports, milling, product retirement, and bioenergy combustion. 
Commodity in-use half-lives were assumed to be 40 years for saw logs, veneer logs, other industrial, and posts, poles, and pilings, based on average values from Skog (2008) and IPCC (2013), 27 years for composite panels, 3.25 years for pulpwood (IPCC 2013), and zero years for fuelwood (bioenergy) assuming fuelwood was burned the year it was harvested. We assumed that all retired products were stored in landfills.

To build up HWP stocks, we ran the CBM-FHWP model for the 50 years prior to the analysis period, from 1940 to 1989. This enabled the incorporation of HWP stocks and emissions that were produced prior to the analysis period but that are still in-use or have been retired during the analysis period. We assumed that historical timber product output increased steadily from 1940 through 1990 levels at a rate of approximately $2 \%$ per year following estimates from National Forest lands in the Northeast (Loeffler et al. 2014). We also applied the 10-year average disposition of harvested roundwood commodity classes from 1990-1999 to this spin-up period.

The substitution benefits of utilizing bioenergy to displace fossil fuel energy and wood products to displace more fossil fuel intensive building materials was also included in this systems approach. Average displacement factors, which were calculated at the national level for Canadian forests were applied to bioenergy and long-lived wood products (saw logs and composite panels).

We utilized the following average displacement factors: 0.54 tonnes of carbon (tC) displaced per tonne of carbon (tC) of sawnwood, $0.45 \mathrm{tC}$ displaced per tC of panels, and $0.89 \mathrm{tC}$ displaced per tC of bioenergy (Smyth et al. 2016). To calculate the avoided emissions for each product type, the displacement factor is then multiplied by the quantity of $C$ utilized for bioenergy or longer-lived products (Smyth et al. 2014).

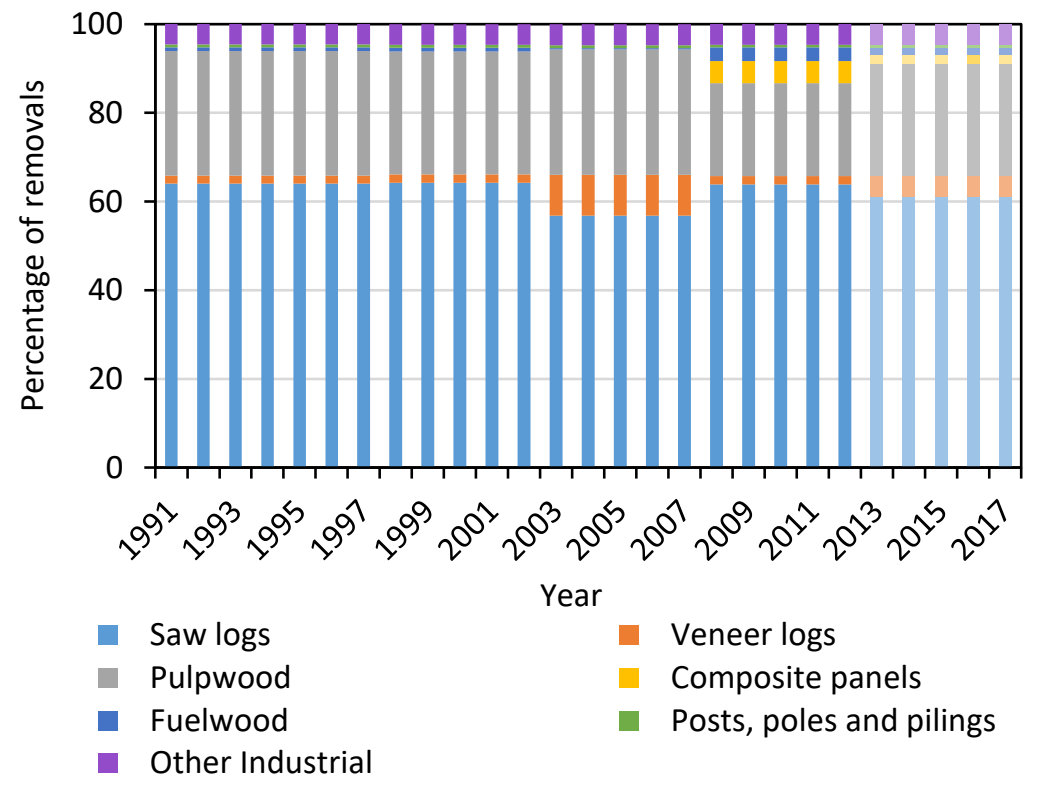

Figure 8. Annualized proportions of roundwood removals in each commodity class for Pennsylvania. Lighter colored bars from 20122017 indicate historical 10-year averages applied from 2013 through 2050. 


\subsubsection{Mitigation Analysis}

We evaluated ten mitigation scenarios that target the forest ecosystem and/or the product sector beginning in 2020 (Table 1). Scenarios or scenario intensities sometimes target individual ownerships. The mitigation effect is calculated as:

$$
M=E_{S}-E_{B}
$$

Where $M$ is the mitigation effect, $E_{B}$ is the baseline scenario emissions and $E_{S}$ is the mitigation scenario emissions. By calculating mitigation as the difference between the net GHG emissions of the mitigation scenario and of the baseline scenario the analysis accounts for "additionality" by isolating the effects of each mitigation activity while factoring out effects common to the scenarios. For each scenario, net emissions were estimated as the sum of emissions from the three forest sector components:

$$
E=F+P+D
$$

Where $E$ is the net GHG emissions, $F$ is the net emissions from the forest ecosystem, $P$ is the emissions from the products sector (includes bioenergy and landfill emissions), and $D$ is the displaced emissions from substituting wood for bioenergy and other materials.

A baseline "business as usual" (BAU) scenario involves the projection of current trends based on the average of recent past observations of disturbance and management and land-use change over the last 10 years of the historical period (2002-2011). For each scenario the baseline rates of disturbance and LUC were applied from 2012 through 2050 unless a particular activity was otherwise targeted by the mitigation activity. Insect disturbances were excluded from the simulation period due to the relatively small area of historical impacts and high uncertainty in the future affected area.. Furthermore, insect impacts in the baseline and the mitigation scenarios would be cancelled out in the mitigation analysis to isolate the mitigation activity. Also, even though they have been the most common disturbance in terms of area affected (Fig. 5), insect disturbances are typically low severity, often causing only temporary loss of leaf cover (defoliation). While recent ash mortality from the EAB has been significant, ash represent a small component (3.6\%) of the forests in PA (Liu 2013).

The ten mitigation scenarios are described in detail below and in Table 1.

Scenario 1 - Short rotation: The goal of this scenario was to reduce harvest rotations which increases the amount of wood harvested and increase average growth rates by shifting more stands to younger age classes. While this scenario targets all ownerships, we applied a more significant decline in harvest rotations on State Forests. To implement this scenario we reduced the minimum age for harvesting from 70-80 years (depending on forest type) to 40 years for all forest types on State Forest lands and from 40 years to 35 years for all other ownerships (National Forest, Private, Other Public). Reducing harvest rotations also results in an increase of the volume of timber harvests. Thus we increased the merchantable carbon harvested by $20 \%$ from baseline levels for SFL and by $10 \%$ for all other landowners. All of the additional harvested wood was used for bioenergy.

Scenario 2 - Extend rotation, High: This mitigation scenario is essentially the opposite of the short rotation scenario in that it seeks to increase carbon stocks in the ecosystem by extending the rotation length. We achieved an extension in rotation length by increasing the minimum harvest age from 70-80 years (depending on forest type) to 130 years for all forest types on SFL and from 40 to 60 years for all other ownerships. Extending harvest rotations also results in a reduction of timber removals. Thus we reduced removals by $20 \%$ from baseline levels on SFL and by $10 \%$ for other ownership classes. Extending rotations can also increase the size of merchantable trees making 
them more likely to be used for long-lived wood (LLP) products, thus we also increased the proportion of wood for LLP by $5 \%$ while decreasing the proportion of wood for paper products by $5 \%$.

Scenario 3 - Extend rotation, Low: This scenario is a more modest version of scenario 2. We increased rotation length by reducing the harvest removals by $10 \%$ on SFL and by $5 \%$ on other ownerships. We also increased the minimum harvest age from $70-80$ years to 100 years for SFL and from 40 to 50 years for other ownerships. We increased the proportion of wood for LLP by $2.5 \%$ while decreasing the proportion of wood for paper products by $2.5 \%$.

Scenario 4 - Increase deforestation: This scenario does not seek to achieve a mitigation benefit, but rather evaluate the potential carbon consequences of deforestation if human activities such as natural gas infrastructure were to further expand onto forested lands in the state. In the baseline scenario we assumed State Forests and the Allegheny National Forest did not experience deforestation. For this scenario, we ramped up deforestation starting with 50 ha of forest deforested on SFL every year from 2020 to 2024, then 100 ha per year from 2025-2029, 150 ha per year from 2030-2034, and 200 ha per year were deforested from 2035-2050. On the Allegheny National Forest, we similarly increased deforestation by 25 ha per year every five years until 100 ha per year were deforested from 2035-2050. On Other Public and Private lands deforestation was increased by $5 \%$ from historical levels for the period from $2020-2034$ and by $10 \%$ from historical levels for the period 2035-2050.

Scenario 5- Increase residues: This scenario shifts all clearcut harvests from typical cut-to-length or tree-length logging which leaves some residues (tops, stumps, limbs) behind to whole tree removal which removes the entire trees leaving no residues on the forest floor to decay. The goal of this scenario is to increase the utilization of harvest residue materials for bioenergy. To implement this scenario we increased the percentage of residues that are removed during a clearcut harvest from $70 \%$ (PA DCNR, Shawn Lehman, Pers. communication) to 100\%. All additional residues collected were utilized for bioenergy.

Scenario 6 - Increase productivity: This scenario increases forest productivity by $15 \%$ through advanced silviculture, genetics, and site management. We do not propose specific silvicultural or land management practices, but rather assume that land managers may apply a range of practices that result in an average increase in productivity of $15 \%$. On SFL, this scenario targets 500 ha per year of existing Oak/hickory stands (the dominant timber forest type) which are $\leq 15$ years old. On Private lands, we target 1500 ha of existing Oak/hickory stands per year. To simulate this increased productivity, stands affected follow a new growth curve generated by increasing the modeled Oak/hickory growth curves by $15 \%$ for the duration of the simulation period.

Scenario 7 - Portfolio: This scenario combines scenarios 2 (extend rotation, low), 5 (increase residues), and 6 (increase productivity) and represents an array of potential forest management activities that could be performed simultaneously. These activities interact with one another thus their impacts are not additive and must be modeled together.

Scenario 8 - Increase LLP: The proportion of roundwood used for long-lived wood products (saw logs) are increased by a total of $10 \%$ per year, while paper products (pulpwood) are decreased by $10 \%$ per year from average levels (Fig. 8). In the baseline scenario, $61 \%$ of harvested roundwood is used for sawlogs and $25 \%$ is used for pulpwood (Fig. 8 ). In this scenario $71 \%$ of roundwood goes to sawlogs and $15 \%$ of roundwood goes to pulpwood. Total removals from the forest are not changed, only the product mix is altered as simulated by the harvested wood product model. 
Scenario 9-Increase bioenergy, decrease pulp and paper: The proportion of harvested wood used for bioenergy production is increased by $10 \%$ at the cost of pulp and paper products. Only the product mix is altered, but the total removals from the forest are not changed.

Scenario 10-Increase bioenergy, decrease LLP: The proportion of harvested wood used for bioenergy production is increased by $10 \%$ at the cost of long-lived wood products. Only the product mix is altered, but the total removals from the forest are not changed.

Table 1. Indicators for the ten mitigation scenarios for Pennsylvania. The parameter changes are relative to the baseline scenario and all scenarios are implemented from 2020-2050.

\begin{tabular}{|c|c|c|c|}
\hline Scenario & Description & Parameter changed & Parameter value \\
\hline Short rotation & $\begin{array}{l}\text { Increase harvests and reduce } \\
\text { minimum harvest age. All } \\
\text { additional harvested wood is used } \\
\text { for bioenergy }\end{array}$ & $\begin{array}{l}\text { Harvested area } \\
\text { Minimum harvest age } \\
\text { HWP components change }{ }^{c}\end{array}$ & $\begin{array}{l}+10 \%^{\mathrm{a}},+20 \% \mathrm{SFL}^{\mathrm{b}} \\
35 \mathrm{yrs}^{\mathrm{a}}, 40 \text { yrs SFL } \\
\text { Additional harvests to } \\
\text { bioenergy }\end{array}$ \\
\hline $\begin{array}{l}\text { Extend } \\
\text { Rotation, high }\end{array}$ & $\begin{array}{l}\text { Extend the length of harvest } \\
\text { rotation, reduce harvest removals, } \\
\text { and increase the proportion of LLP } \\
\text { at the cost of paper products (PP). }\end{array}$ & $\begin{array}{l}\text { Harvested area } \\
\text { Minimum harvest age } \\
\text { HWP components change }{ }^{c}\end{array}$ & $\begin{array}{l}-10 \%^{\mathrm{a}},-20 \% \text { SFL } \\
60 \mathrm{yrs}^{\mathrm{a}}, 130 \text { yrs SFL } \\
\text { LLP }+5 \%, \text { PP }-5 \%\end{array}$ \\
\hline $\begin{array}{l}\text { Extend } \\
\text { rotation, low }\end{array}$ & $\begin{array}{l}\text { Extend the length of harvest } \\
\text { rotation, reduce harvest removals, } \\
\text { and increase the proportion of LLP } \\
\text { at the cost of paper products (PP). }\end{array}$ & $\begin{array}{l}\text { Harvested area } \\
\text { Minimum harvest age } \\
\text { HWP components change }{ }^{c}\end{array}$ & $\begin{array}{l}-5 \%^{a},-10 \% \text { SFL } \\
50 y^{a}{ }^{a}, 100 \text { yrs SFL } \\
\text { LLP }+2.5 \%, \text { PP }-2.5 \%\end{array}$ \\
\hline Deforestation & $\begin{array}{l}\text { Steadily increase the annual area } \\
\text { deforested from 2020-2050. }\end{array}$ & Deforestation rate & $\begin{array}{l}+50 \text { ha/yr SFL } \\
+25 \text { ha/yr National Forest } \\
+5-10 \% / y r \text { Private, public }\end{array}$ \\
\hline Residues & $\begin{array}{l}\text { Increase harvest residues collected } \\
\text { for use in bioenergy to } 100 \% \text {. }\end{array}$ & $\begin{array}{l}\text { Residues recovered (\%) } \\
\text { HWP component changes }{ }^{c}\end{array}$ & $\begin{array}{l}70 \% \text { to } 100 \% \\
\text { Additional residues to } \\
\text { bioenergy }\end{array}$ \\
\hline Productivity & $\begin{array}{l}\text { Increase productivity of existing } \\
\text { Oak/hickory stands through } \\
\text { silvicultural activities. }\end{array}$ & $\begin{array}{l}\text { Growth curve } \\
\text { Area affected }\end{array}$ & $\begin{array}{l}+15 \% \\
500 \text { ha/yr SFL } \\
1500 \text { ha/year Private }\end{array}$ \\
\hline Portfolio & $\begin{array}{l}\text { Combine the Extend Rotation } \\
\text { (low), residues, and productivity } \\
\text { scenarios. }\end{array}$ & $\begin{array}{l}\text { Harvested area } \\
\text { Minimum harvest age } \\
\text { Residues recovered (\%) } \\
\text { HWP components change }{ }^{c} \\
\end{array}$ & $\begin{array}{l}-5 \% \text { a },-10 \% \text { SFL } \\
50 y^{a}, 100 \text { yrs SFL } \\
70 \% \text { to } 100 \% \\
\text { LLP }+2.5 \%, \text { PP }-2.5 \%\end{array}$ \\
\hline $\begin{array}{l}\text { Longer-lived } \\
\text { products (LLP) }\end{array}$ & $\begin{array}{l}\text { Increase the proportion of } \\
\text { harvested wood for LLP at the cost } \\
\text { of pulp and paper (PP). }\end{array}$ & HWP components change ${ }^{c}$ & LLP +10\%, PP -10\% \\
\hline $\begin{array}{l}\text { Increase } \\
\text { Bioenergy } \\
\text { (decrease PP) }\end{array}$ & $\begin{array}{l}\text { Increase the proportion of } \\
\text { harvested wood for bioenergy at } \\
\text { the cost of pulp and paper. }\end{array}$ & HWP components change ${ }^{c}$ & Bioenergy $+10 \%$, PP $-10 \%$ \\
\hline $\begin{array}{l}\text { Increase } \\
\text { Bioenergy } \\
\text { (decrease LLP) }\end{array}$ & $\begin{array}{l}\text { Increase the proportion of } \\
\text { harvested wood for bioenergy at } \\
\text { the cost of LLP. }\end{array}$ & HWP components change ${ }^{c}$ & $\begin{array}{l}\text { Bioenergy }+10 \% \text {, LLP - } \\
10 \%\end{array}$ \\
\hline
\end{tabular}




\subsection{RESULTS}

\subsection{Past and Prospective Carbon Stocks and Emissions in Forests and Wood Products}

In this section we examine results from the ecosystem model (CBM-CFS3) and the HWP model (CBMFHWP) of estimates of past and prospective carbon stocks and emissions. As described in detail in the methods section, we evaluated prospective carbon trends by modeling the baseline "business as usual" scenario through 2050. We applied average historical rates of disturbances, management, and land use change over the last decade that data were available through the projection period. These estimates also assume that climate, atmospheric $\mathrm{CO}_{2}$, nitrogen deposition, and growth and yield relationships are constant throughout the historical and future periods. Results reported here show historical (19902017) and projected (2018-2050) carbon stocks and emissions for each of the main ownership groups within PA, with a focus on State Forests. Corresponding figures for each of the ownership classes as well as all ownerships combined can be found in Appendix (Sections 11.3 to 11.6).

It is important to recognize that the results presented here are approximations and estimates that depend on models, datasets, and assumptions each with varying levels of uncertainty. For example, inventory data contains measurement errors (e.g. species identification, tree dimensions) and sampling errors (estimates are based on a network of plots, not a census). Disturbance and land use change maps may have omission and commission errors. Sources of model errors may be extensive. For instance, model error may be associated with stand volume models applied convert volumes to biomass and carbon, carbon pool models that allocate ecosystem stocks, decay rates that are influenced by climate and wood characteristics, and the impacts of disturbances on $C$ estimated by disturbance matrix parameters (Kull et al. 2016), to name a few. Assumptions also impact results. For instance, here we assumed climate (temperature, precipitation, atmospheric $\mathrm{CO}_{2}$ ) remained constant throughout the simulation, and average rates of historical disturbances were applied into the future, which may not be a realistic representation of future conditions. Furthermore, all results beyond 2011 (the last year in which most input datasets were available), are projections. Therefore, values presented here are one representation of reality, but may differ from estimates using other models, datasets, parameters, and assumptions. See section 6.4 for further discussion of uncertainty and limitations.

In section 5.1.1 we report forest ecosystem carbon stocks and emissions. The net carbon balance of the forest sector includes emissions of carbon dioxide $\left(\mathrm{CO}_{2}\right)$, methane $\left(\mathrm{CH}_{4}\right)$, and carbon monoxide (CO) and are converted here to carbon dioxide equivalents $\left(\mathrm{CO}_{2} \mathrm{e}\right)$. Although forests absorb $\mathrm{CO}_{2}$ from the atmosphere via photosynthesis, disturbances such as fires also emit $\mathrm{CO}$ and $\mathrm{CH}_{4}$. We used global warming potentials (GWP) to convert all gases to $\mathrm{CO}_{2}$ equivalents $\left(\mathrm{CO}_{2} \mathrm{e}\right)$. Also, to avoid double counting emissions among components, we did not account for emissions associated with carbon transferred to the wood products sector as instantaneous oxidation from the forest ecosystem (Stinson et al. 2011). Instead carbon harvested from the forest is transferred out of the forest ecosystem and emissions associated with the harvested wood are tracked in the product sector. Forest ecosystem emissions without oxidation of removals are denoted here as $G H G_{E c o}$. Given the inclusion of these other GHGs as well as the tracking of emissions associated with harvest removals in the product sector, the fraction of GHG emissions to carbon stocks will be smaller than the ratio of their molecular weights (3.67). For 
reference, we present forest ecosystem emissions with oxidation of harvested wood in Appendix section 11.4, which are denoted as $I N V_{G H G}$ following Stinson et al. 2011.

In Section 5.1.2, we report on carbon storage in HWP and post-consumer use (i.e., landfill storage) and emissions associated with wood harvested from the ecosystem including transport, processing, bioenergy burning, and post-consumer uses (i.e., landfill emissions). The emissions related to harvests reported in section 5.1.1 ( $\mathrm{GHG}_{\mathrm{Eco}}$ ) and emissions related to HWP reported in 5.1.2 can be combined and would not result in double counting.

In Section 5.1. 3, we report the net carbon balance of the forest sector (section 5.1.3), which includes the combination of forest ecosystem and HWP stocks, as well as emissions associated with the forest ecosystem and HWP, and product/energy substitution (displaced emissions).

In section 5.1.4, we explore the various factors that have influenced carbon stock and emission trends across the ownership classes in Pennsylvania.

Box 2 - Carbon Units. The following table provides a crosswalk among various measurements units used in the assessment of carbon stocks and emissions.

\begin{tabular}{|c|c|c|c|c|c|}
\hline \multicolumn{3}{|c|}{ Tonnes } & \multicolumn{3}{c|}{ Grams } \\
\hline Multiple & Name & Symbol & Multiple & Name & Symbol \\
\hline & & & $10^{0}$ & Gram & $\mathrm{G}$ \\
\hline & & & $10^{3}$ & kilogram & $\mathrm{Kg}$ \\
\hline $10^{0}$ & tonne & $\mathrm{t}$ & $10^{6}$ & Megagram & $\mathrm{Mg}$ \\
\hline $10^{3}$ & kilotonne & $\mathrm{Kt}$ & $10^{9}$ & Gigagram & $\mathrm{Gg}$ \\
\hline $10^{6}$ & Megatonne & $\mathrm{Mt}$ & $10^{12}$ & Teragram & $\mathrm{Tg}$ \\
\hline $10^{9}$ & Gigatonne & $\mathrm{Gt}$ & $10^{15}$ & Petagram & $\mathrm{Pg}$ \\
\hline $10^{12}$ & Teratonne & $\mathrm{Tt}$ & $10^{18}$ & Exagrame & $\mathrm{Eg}$ \\
\hline $10^{15}$ & Petatonne & $\mathrm{Pt}$ & $10^{21}$ & Zettagram & $\mathrm{Zg}$ \\
\hline $10^{18}$ & Exatonne & $\mathrm{Et}$ & $10^{24}$ & yottagram & $\mathrm{Yg}$ \\
\hline
\end{tabular}

I hectare (ha) $=0.01 \mathrm{~km}^{2}=2.471$ acres $=0.00386 \mathrm{mi}^{2}$

1 tonne $($ metric) $=1.1023$ short tons (U.S.) 


\subsubsection{Baseline forest carbon stocks and emissions}

Despite the high variability of carbon stocks and stock density among Pennsylvania's main ownership classes, modeling results indicated similar trends across ownerships in the state. Total ecosystem carbon

Table 2. Estimates of total change (sequestration) in forest carbon stocks and carbon stock density from 1990 to 2017 by ownership.

\begin{tabular}{lcc}
\hline Ownership & $\begin{array}{c}\text { Stock Density } \\
t \mathrm{Ch}^{-1}\end{array}$ & $\begin{array}{c}\text { Total Stocks } \\
\mathrm{MtC}\end{array}$ \\
\hline State Forest & 9.3 & 7.7 \\
Private & 10.1 & 49.9 \\
National Forest & 17.6 & 3.6 \\
Other Public & 16.2 & 16.3 \\
\cline { 2 - 3 } All owners & 11.1 & 77.5 \\
\hline
\end{tabular}

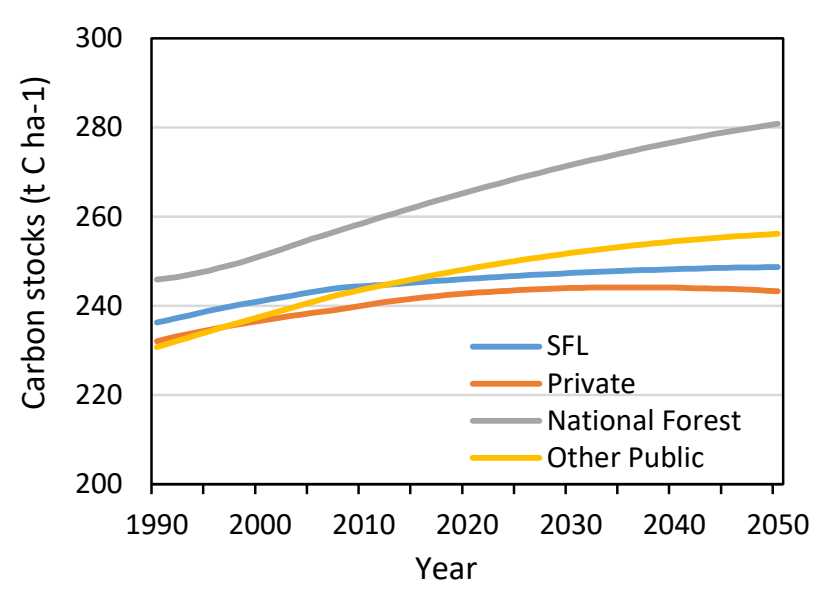

Figure 9. Modeled total forest carbon stock density from 1990 to 2050 across ownership classes in Pennsylvania. Values beyond roughly 2011 are proiected. stocks and carbon stock density (amount of carbon stock per unit area) have increased across the four ownership classes in Pennsylvania over the historical period from 1990 to 2017 (Fig. 9, Table 2). Our modeling estimates suggest that ecosystem carbon stocks across the commonwealth increased by approximately $77.5 \mathrm{MtC}\left(11.6 \mathrm{t} \mathrm{C}^{-1}\right.$ ) (Table 2 ), or at a rate of about 0.41 tonnes $C$ per ha per year since 1990 . On SFL, total ecosystem carbon stocks increased from roughly 195.6 MtC (236.4 t C ha-1) in 1990 to about 203.3 MtC (248.7 t C ha-1) in 2017, for a net sequestration of roughly $7.7 \mathrm{MtC}(9.3 \mathrm{t} \mathrm{C} \mathrm{ha-1})$. Between 1990 and 2017, National Forest ownership class (Allegheny National Forest) had on average higher carbon density than the other ownerships, followed by SFL. Although private owners comprise $70 \%$ of the forestland in the state and thus store much more total carbon than the other ownership classes combined (Table 2, 3), Private lands have consistently had the lowest carbon density (Table 4).

If current conditions are maintained over the next few decades, ecosystem carbon stocks are projected to continue to increase and

Table 3-Estimates of average forest carbon stocks (million tonnes carbon) from 1990-2017 by ownership class and carbon pool, Pennsylvania. Estimates include carbon on all land classes (forestland remaining forestland and conversions).

\begin{tabular}{lllllll}
\hline & \multicolumn{6}{c}{ Carbon pool } \\
\cline { 2 - 7 } Ownership class & $\begin{array}{l}\text { Above- } \\
\text { ground }\end{array}$ & $\begin{array}{l}\text { Below- } \\
\text { ground }\end{array}$ & $\begin{array}{l}\text { Dead } \\
\text { wood }\end{array}$ & $\begin{array}{l}\text { Forest } \\
\text { floor }\end{array}$ & Soil & Total \\
\hline \multirow{2}{*}{ State Forest } & 59.7 & 13.7 & 30.8 & 15.6 & 80.9 & 200.6 \\
Private & 314.1 & 74.0 & 189.0 & 93.3 & 507.5 & 1178.0 \\
National Forest & 15.1 & 3.4 & 8.2 & 4.0 & 21.0 & 51.7 \\
Other Public & 68.6 & 15.9 & 38.0 & 18.3 & 100.5 & 241.4 \\
\cline { 2 - 8 } All owners & 457.6 & 107.0 & 266.0 & 131.2 & 709.9 & 1671.6 \\
\hline
\end{tabular}


Table 4-Estimates of average forest carbon stock density (tonnes carbon per ha) from 1990-2017 by ownership class and carbon pool, Pennsylvania.

\begin{tabular}{lllllll}
\hline & \multicolumn{6}{c}{ Carbon pool } \\
\cline { 2 - 7 } Ownership class & $\begin{array}{l}\text { Above- } \\
\text { ground }\end{array}$ & $\begin{array}{l}\text { Below- } \\
\text { ground }\end{array}$ & $\begin{array}{l}\text { Dead } \\
\text { wood }\end{array}$ & $\begin{array}{l}\text { Forest } \\
\text { floor }\end{array}$ & Soil & Total \\
\hline \multirow{2}{*}{ State Forest } & 72.1 & 16.5 & 37.2 & 18.8 & 97.7 & 242.3 \\
Private & 63.4 & 14.9 & 38.1 & 18.8 & 102.4 & 237.7 \\
National Forest & 74.1 & 16.6 & 40.4 & 19.9 & 103.1 & 254.0 \\
Other Public & 68.1 & 15.8 & 37.7 & 18.2 & 99.8 & 239.5 \\
All owners & 65.2 & 15.3 & 37.9 & 18.7 & 101.2 & 238.3 \\
\hline
\end{tabular}

Table 5-Estimates of average annual change in carbon stock density (rate of sequestration) by ownership class per decade from 1991 to 2050, Pennsylvania. A negative value indicates a decrease in carbon stocks.

\begin{tabular}{rllllll}
\hline & \multicolumn{7}{c}{ Period } \\
\hline & $1991-$ & $2001-$ & $2011-$ & $2021-$ & $2031-$ & $2041-$ \\
Ownership class & 2000 & 2010 & 2020 & 2030 & 2040 & 2050 \\
\hline & & \multicolumn{6}{c}{$t$ Cha-1 } & yr-1 \\
State Forest & 0.48 & 0.33 & 0.16 & 0.13 & 0.09 & 0.05 \\
Private & 0.46 & 0.35 & 0.27 & 0.12 & 0.01 & -0.08 \\
National Forest & 0.52 & 0.75 & 0.69 & 0.61 & 0.52 & 0.41 \\
Other public & 0.69 & 0.61 & 0.45 & 0.36 & 0.26 & 0.17 \\
\cline { 2 - 8 } All owners & 0.32 & 0.28 & 0.18 & 0.08 & 0.00 & -0.08 \\
\hline
\end{tabular}

forests will continue to sequester carbon. However, the rate of carbon sequestration is projected to decline across all ownerships (Table 5). For instance, from 1990-2000 SFL sequestered carbon at a rate of 0.48 tonnes per ha, but from 2000 to 2010 this rate declined to 0.33 tonnes $C$ per ha and is projected to continue to decline in coming decades (Table 5). On Private lands, carbon stocks are projected to peak in 2036 and then decline through 2050, signifying the switch from an ecosystem $C$ sink to a source. However, this does not account for the carbon removed from the forest ecosystem that continues to be stored in HWP. Estimates indicate that National

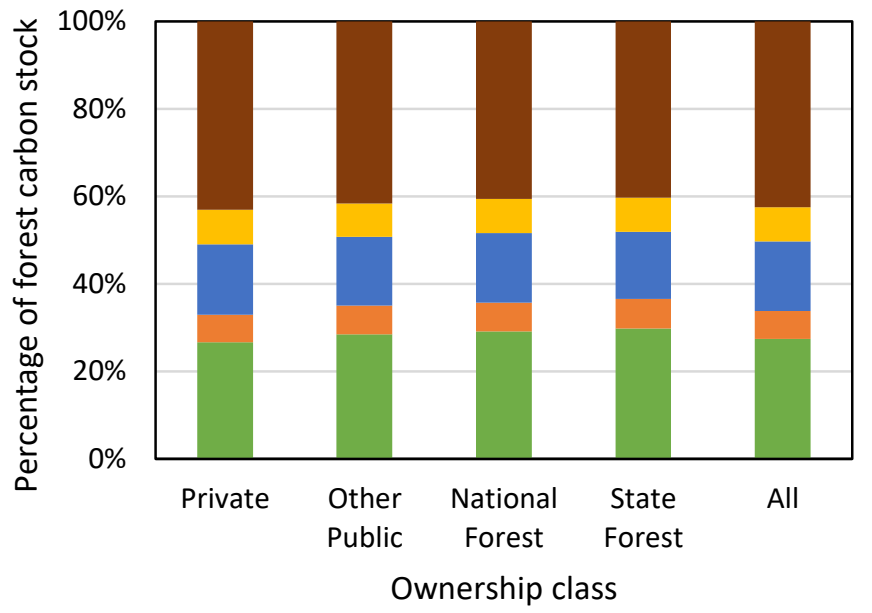

Aboveground Belowground $\square$ Forest floor Dead wood $\square$ Soil

Figure 10. Estimated percentage of carbon stock in each ecosystem carbon pool, averaged from 1990 through 2017 by ownership. The sum of the five pools is the total ecosystem carbon. 
Forest lands have consistently had the highest rate of sequestration, which have increased from 1990 through the early 2000s, but are also projected to decline in coming decades (Table 5).

Across ownerships, the soil pool stores the majority of forest carbon, followed by the aboveground live carbon pool

(Fig. 10, Tables 3, 4). On SFL, $40 \%$ of the forest carbon is stored in the soil, while $30 \%$ is stored in the aboveground live biomass. Over the historical period, the majority of the increase in $\mathrm{C}$ stocks occurred in the aboveground live pool. However, in the projected period (20182050), the forest floor and the dead wood pools are expected to experience the greatest increases as forests continue to age and experience greater mortality.

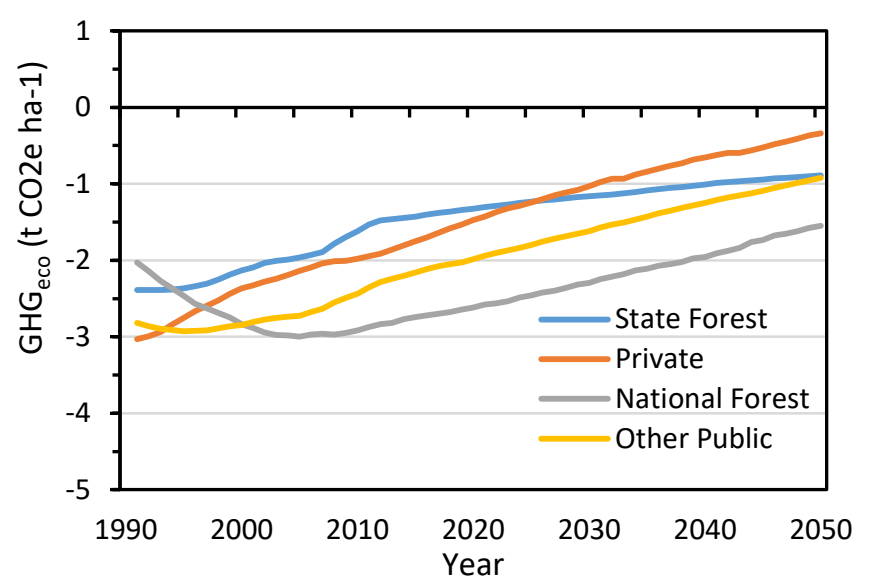

Figure 11. Modeled net GHG emissions per ha (t $\mathrm{CO}_{2}$ e ha1) for the forest ecosystem from 1990 to 2017 by ownership class, Pennsylvania. Negative values indicate a net sink. Estimates include do not include emissions from the removal of HWP. Values beyond roughly 2011 are projected.

Carbon emissions are typically reported from the perspective of the atmosphere. Thus a negative value indicates that the forest is a net sink, removing $\mathrm{CO}_{2}$ from the atmosphere (growth), whereas a positive value indicates the forest is a net source, emitting $\mathrm{CO}_{2}$ to the atmosphere (disturbance, mortality, decay). The balance between absorption and emission determines the carbon balance of the forest.

On average from 1990 through 2017, each ownership class in PA maintained net forest carbon sinks (Fig. 11, Table 6). Annually individual forest ownerships absorbed between 0.4 and 3 million tonnes of $\mathrm{CO}_{2} \mathrm{e}$ per ha throughout this period (Fig. 11). However, as with ecosystem carbon stocks, the strength of the sink of $\mathrm{CO}_{2} \mathrm{e}$ has declined steadily since 1990 on State Forests, Private, and Other Public lands.

Table 6. Estimated average annual net GHG emissions $\left(\mathrm{CO}_{2}\right.$ e) per ha for the forest ecosystem from 1990 to 2017 by ownership class, Pennsylvania. Negative values indicate a net sink. Estimates include do not include emissions from the removal of HWP.

\begin{tabular}{lcc}
\hline \multirow{2}{*}{ Ownership } & \multicolumn{2}{c}{$\mathrm{GHG}_{\mathrm{Eco}}$} \\
\cline { 2 - 3 } & $\mathrm{MtCO}{ }_{2} \mathrm{e}$ & $\begin{array}{c}\mathrm{tCO}_{2} \mathrm{e} \\
\text { per ha }\end{array}$ \\
\hline State Forest & -1.60 & -1.94 \\
Private & -11.21 & -2.26 \\
National Forest & -0.56 & -2.73 \\
Other Public & -2.65 & -2.63 \\
\cline { 2 - 3 } All owners & -16.02 & -2.38 \\
\hline
\end{tabular}

Sequestration of $\mathrm{CO}_{2} \mathrm{e}$ steadily increased on the Allegheny National Forest until 2008, then began to decline. Pulses of increased emissions occurred during periods of elevated harvesting as wood was transferred out of the ecosystem. However, not all carbon was lost during harvesting as much of it is stored in harvested wood products (see section 5.1.2).

From 1990 through 2017 forests in PA absorbed roughly 16 million tonnes $(2.38$ tonnes per ha) $\mathrm{CO}_{2}$ e per year from the atmosphere (Table 6, Fig. 11). The Allegheny 
National Forest had on average the highest rates of $\mathrm{CO}_{2}$ sequestration during the historical period, while SFL and Private lands had had the lowest.

Although forest ecosystem emissions are projected to increase and the strength of the sink may decline in coming decades, all ownership classes will likely maintain a net sink of $\mathrm{CO}_{2} \mathrm{e}$ (Fig. 6). Private forests are projected to experience the most rapid decline in the sink due to both aging and expected net forest loss (see section 5.1.4) (see also Appendix 11.4 Fig. A.4). However, results of ecosystem carbon stocks, which transfer $\mathrm{C}$ in harvested wood out of the forest ecosystem indicated that private lands could shift to a C source in 2037 (Table 5, Fig. 9). When including the emissions associated with the instantaneous oxidation of harvested wood from the forest ecosystem (INV $\left.V_{G H G}\right)$ as presented in Appendix 11.4, the results indicate that Private forests may shift to a source of $\mathrm{CO}_{2} \mathrm{e}$ in 2037. Over the next few decades, Allegheny National Forest is predicted to maintain the strongest C sink (Fig. 6).

The directional trends of stocks (increase), emissions (increase), and sequestration rates (decrease) are a result of multiple factors including forest aging, disturbances, land use change, and environmental conditions. These driving factors and the relationship between trends in carbon stocks and emissions are discussed in Section 5.1.4 of this report.

\subsubsection{Baseline harvested wood products carbon stocks and emissions}

In this analysis of HWP carbon stocks and emissions we assumed that the product sector started accumulating stocks in 1940 as part of a spin-up simulation. Thus, stocks and emissions contain inherited stocks from products in-use as well as products that have been retired to landfills prior to 1990.

Carbon storage in HWP across all ownerships increased from an estimated $36.4 \mathrm{MtC}$ in 1990 to 61.4 MtC in 2017, sequestering $25 \mathrm{MtC}$ (3.6 t C ha ${ }^{1}$ ) or $0.93 \mathrm{MtC}$ per year (Fig. 12). Carbon stocks in products sourced from private lands sequestered a total of approximately 19.9 MtC (4.0 t C ha-1) from 1990 to 2017. For State Forests only, HWP C storage increased from about 2.4 MtC in 1990 to

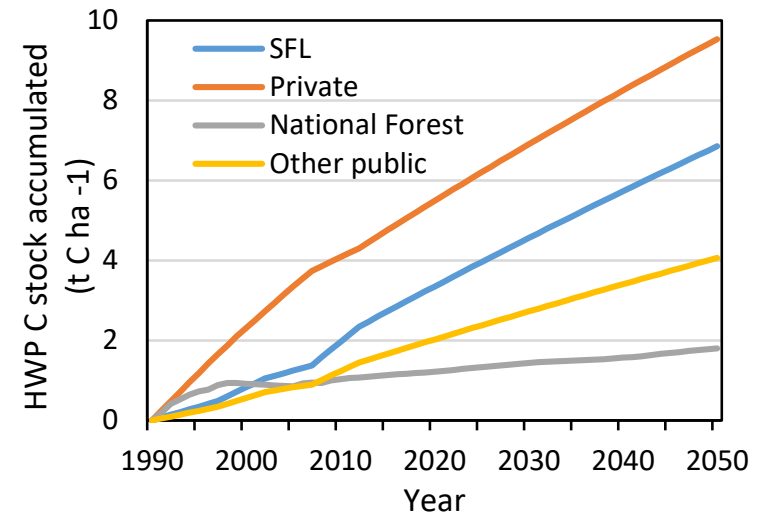

Figure 12. Estimated accumulation of HWP carbon stocks (per unit area) by ownership class in Pennsylvania. Values beyond roughly 2011 are projected. roughly 5.2 MtC in 2017, for a total sequestration of $2.8 \mathrm{MtC}\left(3.4 \mathrm{t} \mathrm{C} \mathrm{ha}^{-1}\right.$ ) (Fig. 12, 13a). Wood sourced from Private lands accounts for about $80 \%$ of the carbon sequestered in wood products from 1990 to 2017, while State Forests account for $11 \%$, Other Public lands $-8 \%$, and the Allegheny National Forest $-1.0 \%$.

Across ownerships, most of the harvested wood carbon is stored in sawlogs followed by pulpwood. In 2017 roughly $60 \%$ of the carbon harvested from SFL was stored in sawlogs, while pulpwood stored roughly $20 \%$, and mill residues stored $11 \%$ (Fig. 13a).

Harvested wood C storage should continue to increase even as the volume of wood harvested may level off. This is because the addition of carbon in the HWP pool through harvest exceeds the rate of decay of products. Thus if harvest rates and commodity ratios remain as they were in the recent past as in this 
simulation, HWP C storage as well as the rate of carbon sequestration in HWP are still projected to increase as more commodities are produced (e.g. Fig. 13a). If commodities are retired and transferred to landfills, as we assumed in this analysis, the $\mathrm{C}$ is retained for many decades to centuries depending on the commodity resulting in long-term carbon storage even after product retirement. However, the timeframe for which carbon is retained after product retirement depends on commodity ratios, the product decay rates associated with those commodities, and end of life disposal (landfill or burning), which may change in the future. We explore the impacts on changing commodity ratios and harvest rates in the mitigation analysis.
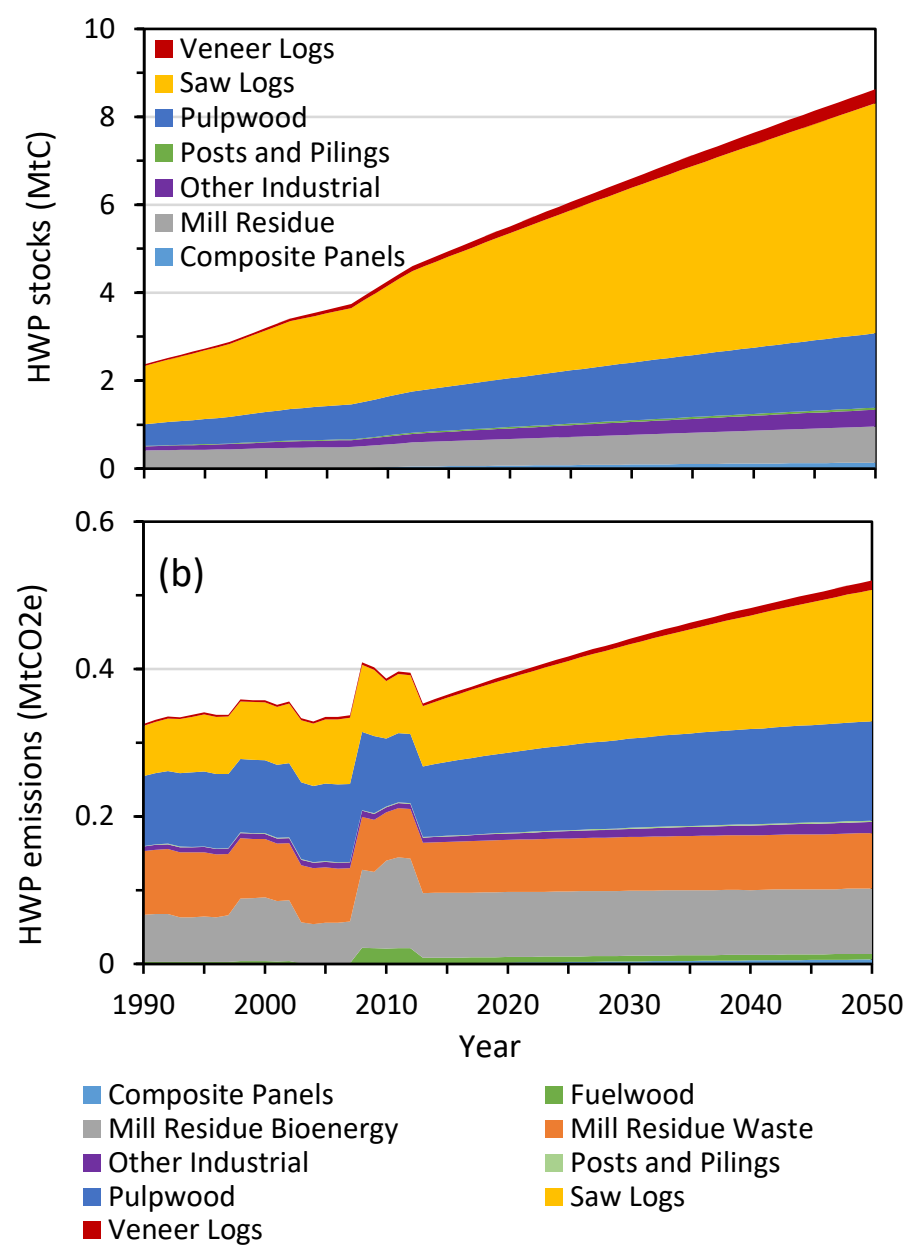

Figure 13. (a) Total carbon accumulation and (b) annual emissions by commodity type from harvested wood products from State Forest lands. Values beyond roughly 2011 are projected.
Although total C storage in HWP has increased overtime, trends in annual emissions have more closely followed harvest rates. Cumulative emissions from the HWP sector across all ownership classes were estimated to total $132 \mathrm{MtCO}_{2}$ e from 1990 to 2017, of which approximately $10 \mathrm{MtCO} 2 \mathrm{e}$ or $7.5 \%$ came from wood products harvested on SFL. Annual HWP emissions between 1990 and 2017 from SFL averaged $0.36 \mathrm{MtCO}_{2} \mathrm{e}$ per year (Fig. 13b). Annual emissions on SFL were elevated between 2008 and 2012 (Fig. 13b) due to elevated harvest volumes during this time period (Fig. 6). Emissions are also projected to gradually increase over the next few decades as more products are retired and begin to slowly decay in landfills.

While saw logs store the most $\mathrm{C}$ (Fig. 13a), the annual emissions associated with saw logs are relatively low and delayed (Fig. 13b) given their longer lifespan compared to other products. On the other hand, wood used for bioenergy (fuelwood) produces immediate emissions thus do not store any $\mathrm{C}$ in HWP, while pulpwood stores $\mathrm{C}$ in short-lived paper products that also produce emissions relatively quickly.

Roughly $75-80 \%$ of roundwood is processed for products and the rest ends up as mill residues. Most mill residues are utilized for either bioenergy (roughly 25\%) or goes back into the product stream to be used for commodities like pulpwood (65\%). As a result, although a large portion of harvested wood become mill residues, they account for a small fraction of HWP C storage, but almost half of all HWP emissions 
(mill residue waste and mill residue bioenergy) as they are utilized immediately in bioenergy or other short-lived products.

\subsubsection{Forest sector carbon balance}

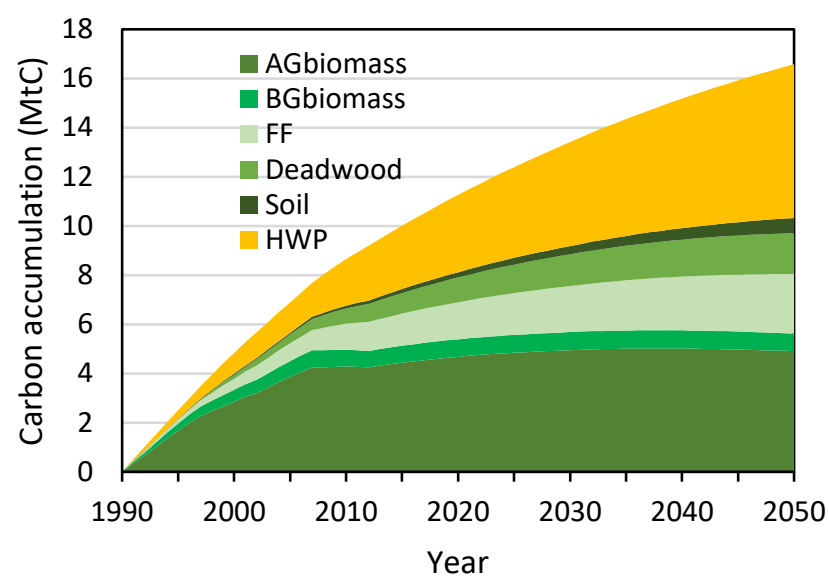

Figure 14. (a) Estimated carbon accumulation in the forest ecosystem pools and harvested wood products from 1990 to 2050 for State Forests in Pennsylvania. Values beyond 2011 are projected.

By combining the carbon storage in the forest ecosystem and HWP we can more comprehensively characterize baseline forest sector carbon trends. Results indicate that the PA forest sector has experienced an increase in C storage, indicating a net sink and is projected to maintain this net $C$ sink through 2050 (see Fig A4, in Appendix section 11.4). Likewise, $C$ storage in HWP and the forest ecosystem of State Forests increased from an estimated $198 \mathrm{MtC}$ in 1990 to 208.5 MtC in 2017 for a total increase of roughly 10.5 MtC (Fig. 14b). Although, HWP-only stored on average $2 \%$ of all forest sector carbon stocks, about $30 \%$ of the increase in stocks from 1990 to 2017 occurred in the product sector (Fig. 14b). If recent

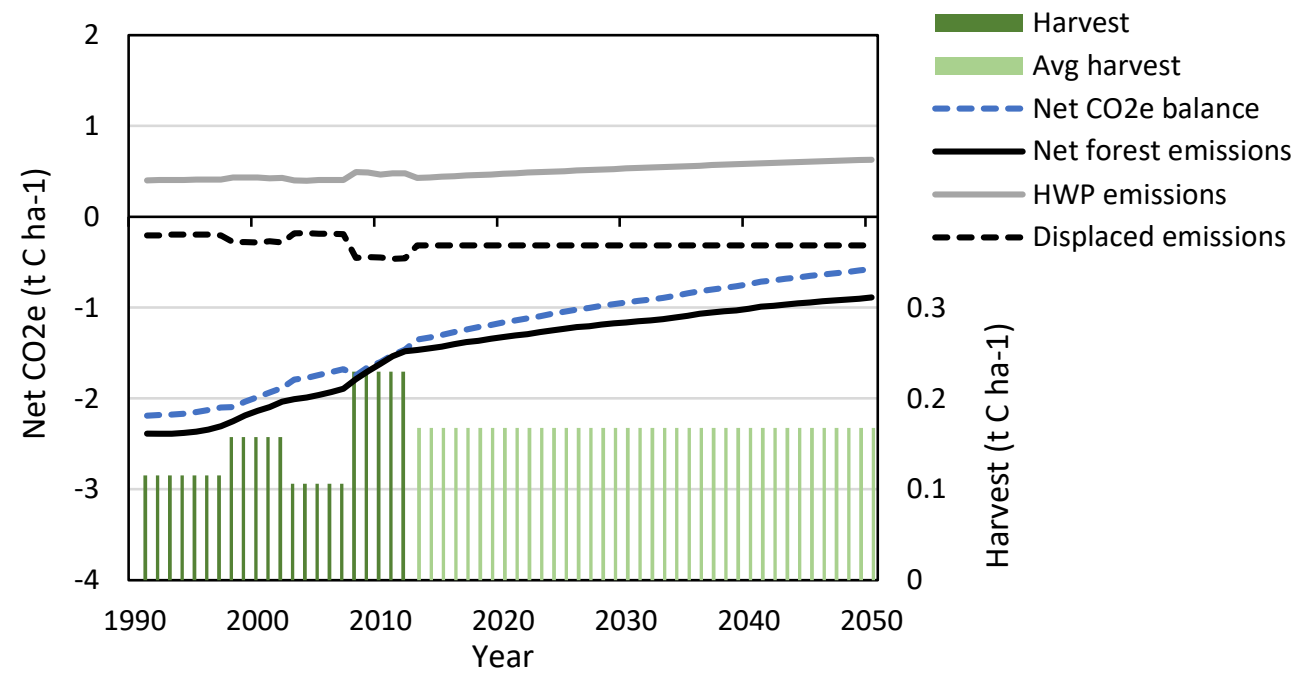

Figure 15. Modeled annual $\mathrm{CO}_{2}$ e balance for State Forest lands, which is the sum of sequestration from the forest ecosystem, emissions from HWP sector, and displaced emissions from substituting wood products for other emission intensive materials and fossil fuels (left axis). The historical harvest (MtC) per year are shown by the dark green bars and the 10-year average (2002-2011) harvest is shown by the light green bars (right axis). Note that carbon associated with harvested carbon are reported in the HWP emissions only and not the net forest emissions. Values beyond roughly 2011 are projected. 
conditions persist into the future, State Forests and the HWP commodities produced on SFL together are projected to sequester an additional 6.1 MtC from 2018 to 2050.

As previously mentioned in section 5.1.1, carbon accumulation in the forest ecosystem of Private lands are projected to decline starting in 2037 signifying a shift to a C source (Fig. 9). However, HWP stocks from Private lands are projected to continue to increase as more products are produced, effectively offsetting this decline and causing the forest sector to maintain a C sink through 2050 (see Fig A4, in Appendix section 11.4).

The net carbon balance of the forest sector is the sum of emissions from the forest ecosystem and HWP sector, minus the emissions displaced due to substituting wood for other materials and fossil fuels (Fig. 15). From 2008 to 2012, the rate of $C$ accumulation of stocks as well as emissions from the product sector were elevated (Fig. 15) on SFL due to an increase in harvest removals indicated by TPO data (Fig. 6). At this same time this increase in harvesting resulted in slightly elevated forest ecosystem emissions due to the decline in growing stock left in the forest. However, additional harvested wood also corresponds to additional substitution benefits as more wood is used for bioenergy and long-lived products. The net carbon balance for the SFL forest sector is estimated to be $\mathrm{C}$ sink and if conditions are maintained, the State Forests are projected to maintain this net sink through 2050. The forest ecosystem accounts for the majority of the carbon sequestered, while the substitution benefits (displacement emissions) offset some of the emissions associated with the HWP sector.

\subsubsection{Factors influencing forest ecosystem carbon trends}

Forest $\mathrm{C}$ dynamics are influenced by a variety of factors including disturbance and management, recovery and aging, climate, and atmospheric concentrations. In this section we qualitatively attribute the main factors influencing forest sector carbon stocks and emissions in Pennsylvania.

\section{Stand age and Disturbances}

Disturbances are explicitly considered as processes that release $\mathrm{C}$ into the atmosphere, modify the terrestrial $C$ balance, initiate regrowth, and subsequently transfer carbon from one pool to another (e.g. live trees to standing dead) in the disturbance year and thereafter. The type and magnitude of each disturbance determine the amount of $C$ released directly to the atmosphere as well as the transfer of $C$ from live pools to dead pools as a result of mortality, and the regrowth trajectory. Stand age acts a proxy for the time since last

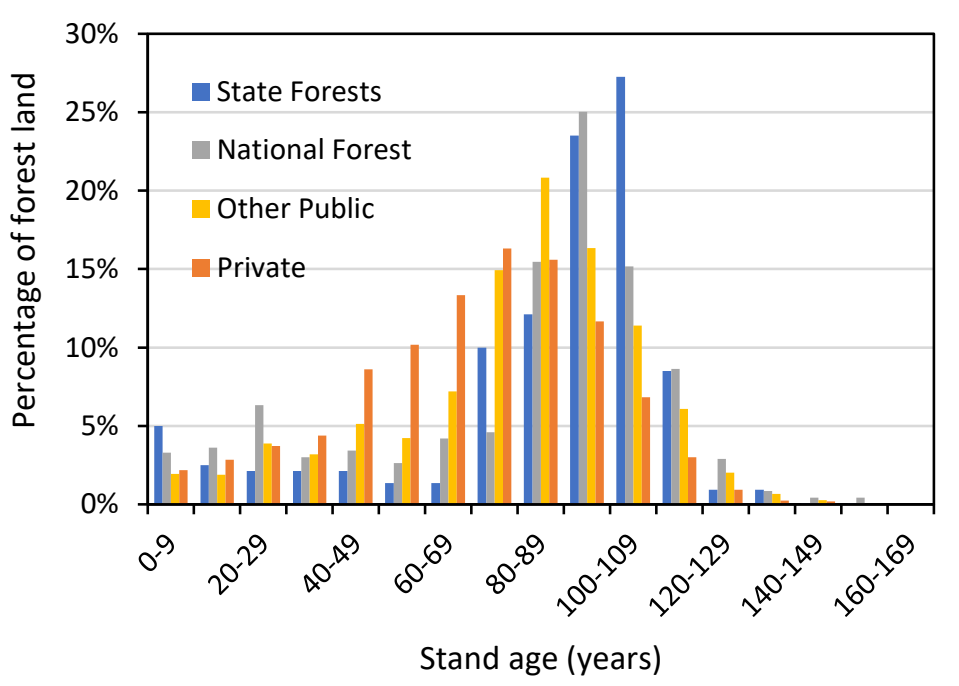

Figure 16. Percentage of forest in 2015 by age class and ownership class, Pennsylvania. 


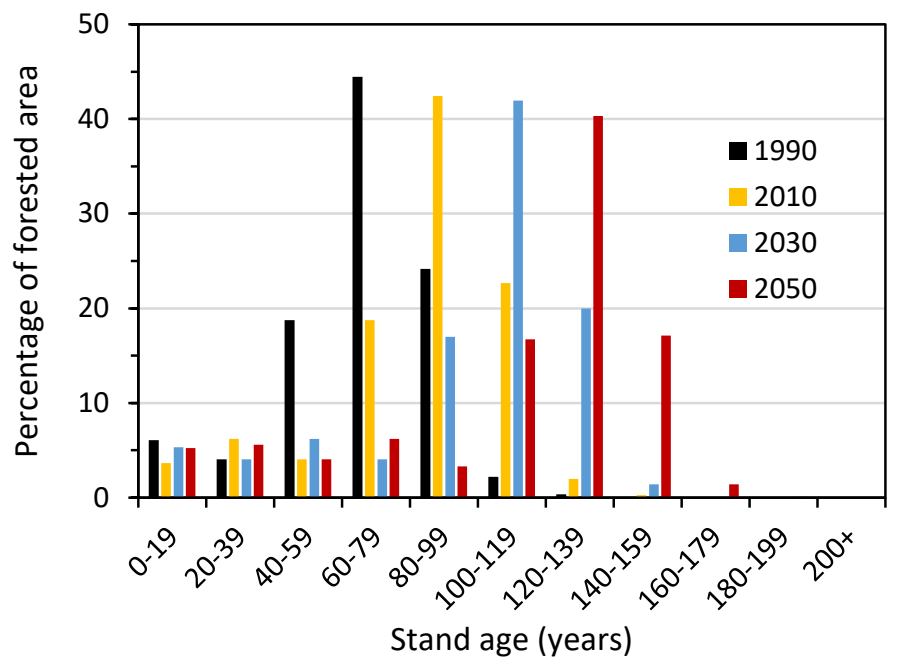

Figure 17. Modeled age-structure time series from 1990 to 2050 for State Forest lands, Pennsylvania. stand-replacing disturbance. After a stand-replacing disturbance event, stand age resets back to zero, and the forested stands recover and continue to grow following relatively predictable patterns (Pan et al. 2011) indicated by the growth and yield curves (e.g. Fig.2b) . The time since last disturbance largely determines whether a forest is a net sink or source. After a disturbance event, recovering forests may initially be a carbon source, for up to 10 years (Amiro et al. 2006) due respiration associated with an increase in dead and decaying material, coupled with a lack of growing stock.

Typically forests grow and accumulate carbon most rapidly at a young age, then reach a peak in productivity when the forest canopy closes at middle age, followed by a decline in productivity and carbon sequestration due to greater mortality and respiration (e.g. Fig. 2b) (Harmon 2001, Malmsheimer et al. 2008). Thus, younger fast growing stands typically have higher rates of $\mathrm{CO}_{2}$ absorption, but store lower amounts of $\mathrm{C}$ because the trees are generally smaller. Older forests tend to have lower rates of $\mathrm{CO}_{2}$ absorption, but can store high levels of $\mathrm{C}$ in both the biomass and soils (Harmon et al. 2001).

Across the commonwealth, the forest stand age shows a peak in the middle to older age classes (Fig. 16), a pattern that is typical of Northeastern forests in the U.S. (Pan et al. 2011). This trend generally reflects a pulse of regrowth and recovery after clearing for agriculture and reversion back to
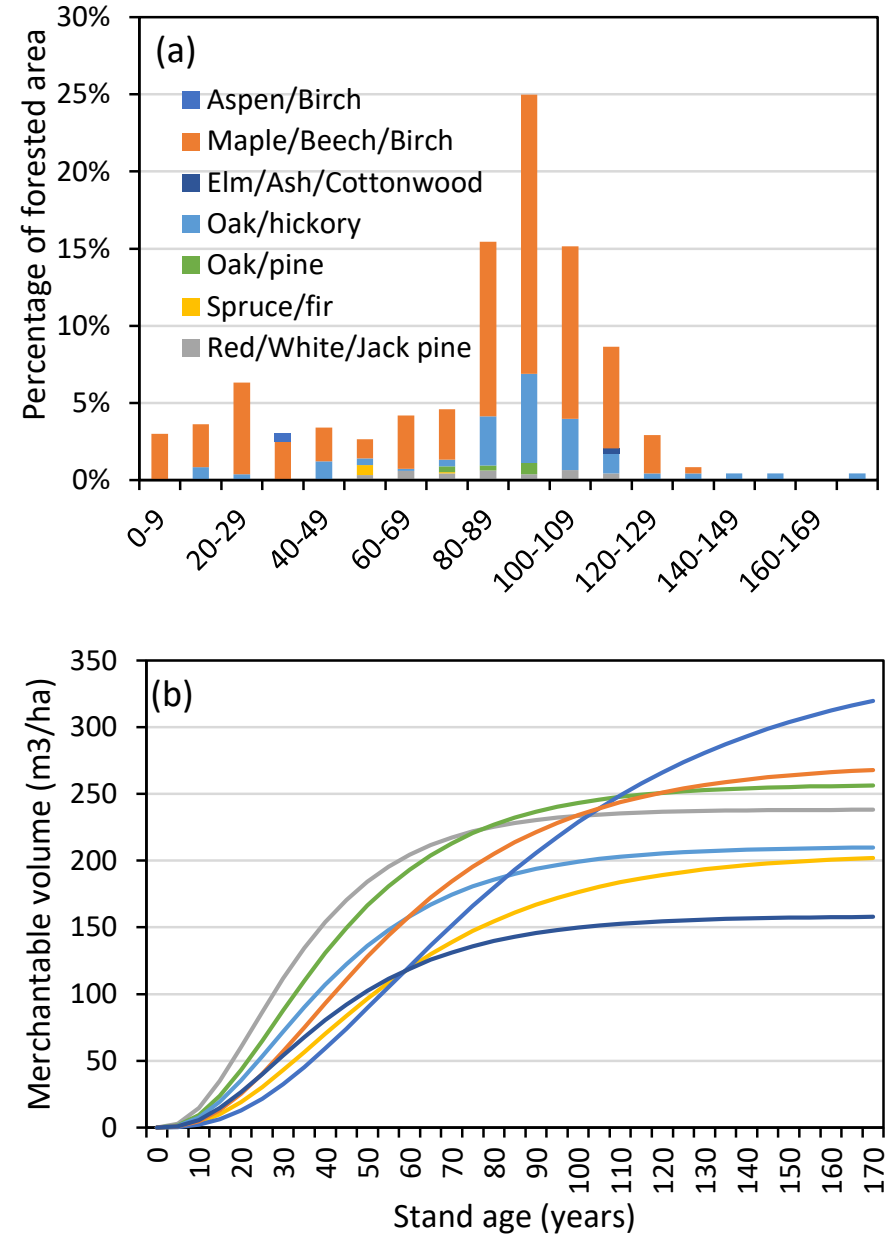

Figure 18. (a) Stand age distribution and (b) growth and yield curves, which represent annual carbon accumulation, by forest type for Allegheny National Forest in Pennsylvania. 
forests as well as periods of intensive harvesting that occurred in the early 1900s (Birdsey et al. 2006). Private lands have the youngest age structure as there is more active industrial timber harvesting and shorter harvest rotations, which maintains younger, more productive age structures (Fig. 16).

PA State Forests and the Allegheny National Forest have relatively older age class distributions as compared to the Private and Other Public ownership classes in the state (Fig. 16). The SFL age class structure shows a peak of stand establishment roughly 90-110 years ago (Fig. 16) or from 1905 through 1925 , or around the time that PA State Forests were established in response to the depletion of PA forestland in the mid-to-late $19^{\text {th }}$ century due to agricultural expansion and over-logging. If current disturbance rates persist into the future, we can expect the age class distribution to continue to shift to the right on SFL (Fig. 17) and other ownerships. Depending on the forest type, these stands would have been most productive from young to middle age, roughly till 60 years old (e.g., Fig. 2b, 18b). Thus, the productivity of most of these older stands has tapered off and stabilized. As a result, the rate of sequestration was higher from 1990 through 2000 than subsequent decades, and this rate of sequestration is projected to continue to decline (Table 5, Fig. 9). Because SFL are older as compared to Private and Other Public ownership classes, they have had higher $\mathrm{C}$ storage over the past few decades (Fig. 9, Table 3). However, because older forests have lower productivity characterized by higher mortality and respiration, the emissions from SFL are slightly higher than the other ownership classes in the state (Fig. 11, Table 6).

In addition to stand age, forest type also influences forest productivity and sequestration. For instance, like SFL, National Forest lands (Allegheny NF) also exhibit older stand age trends but has higher carbon stock density (Fig. 9, Table 3) and higher rates of sequestration (Table 2) compared to SFL. The dominant forest type of the Allegheny NF is Maple/Beech/Birch (Fig. 18a) which has higher productivity and reaches a higher stand volume than Oak/hickory stands (Fig. 18b) which are the dominant forest type on SFL (Fig. 2a).

The age-class distribution which reflects past land use, management, and disturbance trends and is critical to understanding $\mathrm{C}$ trends in the past, is also a useful indicator of prospective carbon dynamics. For instance, a landscape that is dominated by older forests, as is the case for SFL will not likely experience much more of an increase in $\mathrm{C}$ stocks in the future, but rather will see stocks stabilize, unless disturbance regimes and management practices change.

\section{Land use change}

Changes in forested area through deforestation, reforestation and afforestation also impact the rate of $C$ sequestration and emissions on a landscape. In this study, we assumed that the Allegheny National Forest and SFL did not experience significant land use change during the historical period (PA DCNR, pers. communication). However, the Private and Other Public ownership classes experienced net losses of forested area since 1990, according to remotely sensed data. Although deforestation is partially offset by afforestation, removing forest cover reduces $\mathrm{C}$ stocks and increases emissions in a short amount of time, whereas it takes much longer to accumulate $\mathrm{C}$ stocks from afforestation. Results here indicate that forest carbon emissions on Private lands would have been roughly 20\% lower in 2017 if there had not been deforestation from 1990 through 2017 and the net ecosystem carbon balance would more closely resemble the forestland remaining forestland line in Fig. 19. 


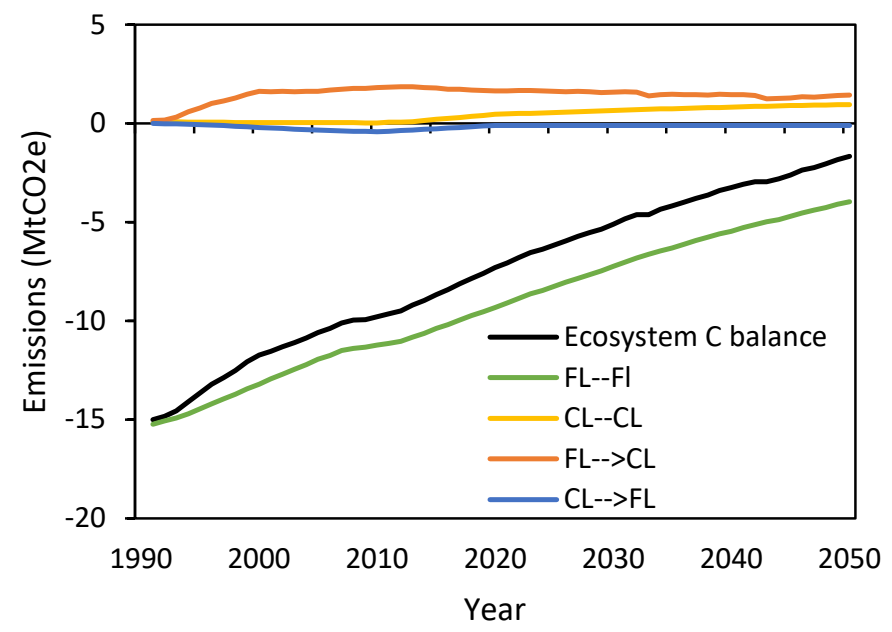

Figure 19. Estimated annual forest ecosystem emissions from each land class within the forest ecosystem including: forest land remaining forest (FLFL), cropland (nonforest) land remaining cropland (CL-CL), forest converted to cropland ( $F L \rightarrow C L$ ), cropland converted to forest $(C L \rightarrow F L$ ), and all land classes combined (Net ecosystem C balance) from 1990-2050 for Private lands, Pennsylvania. Values beyond 2012 are projected.
We assumed that deforestation rates on private and other public lands would remain constant through the projection period.

\section{Climate and Environmental Factors}

Environmental factors including climate, nitrogen deposition, and atmospheric $\mathrm{CO}_{2}$ concentrations also influence forest growth and subsequently carbon sequestration. Both long-term climatic trends and inter-annual climatic variability can impact forest $\mathrm{C}$ dynamics by affecting growth, productivity, and decomposition. Human-induced climate change has caused increases in average temperatures across most of the U.S., as well as regional shifts in precipitation resulting in the northeast becoming wetter (Walsh et al. 2014). Like climate, the amount of greenhouse gases and particulates in the atmosphere impact plant growth and subsequent $\mathrm{C}$ dynamics (e.g. Pan et al. 2009, Law 2013). Atmospheric $\mathrm{CO}_{2}$ levels have increased steadily from 280 ppm in 1901 to 390 ppm 2010 (Keeling et al. 2009) due to human activities including land use change, agriculture, and fossil fuel burning. Elevated atmospheric $\mathrm{CO}_{2}$ concentrations and nitrogen deposition act as a fertilizer, stimulating photosynthesis and biomass production (Pan et al. 2009, Thomas et al. 2010).

As part of a related study (Dugan et al. 2017), we evaluated the impacts of nondisturbance factors (climate, atmospheric $\mathrm{CO}_{2}$, and nitrogen deposition) relative to disturbance factors (fires, harvests, insects, aging/regrowth) on $\mathrm{C}$ accumulation across individual National Forests, including the Allegheny National Forest in Pennsylvania. We utilized the Integrated Terrestrial Ecosystem Carbon (InTEC) model, a process-based

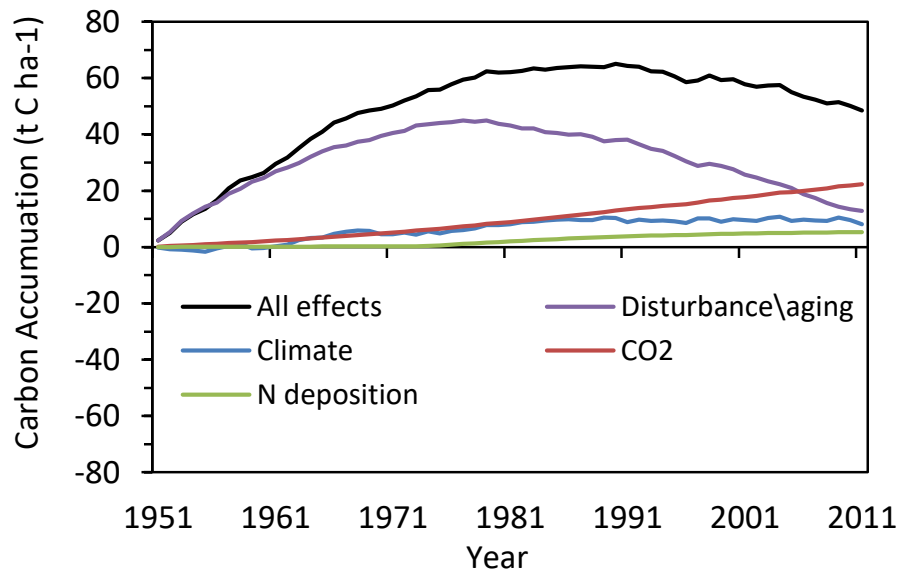

Figure 20. Modeled accumulated carbon (t C ha-1) due to individual disturbancelaging and non-disturbance factors and all factors combined from 1951-2011 excluding $C$ accumulated pre-1950 for Allegheny National Forest in Pennsylvania. A positive slope indicates that the forest is accumulating carbon; a negative slope indicates a decline in forest carbon. 
model which simulates biogeochemical processes using mathematical equations as well as remotely sensed and forest inventory input datasets (Chen et al. 2000).

Results indicate that disturbance/aging are the dominant factors influencing long-term carbon accumulation on the Allegheny National Forest (Fig. 20). Atmospheric $\mathrm{CO}_{2}$ concentrations have caused an increase in $\mathrm{C}$ accumulation though mostly over the last few decades. Climate and nitrogen deposition had relatively small but positive impacts on $\mathrm{C}$ accumulation since the 1950s. The climate impact shows significant interannual variability following variability in temperature and precipitation. Although nitrogen deposition is relatively high in the northeastern U.S., the effects of nitrogen deposition on C accumulation were small, likely due to nitrogen saturation which has been exhibited in northeastern forests (Aber et al. 1998). Though the InTEC model was not run across all ownership classes in PA, the broad environmental factors that we analyzed would have similar effects across forests regionally.

\subsection{Mitigation Scenarios}

In this section we evaluate and rank the climate change mitigation scenarios tested across Pennsylvania. Although the scenarios were run for each ownership class, here we focus on the mitigation potential of State Forest lands (SFL), but results for the other ownerships are shown in Appendix section 11.6.

Of the ten mitigation scenarios we evaluated on SFL the extend rotation - high scenario had by far the greatest projected cumulative mitigation benefit, resulting in a net reduction in cumulative forest sector GHG emissions of approximately $4 \mathrm{MtCO}_{2} \mathrm{e}$ by 2050 (Fig. 22, 21). This represents a $6 \%$ reduction in cumulative emissions by 2050 . To achieve an extended rotation harvests were reduced by $20 \%$ on SFL causing a mitigation benefit in the forest ecosystem (Fig. 22, 23a) as more live biomass is left in the forest to sequester $\mathrm{CO}_{2}$. At the same time, less biomass was transferred to the product pools, thus reducing HWP sector emissions (Fig. 22b). An additional 5\% of harvested wood was shifted from paper products to long-lived products (LLP), which had a small displacement benefit (Fig. 22, 23c), but because less wood was harvested there was less product and bioenergy substitution. The more moderate extend rotation - low scenario, which reduced harvests by $10 \%$ and had a minimum harvest stand age of 100 years had similar but lesser mitigation impacts, reducing GHG emissions by an estimated $1.8 \mathrm{MtCO}_{2} \mathrm{e}$ by 2050 , or a $2.8 \%$ reduction in cumulative emissions. On the other hand, the short rotation scenario had the opposite effect and ranked last, resulting in a net increase in GHG emissions of roughly $2.1 \mathrm{MtCO}_{2} \mathrm{e}$ by 2050 , or a $3.2 \%$ increase in cumulative emissions. To achieve a shortened rotation, harvests were increased by $20 \%$ on SFL (10\% on other ownerships) which caused less biomass to remain in the forest to sequester carbon. Also, all of the additional harvested wood was utilized for bioenergy which had a significant displacement effect by reducing fossil fuels, but also caused additional emissions in the HWP sector through the burning of additional biomass.

The other forest management scenarios had smaller but positive mitigation benefits. Increasing the collection of residues by implementing whole tree harvest operations for clearcut harvests ranked sixth and had a small cumulative mitigation benefit of roughly $0.92 \mathrm{MtCO}_{2} \mathrm{e}$ by 2050 , or a $1.4 \%$ decrease in cumulative emissions by 2050. Increasing residue removal results in less dead wood being left on the forest floor to decay, thus a reduction in emissions from the forest ecosystem. However, all the additional residues were used for bioenergy,y which caused increased emissions from the HWP sector, but a substitution benefit by displacing fossil fuel energy. 
Increasing productivity through silvicultural activities had a minimal impact on the forest ecosystem carbon, reducing emissions by an estimated $0.17 \mathrm{MtCO}_{2}$ e by 2050 , for only a $0.25 \%$ decrease in cumulative emissions. For increasing productivity to have a greater impact, it is likely that a significant portion of the landscape would have to be treated, which may not be feasible. Also, increasing productivity had variable impacts across ownerships. It even resulted in a cumulative net increase in emissions on private lands. This may be because if stands that were treated stored more total carbon than in the baseline and were later harvested in the simulation, a greater amount of carbon would have been removed from the ecosystem.

The portfolio scenario which combined several forest management scenarios including the extend rotation - low, the residues, and the productivity scenarios ranked second, reducing cumulative emissions by an estimated $2.5 \mathrm{MtCO}_{2} \mathrm{e}$ by 2050 (3.7\% decline in cumulative emissions). Thus if we had instead combined the rotation-high scenario with the residues and productivity scenarios, we could expect a significant mitigation benefit, greater than $4 \mathrm{MtCO}_{2}$ e by 2050.

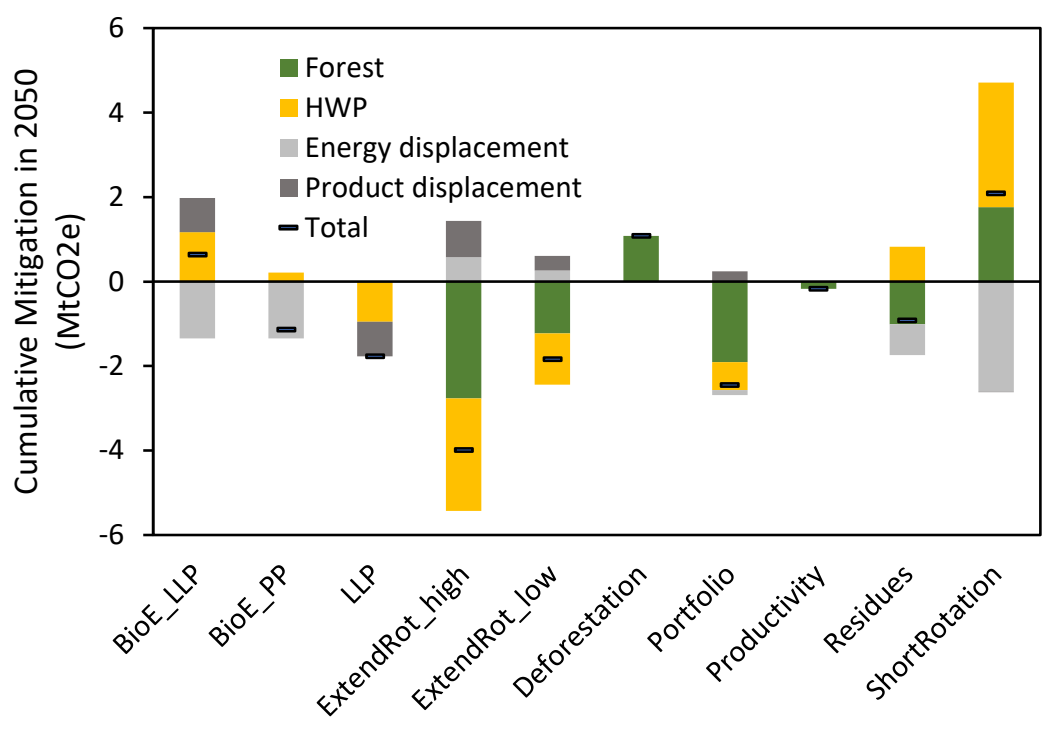

Figure 22. Estimated cumulative mitigation by component in 2050 for the State Forest lands, Pennsylvania. A negative value indicates a mitigation benefit.

Of the HWP scenarios, increasing LLP had greatest projected mitigation benefit, ranking fourth overall and reducing cumulative emissions by an estimated $2.7 \%$ by 2050 . Increasing LLP had no impact on the forest ecosystem, but it reduced emissions from the HWP sector due to longer product half-lives associated with using more wood for saw logs over pulp and paper, thereby displacing emissions from higher emitting materials. The impact of increasing the proportion of harvested wood for bioenergy had varying affects based on the longevity of the product it replaced. For instance, increasing bioenergy at the cost of pulpwood (bioE-PP), another short-lived product had a small mitigation benefit, reducing cumulative emissions by roughly $1.7 \%$ by 2050 , mostly due to the displacement as bioenergy substituted for fossil fuel energy. However, increasing bioenergy while decreasing LLP (bioE-LLP) resulted in a projected cumulative increase in emissions by $0.95 \%$ as the bioenergy substitution benefit was offset by a reduction in product displacement.

To evaluate the carbon consequences of the potential expansion of natural gas development on SFL, we simulated a deforestation scenario. Increasing deforestation by roughly 50 ha every 5 years through 2050 (total forestland loss of 4,700 ha by 2050) only impacted the forest ecosystem component and resulted in a projected increase of GHG emissions of $1.1 \mathrm{MtCO}_{2} \mathrm{e}$ through 2050 (1.6\% increase in emissions). The increase deforestation scenario was implemented differently across ownerships and 
thus had varying degrees of impact on each ownership class. For instance, for private and other public lands, deforestation was increased by $5-10 \%$ above current levels. Since deforestation rates are quite low on Other Public lands, increasing forest cover loss by a small amount ( $<600$ ha by 2050) had little impact.

Scenarios that impact different parts of the land base and do not interact could also be assessed together as well. For instance, increasing the use of logging residues for bioenergy, increasing productivity, and shifting additional harvested wood to LLP had a combined projected cumulative mitigation benefit of $2.8 \mathrm{MtCO}_{2} \mathrm{e}$ through 2050 , or a $4.2 \%$ decline in cumulative emissions. 

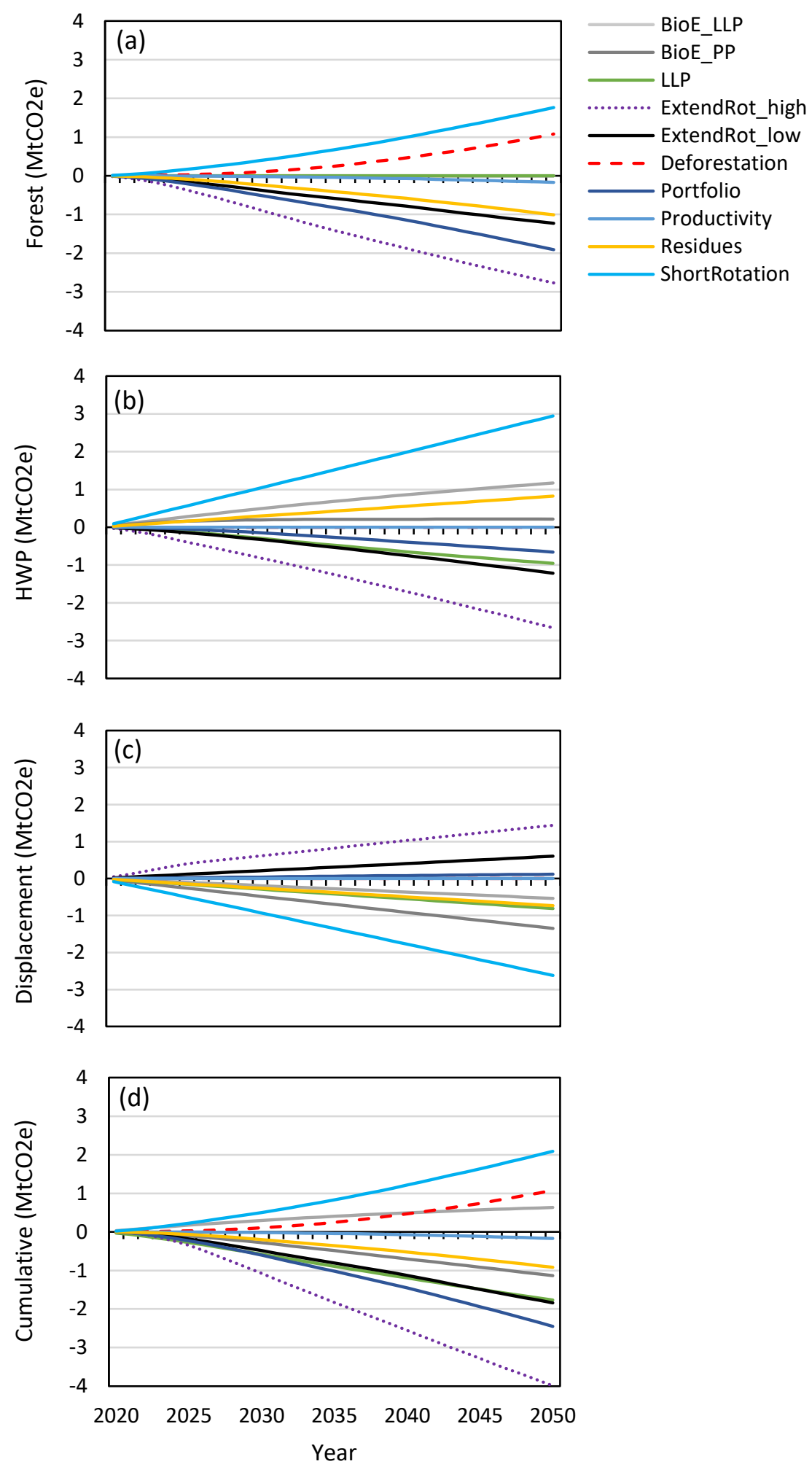

Figure 23. Modeled cumulative mitigation for (a) forest ecosystem, (b) harvested wood products sector, (c) product and fossil fuel displacement, and (d) all components combined, from 2020 to 2050 for State Forest lands, Pennsy/vania. In all cases, negative numbers indicate a net reduction in emissions. 


\subsection{DISCUSSION}

\subsection{Baseline stocks and emissions}

Over the past few decades' forest ecosystem carbon stocks in Pennsylvania have been increasing resulting in forests being a net sink of $\mathrm{CO}_{2}$ from the atmosphere and increasing the storage of carbon (C) in biomass. During the historical period (1990-2017), Allegheny National Forest sequestered the most C per hectare followed by Other Public lands, then State Forests, and lastly Private lands. Private lands, which include commercial timberlands and account for $85 \%$ of the merchantable $C$ extracted in the state, are typically more heavily managed than public lands in the state. Behind private lands, SFL experience more timber extraction (7\%) than Other Public lands (6\%) and the Allegheny National Forest (2\%). Thus, results here may suggest that more intensive management regimes and timber extraction results in lower carbon sequestration in the forest ecosystem, a conclusion supported by other studies in the northeast (Nunery and Keeton 2010, Gunn and Buchholz 2018). Although C stocks have been increasing, model results indicate that sequestration rates have been declining across ownerships. If historical disturbance and land use change (LUC) conditions are maintained, sequestration rates are projected to continue to decline over the next few decades, signifying a reduction in the strength of the $\mathrm{C}$ sink. On private lands, net $\mathrm{C}$ sequestration of $\mathrm{C}$ stocks in the forest may cease by 2037 causing forest ecosystem to shift to a $\mathrm{C}$ source.

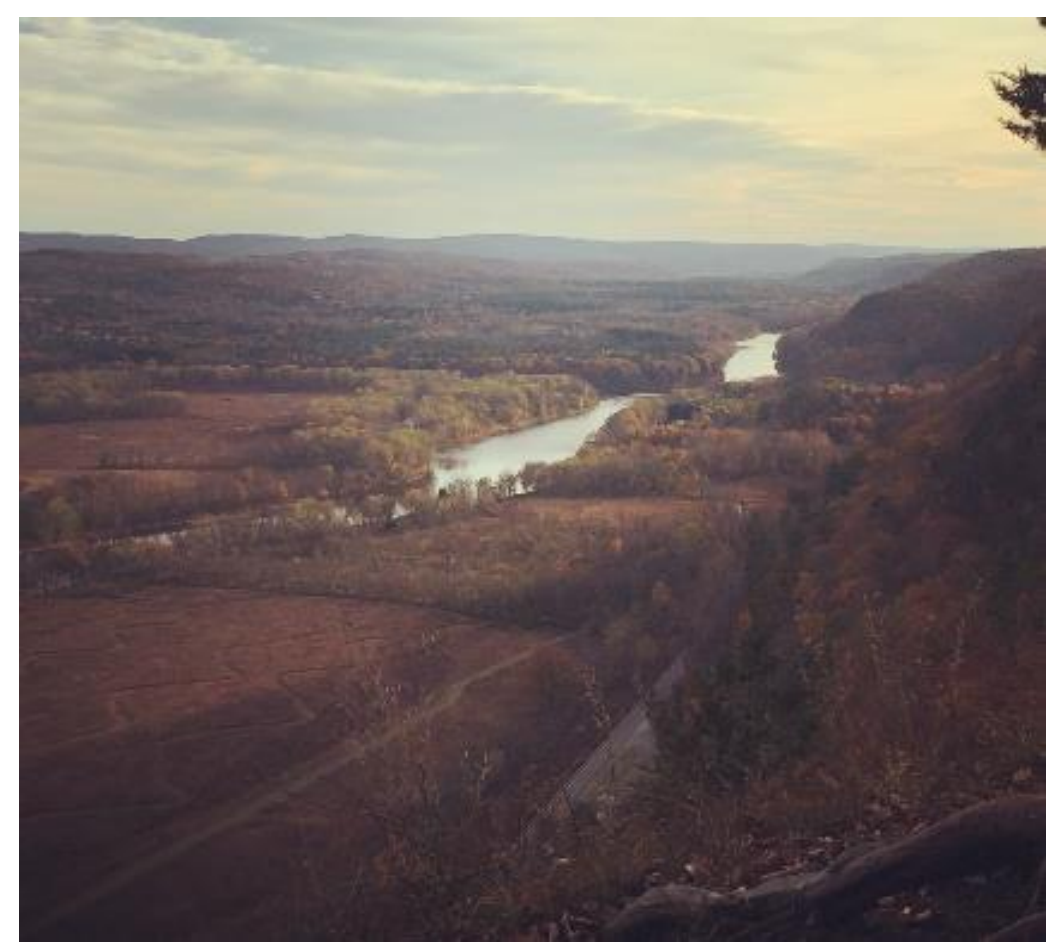

Delaware Water Gap, Pennsylvania. Photo by Alexa Dugan, U.S. Forest Service.
It also necessary to consider the $\mathrm{C}$ stored in harvested wood products (HWP) when characterizing forest sector $\mathrm{C}$ stock change and whether an area is a sink or a source.

Since 1990, C stored in HWP has increased across ownership classes as more commodities are produced and enter the in-use stream. Even when commodities are retired, they continue to store carbon in landfills for many decades as decay rates are slow (IPCC 2006). HWP on private lands are projected to continue to sequester $\mathrm{C}$. HWP C sequestration may partially offset the decline in forest $C$ stocks and enable the forest sector to maintain a net sink

of C through 2050 (HWP and forest). From 1990 to 2017, SFL sequestered 2.8 MtC in HWP and 10.5 MtC (0.4 MtCyr-1) in forests and wood products combined. The rate of sequestration in HWP is projected to slow as more products are retired and in forests as stands continue to age. However, modeled results 
indicate that SFL will maintain a net carbon sink and sequester another $6.1 \mathrm{MtC}$ in forests and products by 2050 . Overall, if baseline conditions are maintained, the PA forest sector is projected to maintain a $\mathrm{C}$ sink through 2050.

The trends in forest $\mathrm{C}$ storage across the state have been predominantly driven by forest aging, which is influenced by disturbance rates and severity. State Forests followed by the Allegheny National Forest have the oldest stand age distributions among ownerships due to their relatively low rates of harvesting and extended rotations. Therefore, SFL and the Allegheny have the highest stores of carbon per hectare. Private lands experience more harvesting and of generally younger stands. This causes fewer stands to reach these older age classes, which are often characterized by larger size classes and higher carbon stores. While older forests typically store more carbon, their productivity (growth rate) and subsequently sequestration is lower due to increased morality and respiration associated with the decay of dead organic matter (Harmon 2001, Malmsheimer et al. 2008) causing higher emissions. On the other hand, higher rates of harvesting may maintain younger and more productive forests. This can result in lower Total $\mathrm{C}$ storage in the forest, but higher $\mathrm{C}$ storage in products. The decline in the rate of forest $\mathrm{C}$ sequestration in Pennsylvania forests due to aging is consistent with results across the National Forest System (Dugan et al. 2017) and projections across U.S. forests (Turner and Koerper 1995, Hurtt et al. 2002, Birdsey et al. 2006, Wear and Coulston 2015). Forest aging indicates a potential shift from a C sink to a source in the future.

The largest decline in $\mathrm{C}$ sequestration is projected to occur on Private lands, which are also experiencing deforestation. We assumed that land use change rates would remain constant in the future. However, projections of population growth, income, and urbanization suggest that there may be increased demand for converting forested lands to agriculture or housing in coming decades (Wear et al. 2013, USDA 2016). Also, if the rate of natural gas development in the state were to continue to increase as it has over recent years (Phillips 2017), this could cause additional deforestation.

In addition to forest aging and land use change, it is broadly recognized that climate change may also increase the severity and frequency of damage caused to forests by wildfire (Anderegg et al. 2013), insects (Kurz et al. 2008, Bentz et al. 2010), hurricanes (McNulty 2002), and drought (Allen et al. 2010). Insect outbreaks are the dominant forest disturbances in Pennsylvania and may pose serious threats to long-term forest health and sustainability (PA DCNR 2015). Since 1990, these disturbances have affected a relatively small percentage of the total forested area in the state (Fig. 5) and were typically not stand replacing. Therefore, insect outbreaks may not result in obvious or long term losses in total ecosystem carbon as compared to harvests or fires (Amiro et al. 2010). There is much concern that the emerald ash borer (EAB) has the potential to eliminate the entire ash genus. However, ash trees represent a small component of the state's forests (Lui 2013). Also, while EAB may cause tree mortality, that carbon is not immediately emitted to the atmosphere. Rather $E A B$ mortality causes $C$ to shift from the live tree pool to the dead tree pool, which may continue to store carbon for many decades. Insects and disease can reduce stand productivity as these dead trees are no longer absorbing carbon, but will rather emit carbon as they slowly decompose. This could reduce the strength in the forest C sink (Kurz et al. 2008, Flower et al. 2013. However, the decline in productivity associated with ash death may be partially offset by a growth response of non-ash trees (Flower et al. 2013). Our analysis did not consider urban and suburban ash trees. Therefore, we may underestimate the impact of EAB on total tree carbon in the state. . As the climate continues to change forests are expected to become more susceptible to insects, 
pathogens and invasive species (Dukes et al. 2009, Allen et al. 2010) which could reduce forests ability to sequester carbon (Kurz et al. 2008).

Despite forest aging, land-use change, and disturbances in the commonwealth, PA's forests carbon stocks have increased across ownerships. Although, over the past few decades Pennsylvania has experienced warming temperatures and increased variability in precipitation, results from a related study indicate that climate has slightly enhanced carbon accumulation on the Allegheny National Forest lands (Dugan et al. 2017). Furthermore, elevated levels of atmospheric $\mathrm{CO}_{2}$ have also increased growth rates, partially offsetting the decline in growth rates associated with the aging forests. Other studies have indicated enhanced productivity in the northeastern hardwood forests due to longer growing seasons and $\mathrm{CO}_{2}$ fertilization (Ollinger et al. 2008). It is unlikely that potential enhancements in forest growth would be able to fully offset the projected age-related declines in productivity.

\subsection{Mitigation Analysis}

Our modeling results indicate that there is a potential to reduce forest sector carbon emissions in Pennsylvania through altered management activities and changes to harvested wood products commodity ratios. However, it is critical to recognize that the results here are influenced by the specific scenario parameters and assumptions evaluated, as well as the modeling framework and inputs used to derive these estimates.

Of all scenarios evaluated, extending harvest rotations ranked first in reducing emissions, while more intensive forest management that shortens harvest rotations increased emissions, a conclusion that is supported by several other mitigation analyses in North America (Li et al. 2007, Liski et al. 2001; Euskirchen et al. 2002, Nunery and Keeton 2010, McKechnie et al. 2011; Ter-Mikaelian et al. 2011, Smyth et al. 2014, Gunn and Buchholz 2018. Dugan et al. in review) and Europe (Liski et al. 2001). There are important carbon trade-off to extending rotations including the loss of carbon stored in HWP and subsequently less substitution of wood for fossil fuel energy or alternative products. There are also economic trade-offs to consider such as the loss of revenue from the reduction in timber harvests. In our shortened rotation scenario, all of the additional harvested material relative to the baseline were used for bioenergy. The increase in bioenergy caused large and immediate emissions from both the ecosystem through the removal of growing stock and the HWP sector through the combustion of bioenergy. The increase in emissions were not fully offset by the substitution for fossil fuels during this 30 year analysis period. If the additional harvested wood had been used for long-lived products, the emissions from the HWP sector would still be elevated due to additional products, but less than if used for bioenergy (Van Deuson 2010), at least over this short time span.

Several studies suggest that high harvest frequencies which increase carbon stored in wood products or biofuels have long-term mitigation potential (longer timeframes than simulated here) when considering substitution (Eriksson et al. 2007, Miner et al. 2014). Others suggest that retaining older forests results in lower emissions than promoting young, fast growing stands (Harmon et al. 1990, Harmon and Marks 2002). Our results would seem to agree with the latter. Results of the baseline analysis indicate that sequestration rates are declining and ecosystem emissions are increasing because forests are becoming older and less productive, which counters this argument. However, it may take several decades or centuries to pay back the "carbon debt" associated with the loss of stored biomass and even longer to 


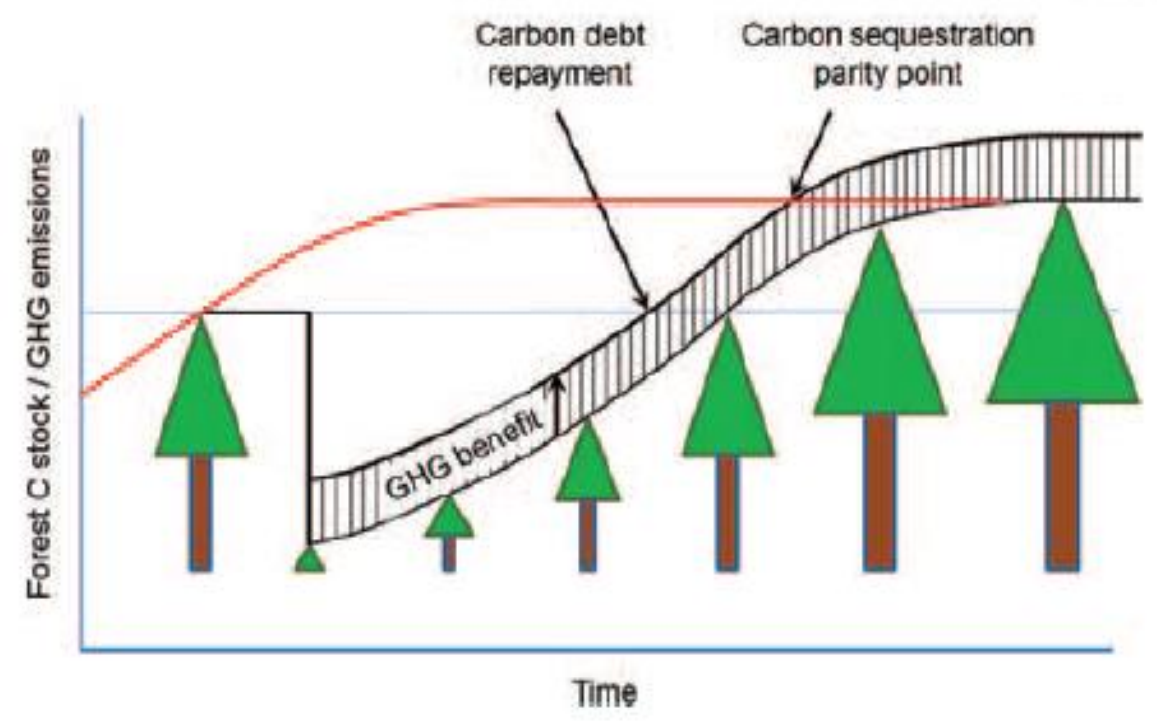

Figure 24. Hypothetical effects of harvesting forests for bioenergy to replace coal used to generate electricity on forest carbon stock change and total GHG emissions. The carbon sequestration parity is achieved when the sum of the carbon in the regenerating stand and the GHG benefits of using wood to replace coal reaches the amount of carbon in the stand if it had remained unharvested. The carbon debt repayment is achieved when the sum of carbon in the regenerated stand and GHGH benefits of using wood bioenergy to replace coal reaches the preharvest amount of carbon in the stand (Figure $2 d$ from Ter-Mikaelian et al. 2015).

realize net benefits from using whole trees for bioenergy (Walker et al. 2013, Miner et al. 2014, TerMikaelian et al. 2015, Buchholz et al. 2015, Birdsey et al. 2018; Fig. 24). Our mitigation analysis was fairly short (30 years), not even spanning a full rotation. If we continued to run the simulation for another 100 years, we would likely see net benefits from the short rotation scenario as it may take several decades and multiple rotations for the forest system to accrue the $\mathrm{C}$ lost from the ecosystem via sequestration in landfills, products, and with substitution and reach the "carbon sequestration parity" (Ter-Mikaelian et al. 2015, Birdsey et al. 2018, Fig. 24). For instance, the Manomet Report released in 2010 which examined a range of forest bioenergy scenarios in Massachusetts found that it required around 45-75 years to achieve net benefits from using whole trees to displace fossil fuels (Manomet Center for Conservation Sciences 2010, Walker et al. 2013). Similarly Buchholz et al. (2015) found a mean carbon payback period of 51 years in their global meta-analysis of forest bioenergy studies. On the other hand, the extend rotation scenario may show benefits in the short-term. However, as stands age, productivity further declines and trees experience mortality, causing the $C$ stocks to plateau or eventually decline (Van Deuson 2010, Nunnery and Keaton 2010, Malmsheimer et al. 2011). Though bioenergy scenarios may be effective over longer timeframes, to reduce global temperature increase to 2 degree $C$ by the end of the century, the IPCC recommends that we reach net zero emissions by 2060-2070 and net negative emissions thereafter. Consequently, the time desired to achieve mitigation is an important consideration when implementing management strategies.

The impacts of using forests for bioenergy also depends on the feedstock utilized and the alternative fate of the wood (Birdsey et al. 2018). Harvesting live trees for bioenergy increased emissions over the 
short timeframe of this analysis. Alternatively, utilizing forest residues for bioenergy resulted in net emissions reductions over a shorter term, which is consistent with results of other studies (Gan and Smith 2007, McKechnie et al. 2011, Lamers and Junginger 2013, Lamers et al. 2014, Smyth et al. 2016, Dugan et al. in review). This is because the wood residues would have otherwise decomposed in the forest (as in this study), or in some regions it may be piled and burned (Smyth et al. 2016); both methods result in releasing the $\mathrm{CO}_{2}$ back into atmosphere. We did not consider the potential impacts on forest productivity associated with complete removal of residues. It is generally suggested that at least $30 \%$ of residues should be left on the forest floor after clearcut harvests (Stokes 1992) as they serve as an important nutrient input supporting forest productivity (Walmsley and Godbold 2010; Trottier-Picard et al. 2014; Adamczyk et al. 2015).

Mitigation benefits may be experienced by leaving harvest levels constant but shifting commodity ratios. For instance, shifting commodities from pulpwood to bioenergy had little impact on product sector emissions as both are considered short-lived products. However, this shift resulted in a decline in net emissions when also considering the substitution benefits associated with bioenergy. On the other hand, shifting commodities from long-lived products to bioenergy causes product sector emissions as it decreases product lifetimes. Results of this study and others (Werner et al. 2010, Smyth et al. 2014,

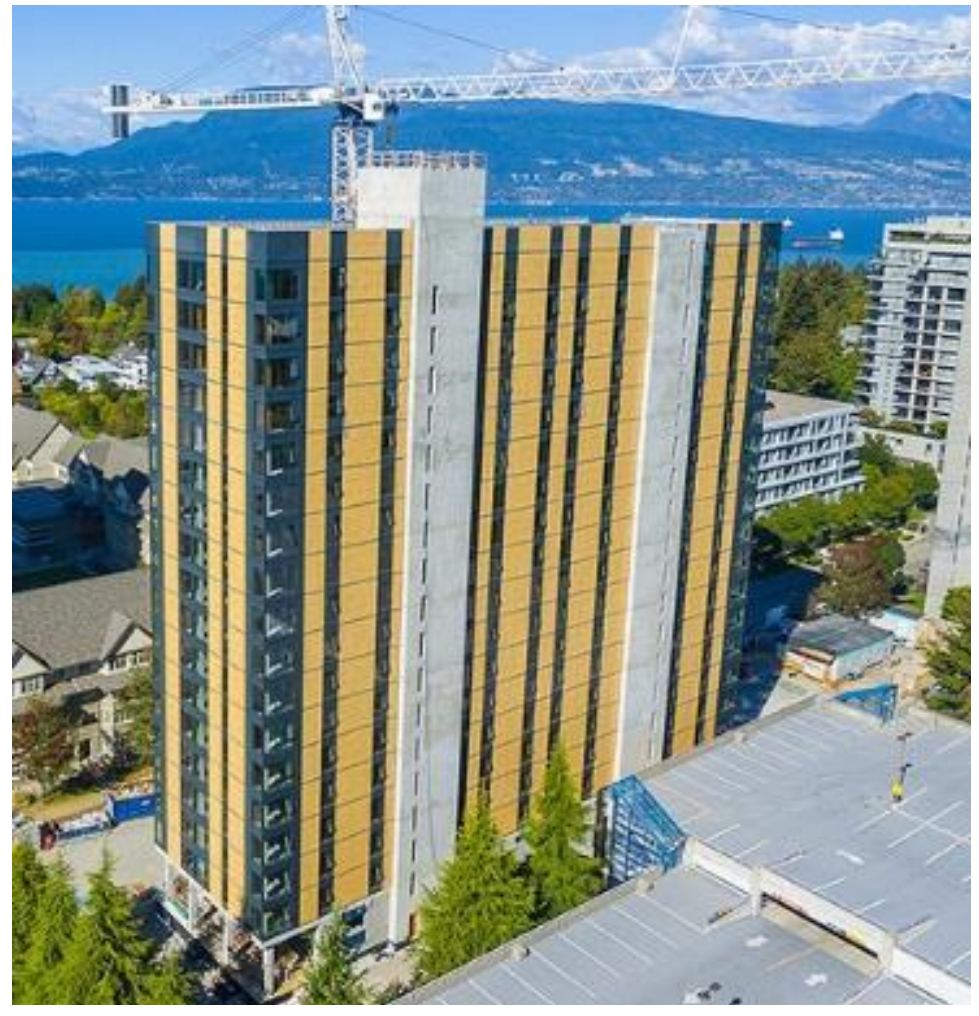

The University of British Columbia's Brock Commons is an 18story dormitory constructed of wood. It is the tallest wood building to date.
Lundmark et al. 2016, Dugan et al. in review) indicate that utilizing wood for long-lived products has larger and more immediate mitigation benefits than using wood for bioenergy. Likewise, shifting the commodity mix from shorter-lived pulpwood to longer-lived products (saw logs and veneer logs) increases product lifetimes and delays end-of-life emissions associated with retiring products in landfills, while also achieving product substitution benefits. Thus shifting commodity ratios tends to have a positive effect if it increases product lifetimes or results in substitution benefits.

Increasing forest productivity had a negligible mitigation impact. This is likely because only young stands ( $<15$ years old) could be theoretically treated to enhance growth rates. Silvicultural treatments including improved seed, chemical and mechanical release, and

fertilization are costly to apply across broad landscapes (Mead 2005). We only treated about 1-2\% of the SFL stands per year without considering the type of treatment being applied. In addition, by 2020, the stands were mostly older, leaving fewer young stands to be treated. Smyth et al. (2014) and Dugan et al. (in review) similarly found only small mitigation benefits from a comparable increased productivity 
scenario. It is likely that the result of silvicultural treatments would vary by treatment and forest type or region. Further study on the feasibility and impacts of growth enhancement activities is warranted.

Since 2009, Pennsylvania has been experiencing a natural gas boom from the abundant Marcellus and Utica shale reserves in the state. If urban development and natural gas extraction (or any development) were to continue to expand into additional forested lands, the impacts of the associated deforestation on carbon emissions would be significant. For instance, a small increase in deforestation annually on SFL totaling 4,700 ha by 2050, would result in a roughly 1 million tonne increase $\mathrm{CO}_{2}$ emissions by 2050 .

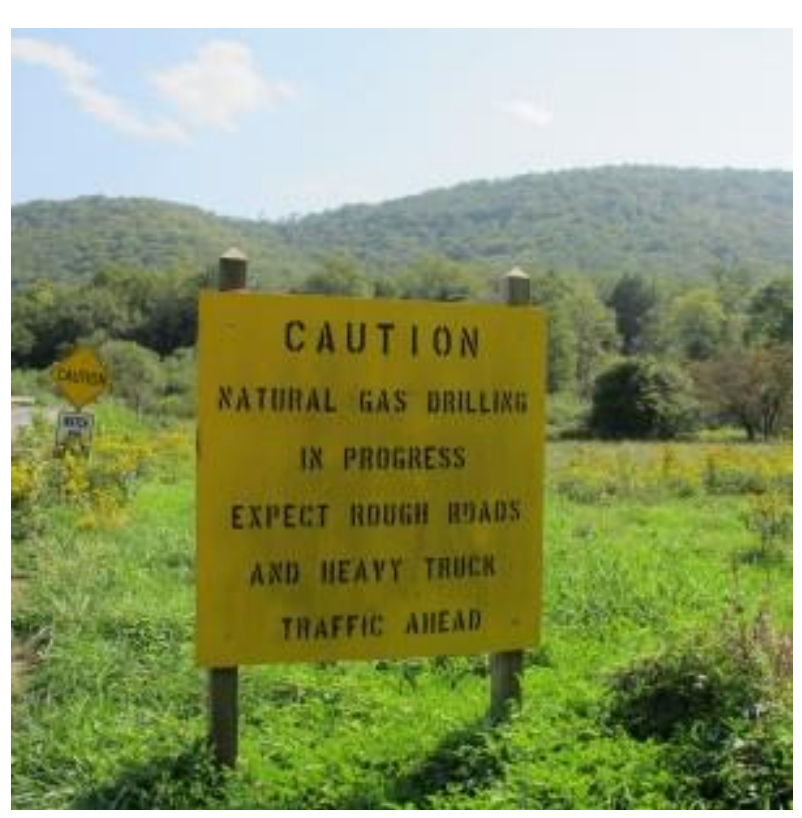

A sign posted in Susquehanna State Forest where land has been leased for drilling. Photo: Susan Phillips, Statelmpact Pennsylvania.
Also, the increase in emissions will continue to accrue over time as every year the trees that would have been growing and sequestering carbon is lost or foregone. Also the impacts of deforestation for natural gas expansion would be far greater when considering the emissions associated with natural gas burning as well. The increase deforestation scenario deforested an additional 20,000 ha of forest across all landowners by 2050 and resulted in an increase of 9.2 million tonnes of $\mathrm{CO}_{2}$ emissions. However, these estimates may be low considering a Nature Conservancy report projects that the commonwealth will lose approximately 24,000 ha of forest to Marcellus Shale development by 2030 (Johnson et al. 2010). Although governor Tom Wolf imposed a moratorium on leasing any more state park and forest land to Marcellus Shale drillers (Executive Order No. 2015-3), as of May 2017, the PA DCNR had already approved 239 well pads since 2008 (DCNR 2017). However, conversion of

forestland on SFLs has been negligible due to strict guidelines for drill sites (DCNR 2014). Though the rate of new well drilling has slowed in recent years, natural gas production continues to grow (Phillips 2017) and may have significant carbon consequences beyond the forest sector.

\subsection{Uncertainty and Limitations}

It is important to recognize that all results and conclusions presented here are contingent on the models, data, and assumptions. While we applied an ecosystem model that has been extensively used to evaluate ecosystem C stocks and mitigation potential (e.g. Stinson et al. 2011, Pilli et al. 2013, Smyth et al. 2014, 2016, Xu et al. 2018, Olgiun et al. 2018, Dugan et al. in review), it is a model of the ecological system, that is used as an estimation tool. Other models that rely on different data inputs, modeling approaches, and assumptions would yield different results (e.g. see Section 11.7). At the national scale in Canada the $95 \%$ confidence intervals of total ecosystem C stocks estimated with the CBM-CFS3 model averaged $\pm 15 \%$ for recent decades (Metsaranta et al. 2017). The largest sources of uncertainty were biomass increment and biomass turnover and dead organic matter modelling parameters. Uncertainty will invariably increase as estimates are projected further into the future as done here. Likewise, 
uncertainty simulations at scales far smaller than the Nation (e.g., an individual state or province) should greatly exceed $15 \%$ as the sample size declines. This $15 \%$ uncertainty only considers model uncertainty, which can be further compounded by uncertainty in datasets (e.g. land-use change, forest inventory) used in the model.

The selection of datasets used for modeling can have a significant impact on modeling results. Rates of LUC may vary significantly by data source. For instance, remotely-sensed land cover change products like NLCD, which we used here, may overestimate deforestation (Nelson and Reams 2017). Inventory based estimates of land use change indicate net increases in forestland in Pennsylvania (Albright et al. 2014) and the U.S. (Wear and Coulston 2015) which is contrary to the NLCD product applied here. However, we constrained the NLCD product to reduce the likelihood that clearcut harvests and subsequent regrowth were classified as land use change. Nonetheless, results still suggest that $C$ stocks are declining primarily due to forest aging.

Additionally, to estimate the substitution benefits we applied average displacement factors that were developed at the national level for Canada (Smyth et al. 2017) given the similar system boundaries and end-use products. However, displacement factors for bioenergy may vary regionally based on population, energy demand, the type of fuel displaced, and accessibility to forests. The displacement factors for wood products applied here $\left(0.54 \mathrm{tC} \mathrm{tC}^{-1}\right.$ for sawnwood and $0.45 \mathrm{tC} \mathrm{tC}^{-1}$ for panels) are low compared to the average displacement factor $\left(2.1 \mathrm{tC} \mathrm{tC}^{-1}\right)$ reported in the meta-analysis by Sathre \& O'Connor (2010) and used in other studies (e.g. Malmsheimer et al. 2011, Macintosh et al. 2015). However, the studies included in the Sathre \& O'Connor study had wide variations in systems boundaries, and when normalized to the methods of Smyth et al. (2017), the displacement factors were actually lower but relatively similar to those in Smyth et al. (2017). Additional studies and information are needed to derive national or regional displacement factors for the U.S.

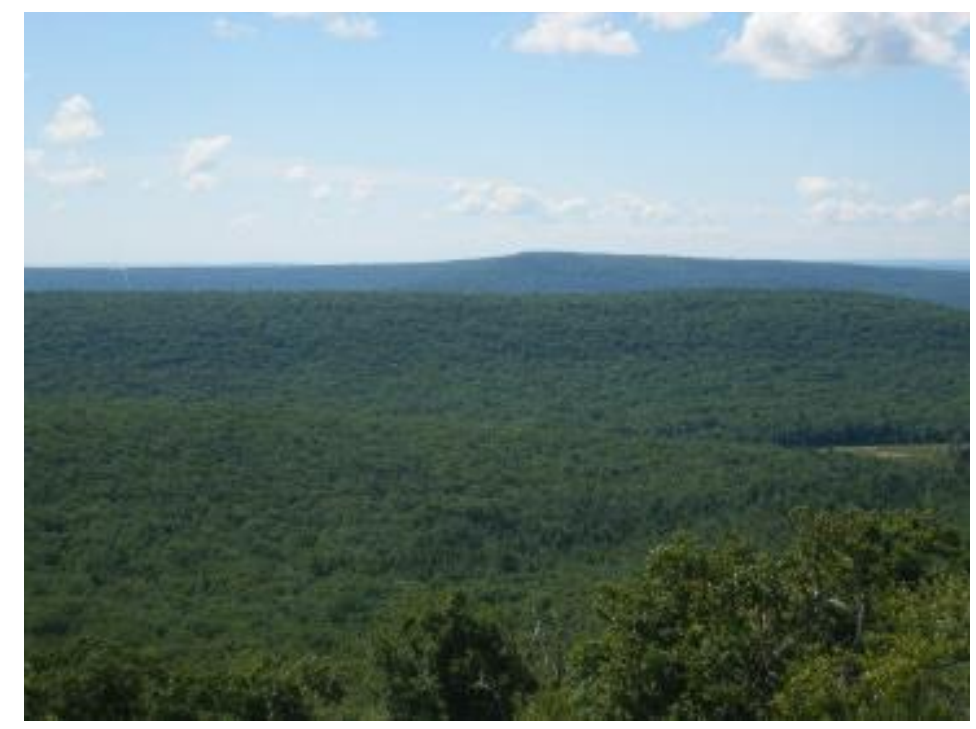

Bald Eagle State Forest, Pennsylvania. Photo by Alexa Dugan, U.S. Forest Service.
Throughout the study period, we assumed that environmental conditions including climate and atmospheric concentrations were constant. We also used one set of growth curves throughout the study period, thus did not consider potential changes in growth rates due to changing climate and atmospheric conditions. The growth-and-yield curves used were derived from FIA plot data so inherently encompass any past or present growth enhancements. However, these factors likely had a minimal impact on the analysis of mitigation scenarios as climate,

other biophysical factors, and growth rates would have been factored out when isolating the impacts of the targeted mitigation activities since these effects were not modeled in both the baseline and scenarios. We did explore historical impacts of changing climate, nitrogen deposition, and atmospheric 
$\mathrm{CO}_{2}$ concentrations on the Allegheny National Forest in western PA and concluded that these factors have enhanced carbon accumulation although $C$ trends are mostly driven by forest aging and disturbances.

We utilized different inventory data across the land ownerships in Pennsylvania. For national forest, private, and other public lands we utilized national FIA data, but for SFL we used the DCNR's vegetation typing spatial inventory data. While both inventories include relevant forest classifications for modeling such as stand age, forested area, protection status, and forest type, there may be inherent discrepancies between definitions, sampling protocols, and forest type classifications, which could result in modeled differences between ownerships.

Lastly, we strictly evaluated the biophysical mitigation potential of selected scenarios, but did not assess the technical or economic feasibility of implementing these scenarios. While project collaborators from the DCNR helped to design the scenarios we evaluated, the driving goal was to understand the biophysical carbon consequences of such management alternatives. Important socioeconomic constraints and tradeoffs are relevant for implementation of these scenarios (Nabuurs et al. 2007, Xu et al. 2018). For instance, reducing harvest rotations to increase bioenergy supply would require a matching demand for bioenergy to make such management economically viable (Nepal et al. 2015). Also, if harvest rotations are extended within Pennsylvania, but the demand for wood remains constant, harvesting may shift to other states, thus negating the mitigation benefits, a phenomenon known as leakage. While using more long-lived wood products may reduce net emissions, we did not evaluate the feasibility of shifting commodities or the impact it would have outside of Pennsylvania. Further research is needed to evaluate the socio-economic implications and potential leakage to determine the relative feasibility of implementation and the broader impacts outside of the state.

\subsection{CONCLUSION}

This project highlights the benefits of developing partnerships between state and federal agencies to share resources to evaluate forest carbon dynamics across the U.S. forest sector. This study provides an evidence-based quantitative evaluation of the biophysical forest sector baseline carbon trends and mitigation potential. We demonstrate how forest sector carbon modeling can provide useful information for land management decision-making and application. This work also

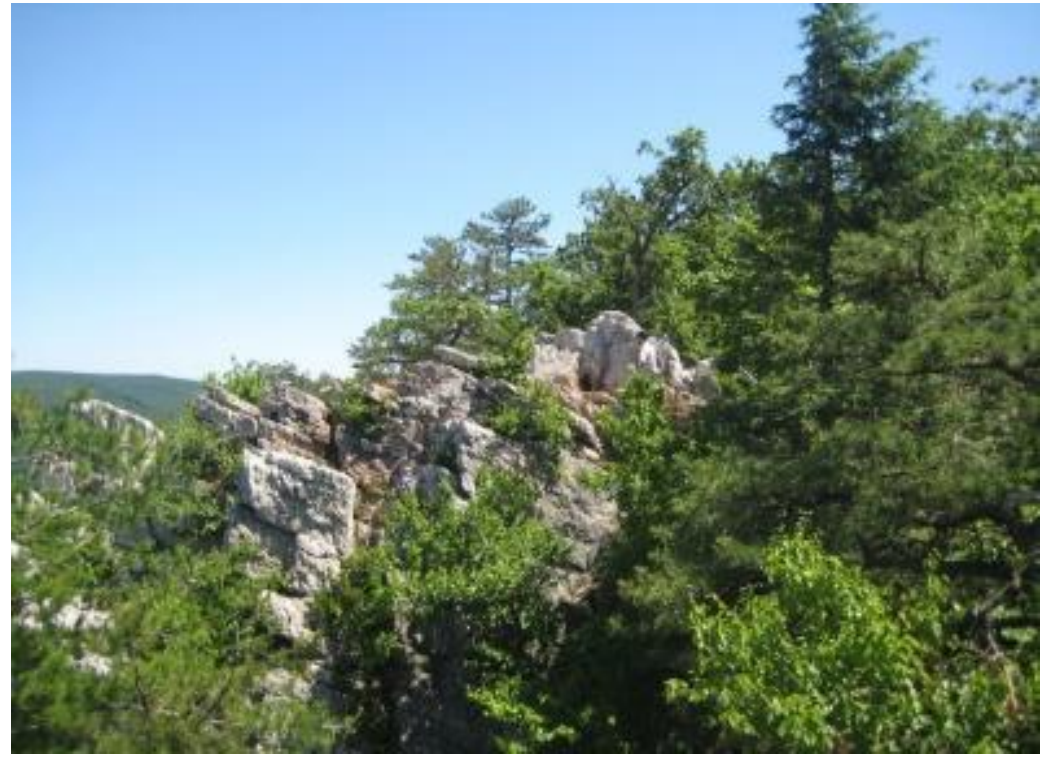

Pine Grove Furnace State Park, Pennsylvania. Photo by Alexa Dugan, U.S. Forest Service. 
illustrates how the national-level and state-level forest inventory data can be integrated for carbon modeling applications.

Although forest ecosystem carbon stocks across ownerships in PA have been increasing over the recent past indicating a net sink of $\mathrm{CO}_{2}$, the strength of this $\mathrm{C}$ sink is expected to decline over the next few decades as forests continue to age. State Forests have relatively older stand age distributions than other landowners in the state thus this age-related decline in sequestration rates may occur sooner on SFL. However, land use change on private lands and other public lands are projected to enhance the already declining $C$ sink potentially resulting in a shift to a $C$ source across the state. Thus, the need for strategic management that accounts for carbon storage in addition to the many other ecosystem benefits these forests provide will be critical if the state's goals are addressing climate change through mitigation and adaptation (PA DCNR 2018).

To evaluate the full carbon consequences of prospective management actions it is important to consider the impacts on all components that make up the forest sector including the forest ecosystem, harvested wood products, and substitution effects. Some activities like extending rotations have a positive effect on the forest ecosystem, but also result in a decline in $\mathrm{C}$ stored in wood products thus reducing substitution benefits. Results indicate that management actions that extend harvest rotations have the greatest mitigation benefits over this 30-year analysis period. Also shifting commodity ratios from products with shorter life spans like paper products to those with longer life spans such as saw logs is projected to be an effective strategy. Creating portfolios of multiple management and harvested wood products scenarios may have considerable mitigation benefits and more realistically reflect the suite of management activities that are often applied across large landscapes.

Some scenarios that increased bioenergy had mitigation benefits while others resulted in increased forest sector emissions, suggesting that bioenergy is not always carbon neutral but may depend on timeframe. Increasing bioenergy use may reduce emissions if the wood is sourced from logging residues or other waste wood such as from urban tree maintenance, but not from harvesting live trees specifically for bioenergy. Also adjusting product ratios to shift short-lived products (pulp and paper) to bioenergy may be an effective mitigation strategy. However, it may require longer timeframes than the relatively short 30-year span of this analysis to realize the full mitigation potential of some bioenergy strategies.

Although reductions in greenhouse gas emissions have not been mandated by Pennsylvania, the state's primary conservation agency, the DCNR has integrated climate change adaptation and mitigation into its mission (PA DCNR 2018). While management actions play an important role in the ability of the forest sector to sequester and store carbon, long-term mitigation potential is also dependent on forest resilience, health, and the capacity to adapt to changing conditions. Carbon sequestration is just one of the many ecosystem services that forests provide. However, if a management objective is to enhance carbon sequestration, it is critical to also consider the impacts on the other benefits that forest ecosystem provide as well as the socio-economic implications, cost effectiveness, and feasibility of implementing of forest sector mitigation strategies along with other management objectives. 


\subsection{ACKNOWLEDGEMENTS}

The authors would like to thank Dan Devlin, Ellen Shulzabarger, Shawn Lehman, and Greg Czarnecki from the Pennsylvania Department of Conservation and Natural Resources who worked closely with the research team to develop project objectives, mitigation scenarios, and key datasets for this project. Thank you to David Haubrick from the PA DCNR for providing key harvest datasets. A sincere thank you to Michael Magnan from Natural Resources Canada (NRC) who provided invaluable assistance on harvested wood products modeling. We appreciate Eric Neilson and Max Fellows from NRC for data and modeling support. Thank you to Michael Nichols from the U.S. Forest Service for assisting with model comparisons.

\subsection{GLOSSARY}

Additionality: A carbon offset project is considered additional if it would not have occurred absent the added incentives provided by the carbon market.

Autotrophic respiration: The process by which some of the photosynthetically fixed carbon is lost by internal plant metabolism and is typically about half of the carbon fixed by plants.

Biomass: The mass of living organic matter (plant and animal) in an ecosystem. Biomass also refers to organic matter (living and dead) available on a renewable basis for use as a fuel. Biomass includes trees and plants (both terrestrial and aquatic), agricultural crops and wastes, wood and wood wastes, forest and mill residues, animal wastes, livestock operation residues, and some municipal and industrial wastes.

Bioenergy: renewable energy derived from biological sources such as wood, wood waste, straw, manure, agricultural crops, and algae.

Carbon cycle: The term used to describe the flow of carbon (in various forms such as carbon dioxide $\left[\mathrm{CO}_{2}\right]$, organic matter, and carbonates) through the atmosphere, ocean, terrestrial biosphere, and lithosphere

Carbon equivalent: The amount of carbon in the form of carbon dioxide $\left(\mathrm{CO}_{2}\right)$ that would produce the same effect on the radiative balance of the Earth's climate system.

Carbon Offset: a reduction in emissions of carbon dioxide or greenhouse gases made in order to compensate for or to offset an emission made elsewhere

Carbon pool: A reservoir that stores carbon. Examples include aboveground biomass, belowground biomass, forest floor, soil, deadwood, and wood products 
Carbon sequestration: The process of increasing the carbon content of a carbon reservoir other than the atmosphere by directly removing $\mathrm{Co} 2$ from the atmosphere through biogenic processes such as forest growth.

Carbon stock change: The change in carbon stocks over time, calculated by taking the difference between successive carbon stock estimates and dividing by the number of years between those estimates.

$\mathrm{CO}_{2}$ Fertilization: The phenomenon in which plant growth increases (and agricultural crop yields increase) due to the increased rates of photosynthesis of plant species in response to elevated concentrations of carbon dioxide in the atmosphere.

Dead organic matter: Matter composed of organic compounds that has come from the remains of organisms such as plants and animals and their waste products in the environment.

Flux: The transfer of carbon from one carbon pool to another.

Greenhouse gas: Gaseous constituent of the atmosphere, both natural and anthropogenic, that absorb and emit radiation at specific wavelengths within the spectrum of infrared radiation emitted by the Earth's surface, the atmosphere and clouds. This property causes the greenhouse effect. Water vapor $\left(\mathrm{H}_{2} \mathrm{O}\right)$, carbon dioxide $\left(\mathrm{CO}_{2}\right)$, nitrous oxide $\left(\mathrm{N}_{2} \mathrm{O}\right)$, methane $\left(\mathrm{CH}_{4}\right)$, and ozone $\left(\mathrm{O}_{3}\right)$ are the primary greenhouse gases in the Earth's atmosphere.

Global warming potential: A factor describing the radiative forcing impact (e.g., warming of the atmosphere) of one unit mass of a given greenhouse gas relative to the warming caused by a similar mass of carbon dioxide $\left(\mathrm{CO}_{2}\right)$; methane $\left(\mathrm{CH}_{4}\right)$, for example, has a global warming potential of 23 .

Harvested wood products: Includes all wood material (including bark) that leaves harvest sites. Slash and other material left at harvest sites should be regarded as dead organic matter.

Heterotrophic respiration: The carbon lost by organisms in ecosystems other than the primary producers (plants). It constitutes carbon lost due to the metabolism of organic matter by bacteria, fungi, and animals.

Leakage: The situation in which a carbon sequestration activity (e.g., tree planting) on one piece of land inadvertently, directly or indirectly, triggers an activity that in whole or part counteracts the carbon effects of the initial activity.

Net ecosystem exchange: A measurement of the quantity of carbon entering and leaving the ecosystem, usually associated with carbon dioxide flux from the ecosystem to the atmosphere.

Net primary productivity: The net uptake of carbon by plants in excess of respiratory loss.

Permanence: The potential that additional sequestration achieved may be reversed either intentionally or unintentionally (through human actions, fire, insects, disease, or weather). 
Mitigation: Human interventions to decrease the amount of $\mathrm{CO}_{2}$ in the atmosphere in order to reduce the effects of climate change.

Respiration: The metabolism of organic matter by plants (autotrophic respiration) or bacteria, fungi, and animals (heterotrophic respiration).

Sink: Any process, activity or mechanism that removes $\mathrm{CO}_{2}$ from the atmosphere.

Source: Any process, activity or mechanism that releases $\mathrm{CO}_{2}$ to the atmosphere

\subsection{REFERENCES}

Aber J, McDowell W, Nadelhoffer K, Magill A, Berntson G, Kamakea M, McNulty S, Currie W, Rustad L, Fernandez I. 1998. Nitrogen saturation in temperate forest ecosystems. Bioscience 48:921-934

Adamczyk B, Adamczyk S, Kukkola M, Tamminen P Smolander A. 2015. Logging residue harvest may decrease enzymatic activity of boreal forest soils. Soil Biology and Biochemistry. 82:74-80.

Albright TA, McWilliams WH, Widmann Rh, Butler BJ, Crocker SJ, Kurtz CM, Lehman S, Lister TW, Miles PD, Morin RS, Riemann R, and Smith JE. 2017. Pennsylvania Forests, 2014. Resource bulletin NRS111, United States Department of Agriculture, Northern Research Station, Newtown Square, PA, USA.

Allen CD, Macalady AK, Chenchouni H, Bachelet D, McDowell N, Vennetier M, ... Cobb N. 2010. A global overview of drought and heat-induced tree mortality reveals emerging climate change risks for forests. Forest Ecology and Management, 259(4), 660-684. https://doi.org/10.1016/j.foreco.2009.09.001

Anderegg WRL, Schwalm C, Biondi F, Camarero JJ, Koch G, Litvak M, Ogle K, Shaw JD, Shevliakova E, Williams AP, Wolf A, Ziaco E \& Pacala S. 2015. Pervasive drought legacies in forest ecosystems and their implications for carbon cycle models. Science, 349 (6247): 528-532.

Bentz BJ, Régnière J, Fettig CJ, Hansen EM, Hayes JL, Hicke JA, ... Seybold SJ. 2010. Climate Change and Bark Beetles of the Western United States and Canada: Direct and Indirect Effects. BioScience, 60(8), 602-613.

Birdsey R, Duffy PB, Smyth C, Kurz W, Dugan AJ \& Houghton RA. 2018. Climate, economic, and environmental impacts of producing wood for bioenergy. Environmental Research Letters. https://doi.org/10.1088/1748-9326/aab9d5

Birdsey R, Pan Y, Janowiak M, Stewart S, Hines S, Parker L, Gower S, Lichstein J, McCullough K, Zhang F, Chen J, Mladenoff D, Wayson C, Swanston C. 2014. Past and prospective carbon stocks in forests of northern Wisconsin: a report from the Chequamegon-Nicolet National Forest Climate Change 
Response Framework. Gen. Tech. Rep. NRS-127. Newtown Square, PA: U.S. Department of Agriculture, Forest Service, Northern Research Station. 52 p.

Birdsey RA, Pregitzer K, Lucier A. 2006. Forest carbon management in the United States: 1600-2100. Journal of Environmental Quality 35:1461-1469

Buchholz T, Hurteau M D, Gunn J and Saah D. 2016. A global meta-analysis of forest bioenergy greenhouse gas emission accounting studies GCB Bioenergy 8: 281-9

Canadell JG and Raupach MR. 2008. Managing forests for climate change mitigation. Science 320: 14561457.

Chen JM, Chen W, Cihlar J. 2000. Integrated terrestrial ecosystem carbon-budget model based on changes in disturbance, climate, and atmospheric chemistry. Ecological Modelling, 135: 55

Conrad DE, Cravens JH, Banzhaf G, and others. 1997. The land we cared for... A history of the Forest Service's Eastern Region, First Edition. Milwaukee, WI: U.S. Department of Agriculture, Forest Service, Region 9.

Daigneault A ,Sohngen B, Sedjo R. 2012. Economic approach to assess the forest carbon implications of biomass energy. Environ. Sci. Technol. 46:5664-5671.

Dugan AJ, Birdsey R, Healey SP, Pan Y, Zhang F, Mo G, Chen J, Woodall C, Hernandez AJ, McCullough K, McCarter JB, Raymond CL, Dante-Wood K. 2017. Forest Sector Carbon Analyses Support Land Management Planning and Projects: Assessing the Influence of Anthropogenic and Natural Factors Climatic Change. 144:207-220.

Dukes JS, Pontius J, Orwig D, Garnas JR, Rodgers VL, Brazee N, Cooke B, Theoharides KA, Stange EE, Harrington R, Ehrenfeld J, Gurevitch J, Lerdau M, Stinson K, Wich R, Ayres M. 2009. Responses of insect pests, pathogens, and invasive plant species to climate change in the forests of northeastern North America: What can we predict? Canadian Journal of Forest Research 39:231-248

Earth Science Data and Information System (ESDIS) 2015 Fire Information for Resource Management System (FIRMS) National Aeronautics and Space Administration https://earthdata.nasa.gov/earthobservation-data/near-real-time/firms.

Eidenshink J, Schwind B, Brewer K, Zhu Z, Quayle B, Howard S. 2007. A project for monitoring trends in burn severity Fire Ecology 3 3-21

Eriksson E, Gillespie A, Gustavsson L, Langvall O, Olsson M, Sathre R, Stendahl J. 2007. Integrated carbon analysis of forest management practices and wood substitution. Canadian Journal of Forest Research, 37(3), 671-681.

Euskirchen ES, Chen J, Li H, Gustafson EJ, Crow TR. 2002. Modeling landscape net ecosystem productivity (LandNEP) under alternative management regimes. Ecological Modelling 154: 75-91

Executive Order, No. 2015-03. Leasing of state forest and state park land for oil and gas development. Commonwealth of Pennsylvania, Governor's Office. 
Flower CE, Knight KS, Gonzalez-Meler M. 2013. Impacts of the emerald ash borer (Agrilus planipennis Fairmaire) induced ash (Fraxinus spp.) mortality on forest carbon cycling and successional dynamics in the eastern United States. Biological Invasions. 15(4): 931-944.

Gan J, Smith CT. 2007. Co-benefits of utilizing logging residues for bioenergy production: The case for East Texas, USA. Biomass and Bioenergy. 31: 623-630.

Goward, S.N., C. Huang, F. Zhao, K. Schleeweis, K. Rishmawi, M. Lindsey, J.L. Dungan, and A. Michaelis. 2016. NACP NAFD Project: Forest Disturbance History from Landsat, 1986-2010. ORNL DAAC, Oak Ridge, Tennessee, USA. http://dx.doi.org/10.3334/ORNLDAAC/1290

Gunn JS, Buchholz T. 2018. Forest sector greenhouse gas emissions sensitivity to changes in forest management in Maine (USA). Forestry, doi:10.1093/forestry/cpy013

Hansen, M. C., Potapov, P. V., Moore, R., Hancher, M., Turubanova, S. A., Tyukavina, A., ... Townshend, J. R. G. 2013. High-Resolution Global Maps of 21st-Century Forest Cover Change. Science, 342(6160), 850-853.

Harmon, M. 2001. Carbon sequestration in forests: addressing the scale question. Journal of Forestry. 99:24-29.

Harmon, M. E., Ferrell, W. K., \& Franklin, J. F. (1990). Effects on carbon storage of conversion of oldgrowth forests to young forests. Science (New York, N.Y.), 247(4943), 699-702.

Harmon, M. E., \& Marks, B. (2002). Effects of silvicultural practices on carbon stores in Douglas-fir western hemlock forests in the Pacific Northwest, U.S.A.: results from a simulation model. Canadian Journal of Forest Research, 32(5), 863-877.

Healey SP, Urbanski SP, Patterson PL, Garrard C (2014) A framework for simulating map error in ecosystem models. Remote Sens Environ 150:207-217

Heath, L S.; Smith, J E.; Birdsey, T A. 2003. Carbon trends in U.S. forestlands: a context for the role of soils in forest carbon sequestration. In: Kimble, J.M.; Heath, L S.; Birdsey, R A.; Lal, R., eds. The potential of U.S. forest soils to sequester carbon and mitigate the greenhouse effect. Boca Raton: CRC Press: 35-45.

Homer C, Dewitz J, Fry J, Coan M, Hossain N, Larson C, Herold N, McKerrow A, VanDriel, J N, and Wickham J 2007 Completion of the 2001 National Land Cover Database for the Conterminous United States Photogrammetric Engineering and Remote Sensing 73 337-341

Homer C G, Dewitz J A, Yang L, Jin S, Danielson P, Xian G, Coulston J, Herold N D, Wickham J D and Megown K. 2015. Completion of the 2011 National Land Cover Database for the conterminous United States-Representing a decade of land cover change information Photogrammetric Engineering and Remote Sensing 81 345-354

Howard JL, Jones KC. U.S. Timber production, trade, consumption, and price statistics, 1965-2013. Research Paper, FPL-RP-679. Madison, WI. US Department of Agriculture Forest Service Forest Products Laboratory. 2016; 100 p. 
Hurteau, M. and North, M. 2009. Fuel treatment effects on tree-based forest carbon storage and emissions under modeled wildfire scenarios, Frontiers in Ecology and the Environment, 7: 409-414.

Hurtt, G.C., S. W. Pacala, P. R. Moorcroft, J. Caspersen, E. Shevliakova, R. A. Houghton, B. Moore. 2002. Projecting the future of the U.S. carbon sink. Proceedings of the National Academy of Sciences, 99 (3) 1389-1394.

Intergovernmental Panel on Climate Change (IPCC), 2003. In: Penman, J., et al. (Eds.), Good Practice Guidance for Land Use, Land-Use Change and Forestry. Institute for Global Environmental Strategies, Hayama (also available at http://www.ipcc-nggip.iges.or.jp).

Intergovernmental Panel on Climate Change (IPCC), 2006. In: Eggleston, S., et al. (Eds.), Guidelines for National Greenhouse Gas Inventories. Institute for Global Environmental Strategies, Hayama. International

Intergovernmental Panel on Climate Change (IPCC). 2007. Climate Change 2007: The Physical Science Basis: Contribution of Working Group I to the Fourth Assessment of the Intergovernmental Panel on Climate Change. Solomon, S., D. Qin, M. Manning, Z. Chen, M. Marquis, K.B. Averyt, M. Tignor, and H.L. Miller (eds). Cambridge United Press, Cambridge, United Kingdom and New York, NY, USA, $996 \mathrm{pp}$.

Intergovernmental Panel on Climate Change (IPCC). 2013. Revised supplementary methods and good practice guidance arising from the Kyoto Protocol, Institute for Global Environmental Strategies, Kanagawa, Japan, 2013a.

Janowiak, M.; Connelly, W.J.;Dante-Wood, K.; Domke, G.M.; Giardina, C.; Kayler, Z.; Marcinkowski, K.; Ontl, T.; Rodriguez-Franco, C.; Swanston, C.; Woodall, C.W.; Buford, M. 2017. Considering Forest and Grassland Carbon in Land Management. Gen. Tech. Rep. WO-95. Washington, D.C.: United States Department of Agriculture, Forest Service. $68 p$

Johnson E W and Wittwer D 2008 Aerial detection surveys in the United States Australian Forestry 71 212-215

Johnson N, Gagnolet T, Ralls R, Zimmerman E, Eichelberger B, Tracey C, Kreitler G, Orndorff S, Tomlinson J, Bearer S and Sargent S. 2010. Pennsylvania Energy Impacts Assessment, Report 1: Marcellus shale natural gas and wind. The Nature Conservancy.

Ju, W.M., Chen, J.M., Harvey, D., \& Wang, S. 2007. Future carbon balance of China's forests under climate change and increasing $\mathrm{CO}_{2}$. Journal of Environmental Management, 85(3): 538-562.

Keenan, T. F., Hollinger, D. Y., Bohrer, G., Dragoni, D., Munger, J. W., Schmid, H. P., \& Richardson, A. D. (2013). Increase in forest water-use efficiency as atmospheric carbon dioxide concentrations rise. Nature, 499(7458), 324-327. https://doi.org/10.1038/nature12291

Keeling, R.F., Piper, S.C., Bollenbacher, A.F. \& Walker, S.J. 2009. Atmospheric CO2 records from sites in the SIO air sampling network, in Trends: A Compendium of Data on Global Change, Carbon Dioxide Information Analysis Center, Oak Ridge Natl. Lab., U.S. Dep. of Energy, Oak Ridge, Tenn. 
Kurz W, Birdsey R, Mascorro V, Greenberg D, Dai Z, Olguin M, Colditz R 2016 Integrated Modeling and Assessment of North American Forest Carbon Dynamics Technical Report: Tools for monitoring, reporting and projecting forest greenhouse gas emissions and removals. Montreal, Canada: Commission for Environmental Cooperation 120 pp

Kurz WA, Dymond CC, Stinson G, Rampley GJ, Neilson ET, Carroll AL, Ebata T, Safranyik L (2008) Mountain pine beetle and forest carbon feedback to climate change. Nature 452:987-990.

Kurz WA, Dymond CC, White TM, Stinson G, Shaw CH, Rampley GJ, Smyth C, Simpson BN, Neilson ET, Trofymow JA, Metsaranta J, Apps MJ. 2008. CBM-CFS3: A model of carbon-dynamics in forestry and landuse change implementing IPCC standards Ecol. Model. 220:480-504.

Lamers $P$, Junginger M, Dymond CC, Faaij A. 2014. Damaged forests provide an opportunity to mitigate climate change. GCB Bioenergy 6: 44-60, doi: 10.1111/gcbb.12055

Law, B. 2013. Biogeochemistry: Nitrogen deposition and forest carbon. Nature, 496 (7445), 307-308.

Lamers, P., \& Junginger, M. (2013). The 'debt' is in the detail: A synthesis of recent temporal forest carbon analyses on woody biomass for energy. Biofuels, Bioproducts and Biorefining, 7(4), 373-385. https://doi.org/10.1002/bbb.1407

Lippke B, Wilson J, Perez-Garcia J, Bowyer J, Meil J. CORRIM: life-cycle environmental performance of renewable building materials Forest Products Journal. 2004;54:8-19.

Liski, J, Pussinen A, Pingoud K, Mäkipää R, Karjalainen, T. 2001. Which rotation length is favourable to carbon sequestration? Canadian Journal of Forest Research. 31:2004-2013.

Loeffler D, Anderson N, Stockmann K, Skog K, Healey S, Jones JG, Morrison J and Young J. 2014. Estimates of carbon stored in harvested wood products from United States Forest Service Eastern Region, 1911-2012. Unpublished report. Missoula, MT: U.S. Department of Agriculture, Forest Service, Rocky Mountain Research Station, Forestry Sciences Laboratory. 27 p.

Lundmark T, Bergh J, Hofer P, Lundstro“m A, Nordin A, Poudel BC, Sathre R, Taverna R, et al. 2014. Potential roles of Swedish forestry in the context of climate change mitigation. Forests 5: 557-578.

Macintosh A, Keith H, Lindenmayer D. 2015. Rethinking forest carbon assessments to account for policy institutions. Nature Climate Change DOI: 10.1038/NCLIMATE2695

Malmsheimer, R.W., P. Heffernan, S. Brink, D. Crandall, F. Deneke, C. Galik, E. Gee, J. Helms, et al. 2008. Forest management solutions for mitigating climate change in the United States. Journal of Forestry 6: 115-118.

Manomet Center for Conservation Sciences 2010 (Brunswick, ME: Manomet Center for Conservation Sciences) Massachusetts biomass sustainability and carbon policy study: report to the Commonwealth of Massachusetts department of energy resources 182 Natural Capital Initiative Report $\mathrm{NCl}-2010-03 \mathrm{p}$

Mascorro VS, Coops NC, Kurz WA and Olguín M. 2015. Choice of satellite imagery and attribution of changes to disturbance type strongly affects forest carbon balance estimates Carbon Balance and Management. 10 doi.org/10.1186/s13021-015-0041-6 
Mascorro VS, Coops NC, Kurz WA, Olguín M. 2016. Attributing changes in land cover using independent disturbance datasets: a case study of the Yucatan Peninsula, Mexico Regional Environmental Change. 16: 213-228.

Masek JG, Goward SN, Kennedy RE, Cohen WB, Moisen GG, Schleeweis K, Huang C (2013) United States forest disturbance trends observed using Landsat time series. Ecosystems 16:1087-1104

McKechnie, J., Colombo, S., Chen, J., Mabee, W., and MacLean, H. L. 2011. Forest bioenergy or forest Carbon? Assessing trade-offs in Greenhouse Gas mitigation with wood-based fuels, Environ. Sci. Technol., 45, 789-795.

McKinley DC, Ryan MG, Birdsey RA, Giardina CP, Harmon ME, Heath LS, et al. 2011A synthesis of current knowledge on forests and carbon storage in the United States Ecological Applications. 21:19021924.

McNulty SG. 2002. Hurricane impacts on US forest carbon sequestration. Environmental Pollution. 116 Suppl: S17-S24.

Mead DJ. 2005. Opportunities for improving plantation productivity. How much? How quickly? How realistic? Biomass and Bioenergy, 28(2), 249-266.

Metsaranta JM, Shaw CH, Kurz WA, Boisvenue C, and Morken S. 2017. Uncertainty of inventory-based estimates of the carbon dynamics of Canada's managed forest (1990-2014). Canadian Journal of Forest Research 47: 1082-1094.

Miner RA, Abt RC, Bowyer JL, Buford MA, Malmsheimer RW, O'laughlin J, Oneil EE, Sedjo RA, Skog KE. 2014. Forest carbon accounting considerations in US bioenergy policy J. For. 112:32-40.

Nabuurs, G.J., O. Masera, K. Andrasko, P. Benitez-Ponce, R. Boer, M. Dutschke, E. Elsiddig, J. FordRobertson, P. Frumhoff, T. Karjalainen, O. Krankina, W.A. Kurz, M. Matsumoto, W. Oyhantcabal, N.H. Ravindranath, M.J. Sanz Sanchez, X. Zhang. 2007. Forestry. In Climate Change 2007: Mitigation. Contribution of Working Group III to the Fourth Assessment Report of the Intergovernmental Panel on Climate Change [B. Metz, O.R. Davidson, P.R. Bosch, R. Dave, L.A. Meyer (eds)], Cambridge University Press, Cambridge, United Kingdom and New York, NY, USA

National Climate Assessment. 2014. Melillo, J. M., Richmond, T. \& Yohe, G.W. 2014. Climate Change Impacts in the United States: The Third National Climate Assessment. U.S. Global Change Research Program, $841 \mathrm{pp}$.

Nelson MD and Reams GA. 2017. Is the area of US forests increasing or decreasing? The Forestry Source 22: 16-17.

Nemani, R., White, M., Thornton, P., Nishida, K., Reddy, S., Jenkins, J., \& Running, S. 2002. Recent trends in hydrologic balance have enhanced the terrestrial carbon sink in the United States. Geophysical Research Letters, 29 (10): 106-1.

Nepal P, Wear DN, Skog KE. 2015. Net change in carbon emissions with increased wood energy use in the United States. GCB Bioenergy. 7:820-835.

Nunery JS, Keeton WS. 2010. Forest carbon storage in the northeastern United States: Net effects of 
harvesting frequency, post-harvest retention, and wood products Forest Ecology and management. 259: 1363-1375.

Olguin M, Wayson C, Fellows M, Birdsey R, Smyth CE, Magnan M, Dugan AJ, Mascorro VS, Alanís A, Serrano E, Kurz WA. 2018. Applying a systems approach to assess carbon emission reductions from climate change mitigation in Mexico's forest sector Environmental Research Letters. 13:035003.

Ollinger SV, Goodale CL, Hayhoe K, Jenkins JP. 2008. Potential effects of climate change and rising CO2. Mitigation and Adaption Strategies for Global Change 13:467-485.

Oswalt SN, Smith WB, Miles PD, Pugh SA. 2014. Forest Resources of the United States, 2012: a technical document supporting the Forest Service 2015 update of the RPA Assessment. Gen. Tech. Rep. WO91. Washington, DC: U.S. Department of Agriculture, Forest Service, Washington Office. 218 p.

Pan Y, Birdsey R, Hom J, McCullough K (2009) Separating effects of changes in atmospheric composition, climate and land-use on carbon sequestration of U.S. mid-Atlantic temperate forests. For Ecol Manag 259:151-164

Pan Y, Chen JM, Birdsey R, McCullough K, He L, Deng F. 2011. Age structure and disturbance legacy of North American forests. Biogeosciences. 8: 715-732.

Pennsylvania Department of Conservation and Natural Resources. 2014. Guidelines for administering oil and gas activity on State Forest lands. Bureau of Forestry

Pennsylvania Department of Conservation and Natural Resources. 2015. DCNR and Climate Change: Planning for the Future.

Pennsylvania Department of Conservation and Natural Resources. 2017. Natural gas development and state forests: Shale gas leasing statistical summary.

Pennsylvania Department of Conservation and Natural Resources. 2018. Climate Change Adaptation and Mitigation Plan.

http://www.docs.denr.pa.gov/cs/groups/public/documents/document/denr_20033598.pdf

Perez-Garcia, J., B. Lippke, J. Comnick, and C. Manriquez. 2005. An assessment of carbon pools, storage, and wood products market substitution using life-cycle analysis results. Wood Fiber Sci. 37:140 148.

Phillips, S. 2017. Gas production increased in 2016, as number of new shale gas wells decreased. State Impact Pennsylvania. May 18, 2017.

Potter, R S, Andrews S, Atwood JD, Kellogg, R.L., Lemunyon, J., Norfleet, L., Oman, D. 2006. Model Simulation of Soil Loss, Nutrient Loss, and Change in Soil Organic Carbon Associated with Crop Production. US Department of Agriculture, Natural Resources Conservation Service, Conservation Effects Assessment Project

PRISM Climate Group, Oregon State University http://prism.oregonstate.edu created 10 November 2016

Ray AD, Grannis J. 2015. From Planning to Action: Implementation of State Climate Change Adaptation Plans. Michigan Journal of Sustainability, 3. http://dx.doi.org/10.3998/mjs.12333712.0003.001 
Raymond CL, Healey S, Peduzzi A, Patterson P (2015) Representative regional models of postdisturbance forest carbon accumulation: integrating inventory data and a growth and yield model. For Ecol Manag 336:21-34

Ryan MG, Harmon ME, Birdsey RA, Giardina CP, Heath LS, Houghton RA, Jackson RB, McKinley DC, Morrison JF, Murray BC, Pataki DE, Skog KE. 2010. A synthesis of the science on forests and carbon for U.S. Forests Ecological Society of America: Issues In Ecology. 13: 1-16.

Sathre R and O'Connor J. 2010. Meta-analysis of greenhouse gas displacement factors of wood product substitution Environ.Sci. Policy 13 104-14

Schlesinger WH. 2018. Are wood pellets a green fuel? Science 359:1328-1329.

Skog KE. 2008. Sequestration of carbon in harvested wood products for the United States Forest Products Journal 58:56-72.

Skog KE, Nicholson GA. 1998. Carbon cycling through wood products: The role of wood and paper products in carbon sequestration Forest Products Journal 48:75-83.

Smith JE, Heath LS, Nichols MC. 2010. US Forest carbon calculation tool: forest-land carbon stocks and net annual stock change. Revised. Gen. Tech. Rep. NRS-13. U.S. Department of Agriculture, Forest Service, Northern Research Station, Newtown Square, PA $34 \mathrm{p}$

Smyth CE, Kurz WA, Rampley G, Lemprière TC, Schwab O. 2016. Climate change mitigation potential of local use of harvest residues for bioenergy in Canada GCB Bioenergy. 9: 817-832.

Smyth CE, Rampley G, Lemprière TC, Schwab O, Kurz WA. 2017. Estimating product and energy substitution benefits in national-scale mitigation analyses for Canada GCB Bioenergy 9:1071-1084.

Smyth CE, Stinson G, Neilson E, Lemprière TC, Hafer M, Rampley GJ, Kurz WA. 2014. Quantifying the biophysical climate change mitigation potential of Canada's forest sector. Biogeosciences 11:35153529.

Stinson G, Kurz W A, Smyth CE, Neilson ET, Dymond CC, Metsaranta JM, Boisvenue C, Rampley G J, Li Q, White TM, Blain D. 2011. An inventory-based analysis of Canada's managed forest carbon dynamics, 1990 to 2008. Global Change Biology, 17(6), 2227-2244.

Stokes BJ. 1992. Harvesting small trees and forest residues Biomass and Bioenergy 2:131-147

Ter-Mikaelian M, McKechnie J, Colombo S, Chen J, and MacLean H. 2011. The carbon neutrality assumption for forest bioenergy: a case study for northwestern Ontario, Forest. Chron., 87, 644652.

Ter-Mikaelian MT, Colombo SJ, and Chen J. 2015. The burning question: Does forest bioenergy reduce carbon emissions? A review \& common misconceptions about forest carbon accounting. J. Forestry 113: $12 \mathrm{p}$.

Trottier-Picard A, Thiffault E, Desrochers A., Paré D, Thiffault N, Messier C. 2014. Amounts of logging residues affect planting microsites: A manipulative study across northern forest ecosystems For. Ecol. Manag. 312:203-215. 
Turner DP \& Koerper GJ. 1995. Carbon sequestration by forests of the United States. Current status and projections to the year 2040. Tellus 47B, 232-239.

Van Deusen PC, Heath LS. 2010. Weighted analysis methods for mapped plot forest inventory data: Tables, regressions, maps and graphs Forest Ecol. Manage. 260:1607-1612.

Van Deusen, P. 2010. Carbon sequestration potential of forest land: Management for products and bioenergy versus preservation. Biomass and Bioenergy 34: 1687-1694

Van Kooten, G.C., Binkley, C.S., and Delcourt, G. 1995. Effect of carbon taxes and subsidies on optimal forest rotation age and supply of carbon services. Am. J. Agric. Econ. 77: 365-374.

Walker T, Cardellichio P, Gunn JS, Saahd DS, Hagan JM. 2013. Carbon accounting for woody biomass from Massachusetts (USA) managed forests: A framework for determining the temporal impacts of wood biomass energy on atmospheric greenhouse gas levels. J. Sustain. For . 32:130-158.

Walmsley JD, Godbold DL. 2010 Stump Harvesting for Bioenergy - A Review of the Environmental Impacts. Forestry (Lond). 83:17-38.

Walsh, J., D. Wuebbles, K. Hayhoe, J. Kossin, K. Kunkel, G. Stephens, P. Thorne, R. Vose, M. Wehner, J. Willis, D. Anderson, S. Doney, R. Feely, P. Hennon, V. Kharin, T. Knutson, F. Landerer, T. Lenton, J. Kennedy, and R. Somerville. 2014: Ch. 2: Our Changing Climate. Climate Change Impacts in the United States: The Third National Climate Assessment, J. M. Melillo, Terese (T.C.) Richmond, and G. W. Yohe, Eds., U.S. Global Change Research Program, 19-67.

Way, D. A., \& Oren, R. 2010. Differential responses to changes in growth temperature between trees from different functional groups and biomes: a review and synthesis of data. Tree Physiology, 30 (6), 669-688.

Wear DN, Coulston JW. 2015. From sink to source: Regional variation in U.S. forest carbon futures. Scientific Reports. 5: 16518.

Wear DN, Huggett R, Li R, Perryman B \& Liu S. 2013. Forecasts of forest conditions in regions of the United States under future scenarios: A technical document supporting the Forest Service 2010 RPA Assessment. Gen. Tech. Rep. SRS-170. US Department of Agriculture, Forest Service.

Werner F, Taverna R, Hofer P, Thürig E, and Kaufmann E. 2010. National and global greenhouse gas dynamics of different forest management and wood use scenarios: a model-based assessment, Environ. Sci. Policy, 13, 72-85.

Wieder WR, Cleveland CC, Smith WK, Todd-Brown K. 2015. Future productivity and carbon storage limited by terrestrial nutrient availability. Nature Geosciences 8: 441-444.

Woodall CW, Coulston JW, Domke GM, Walters BF, Wear DN Smith JE, Andersen H-E, Clough BJ, Cohen WB, Griffith DM, Hagen SC, Hanou IS, Nichols MC, Perry CH, Russell MB, Westfall JA, Wilson BT. 2015 The U.S. forest carbon accounting framework: stocks and stock change, 1990-2016. Gen. Tech. Rep. NRS-154. Newtown Square, PA: US Department of Agriculture Forest Service Northern Research Station 49 p. 
Woodall CW, Heath LS, Domke GM, Nichols MC (2011) Methods and equations for estimating aboveground volume, biomass, and carbon for trees in the U.S. forest inventory, 2010. Gen. Tech. Rep. NRS-88. Newtown Square, PA: U.S. Department of Agriculture, Forest Service, Northern Research Station. $30 \mathrm{p}$

US Department of Agriculture Forest Service. 2015. FSVeg Common Stand Exam User Guide Version 2.12.6. US Department of Agriculture, Forest Service, Natural Resource Manager. http://www.fs.fed.us/nrm/fsveg/

US Department of Agriculture Forest Service. Timber Product Output (TPO) Reports. Knoxville, TN: US Department of Agriculture Forest Service Southern Research Station http://srsfia2.fs.fed.us/php/tpo 2009/tpo rpa int1.php. Accessed 1 November 2016.

US Department of Agriculture Forest Service. 2017 Forest Inventory and Analysis Database, St. Paul MN: http://apps.fs.fed.us/fiadb-downloads/datamart.html. Accessed 10 October 2017.

US EPA. 2015. US Inventory of Greenhouse Gas Emissions and Sinks: 1990 - 2013. Executive Summary. EPA 430-R15-004 United States Environmental Protection Agency. Washington, D.C. $27 \mathrm{pp}$.

Xu Z, Smyth CE, Lemprière, Rampley GJ, Kurz WA. 2018. Climate change mitigation strategies in the forest sector: biophysical impacts and economic implications in British Columbia, Canada. Mitigation and Adaptation Strategies for Global Change 23:257-290.

Zhang F, Chen JM, Pan Y, Birdsey R, Shen S, Ju W \& He L. 2012. Attributing carbon changes in conterminous U.S. forests to disturbance and non-disturbance factors from 1901-2010. Journal of Geophysical Research 117, G02021. 


\subsection{APPENDIX}

Data inputs and model results for individual ownerships in Pennsylvania

\subsection{Stand age}

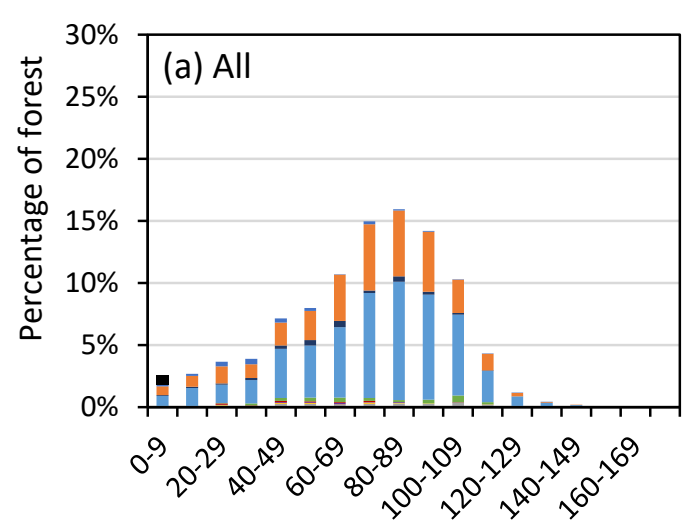

nonstocked

- Aspen/Birch

- Maple/Beech/Birch

- Elm/Ash/Cottonwood

- Oak/Hickory

Oak/Pine

- Exotic softwoods

- Loblolly/Shortleaf pine

Spruce/Fir

White/Red/Jack pine
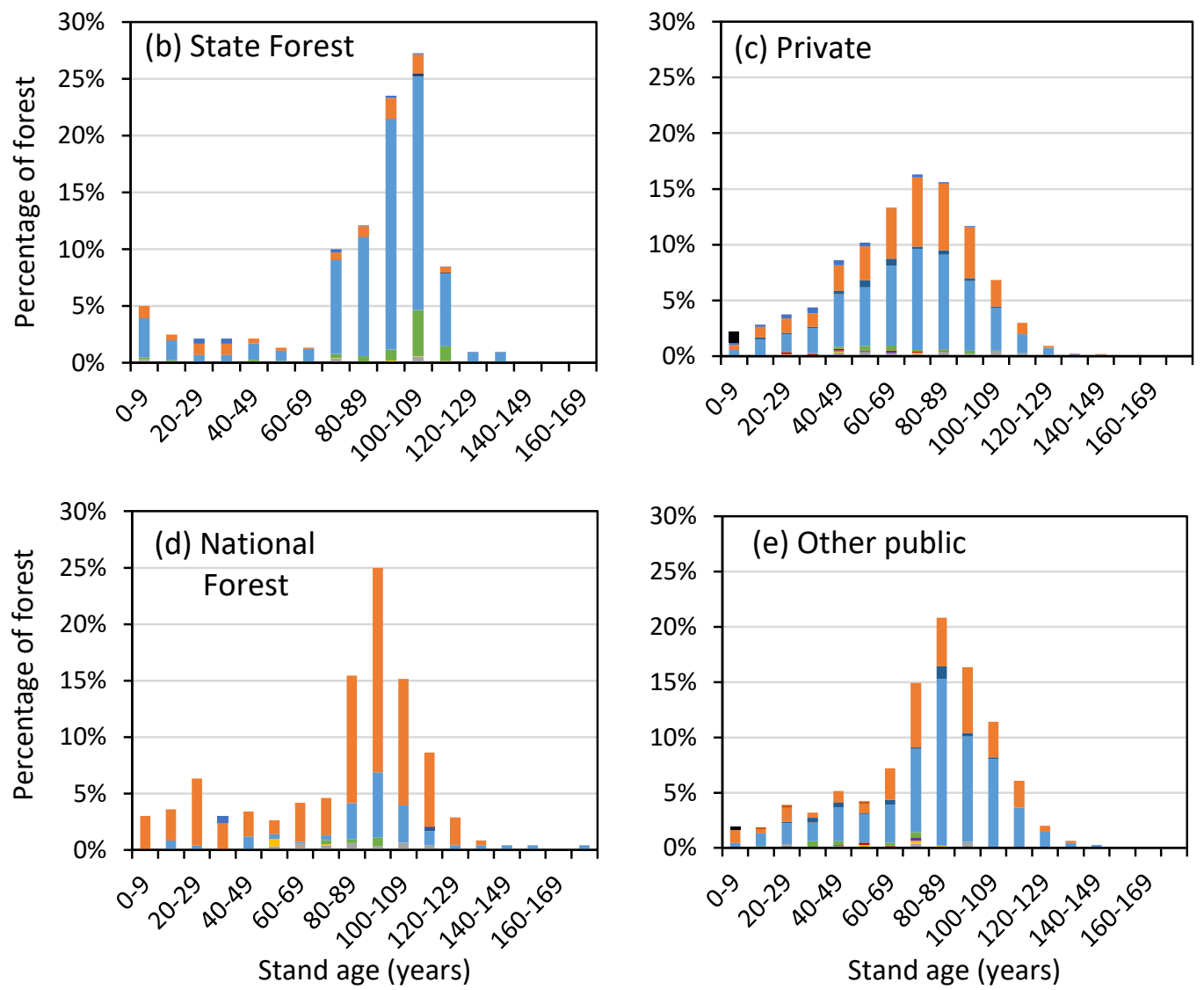

Figure A1. Stand age distribution by forest type group in 2015 for (a) all ownership classes, (b) State Forest lands, (c) Private lands, (d) National Forest (Allegheny), and (e) Other Public lands in Pennsylvania. 


\subsection{Growth and Yield Curves}
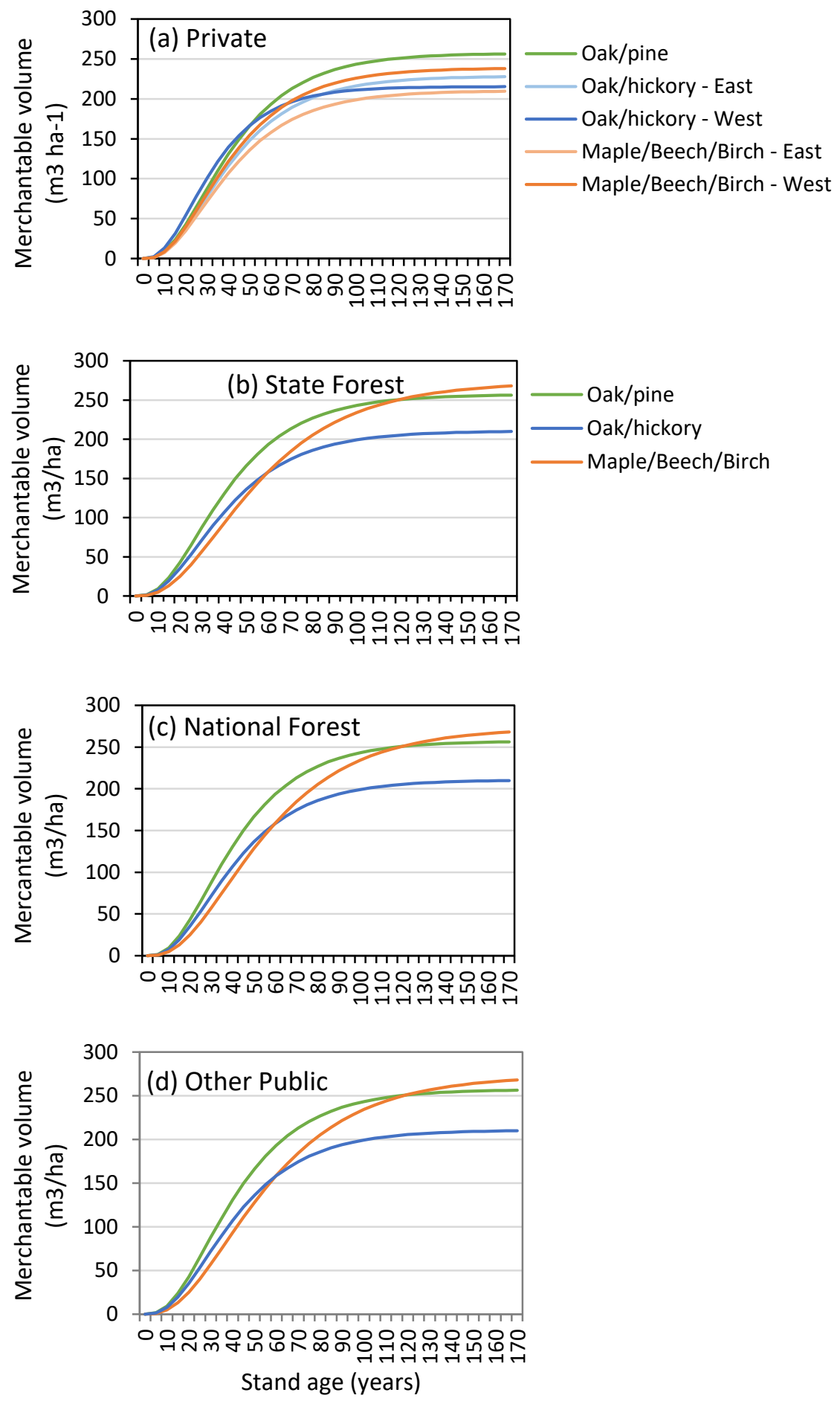

Figure A2. Growth and yield curves derived from forest inventory data for dominant forest types for (a) State Forest lands, (b) Private lands, (c) National Forest (Allegheny), and (d) Other Public lands in Pennsylvania. If there was a sufficient number of stands, regional (east, west) curves were developed for some forest types. 


\subsection{Forest ecosystem emissions with instantaneous oxidation of harvested wood}

Table A1. Estimated average annual net GHG emissions

$\left(\mathrm{CO}_{2} \mathrm{e}\right)$ and emissions per ha for the forest ecosystem

(INV $\left.V_{G H G}\right)$ from 1990 to 2017 by ownership class,

Pennsylvania. Negative values indicate a net sink. Estimates

include emissions from the removal of HWP as

instantaneous oxidation.

\begin{tabular}{lcc}
\hline & \multicolumn{2}{c}{$I N V_{G H G}$} \\
\hline Ownership & $\mathrm{MtCO}_{2} \mathrm{e}$ & $\begin{array}{c}\mathrm{MtCO}_{2} \mathrm{e} \text { per } \\
\text { ha }\end{array}$ \\
\hline State Forest & -1.05 & -1.27 \\
Private & -6.78 & -1.37 \\
National Forest & -0.49 & -2.39 \\
Other Public & -2.22 & -2.20 \\
\hline All owners & -10.55 & -1.51 \\
\hline
\end{tabular}

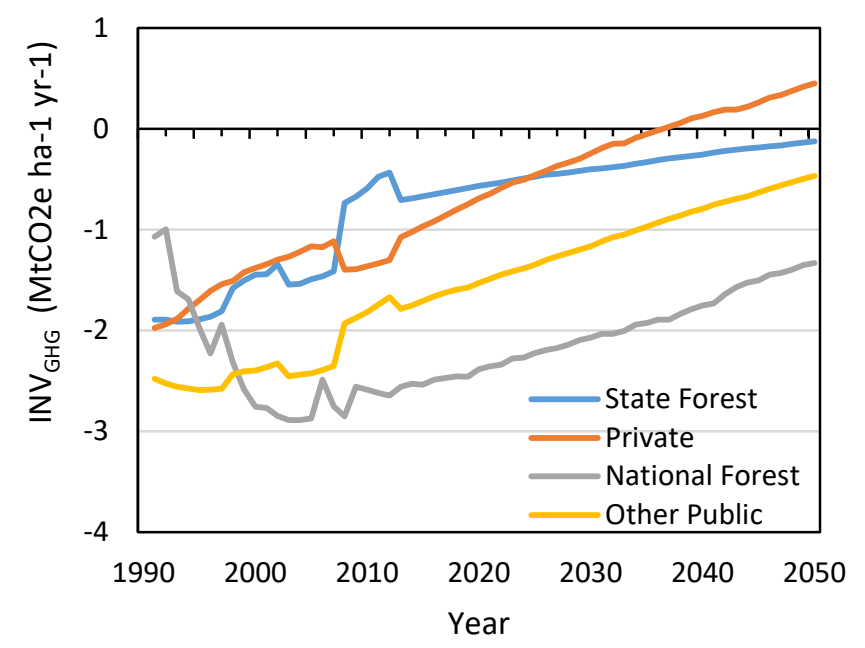

Figure A3. Modeled annual forest ecosystem emissions (MtCO2e) per ha by ownership class in Pennsylvania. A negative value indicates a net sink. Emissions include associated with HWP removal from the forest ecosystem were included. Estimates after roughly 2011 are projected. 


\subsection{Forest Sector Carbon Accumulation}
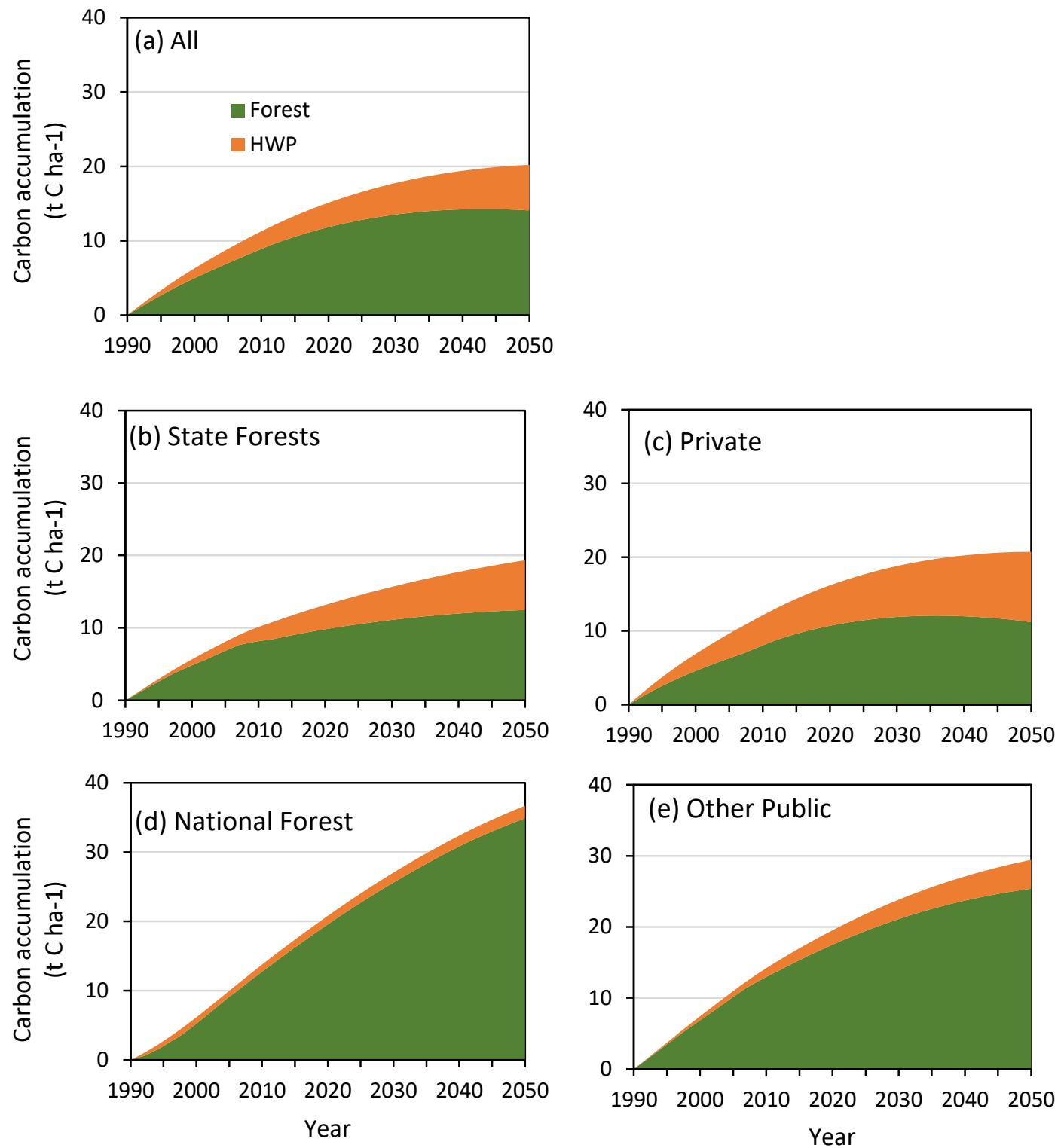

Figure A4. Modeled accumulated carbon (tonnes) per hectare from the forest ecosystem and harvested wood products (HWP) from 1990 to 2050 for (a) all ownership classes, (b) State Forest lands, (c) Private lands, (d) National Forest (Allegheny), and (e) Other Public lands in Pennsylvania. Estimates after roughly 2011 are projected. 


\subsection{Net Carbon Balance of the Forest Sector}
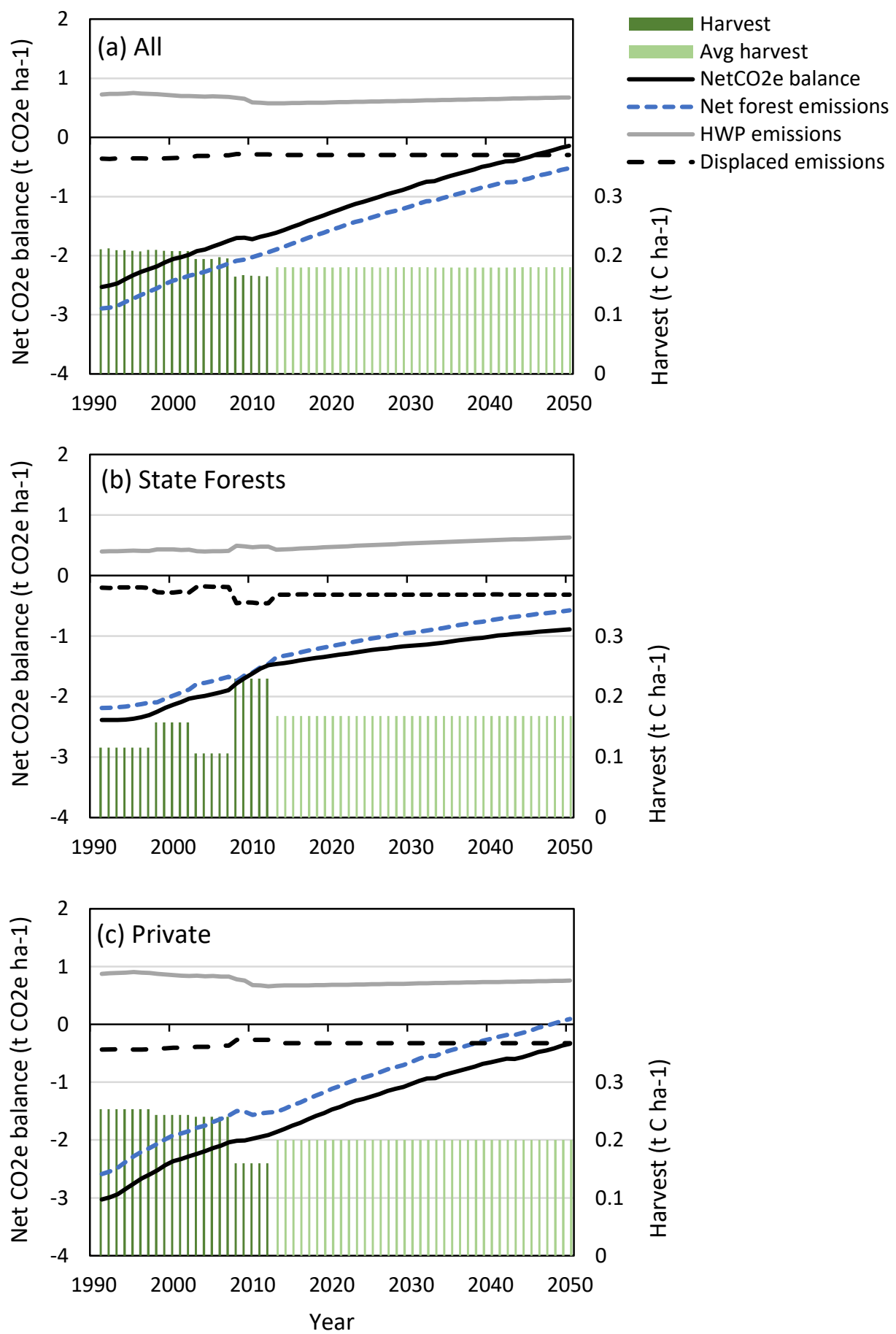

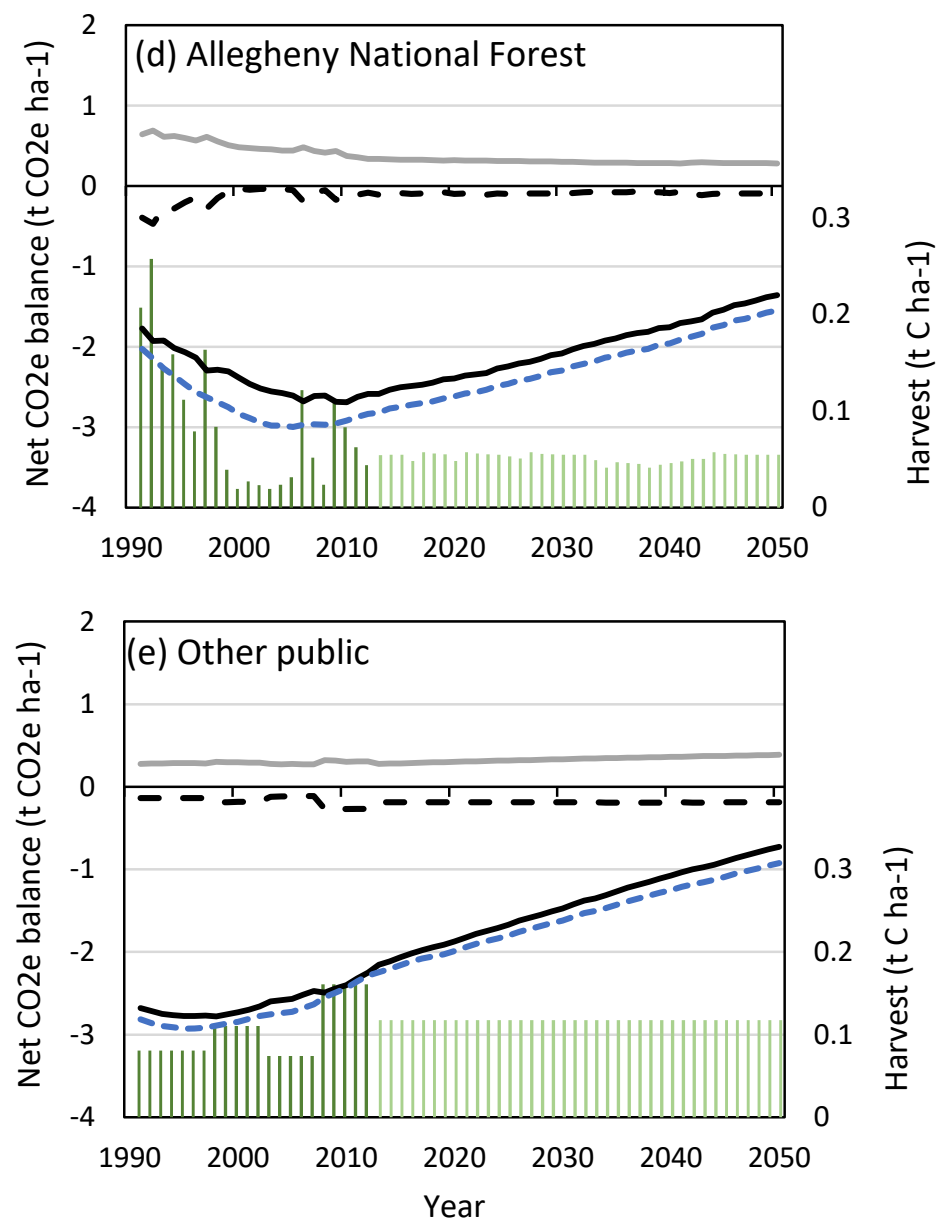

Figure A5. Annual CO2e balance (left axis), which is the sum of sequestration from the forest ecosystem, emissions from HWP sector, and displaced emissions from substituting wood products for other emission intensive materials and fossil fuels for (a) all ownerships, (b) State Forest lands, (c) Private lands, (d) National Forest (Allegheny), and (e) Other Public lands. A positive value indicates a net source and a negative value indicates a net sink. The historical harvest (t $C$ ha-1) per year are shown by the dark green bars and the 10-year average (2002-2011) harvest is shown by the light green bars (right axis). Estimates after roughly 2011 are projected. 


\subsection{Mitigation Scenarios}

\section{i. All ownerships}
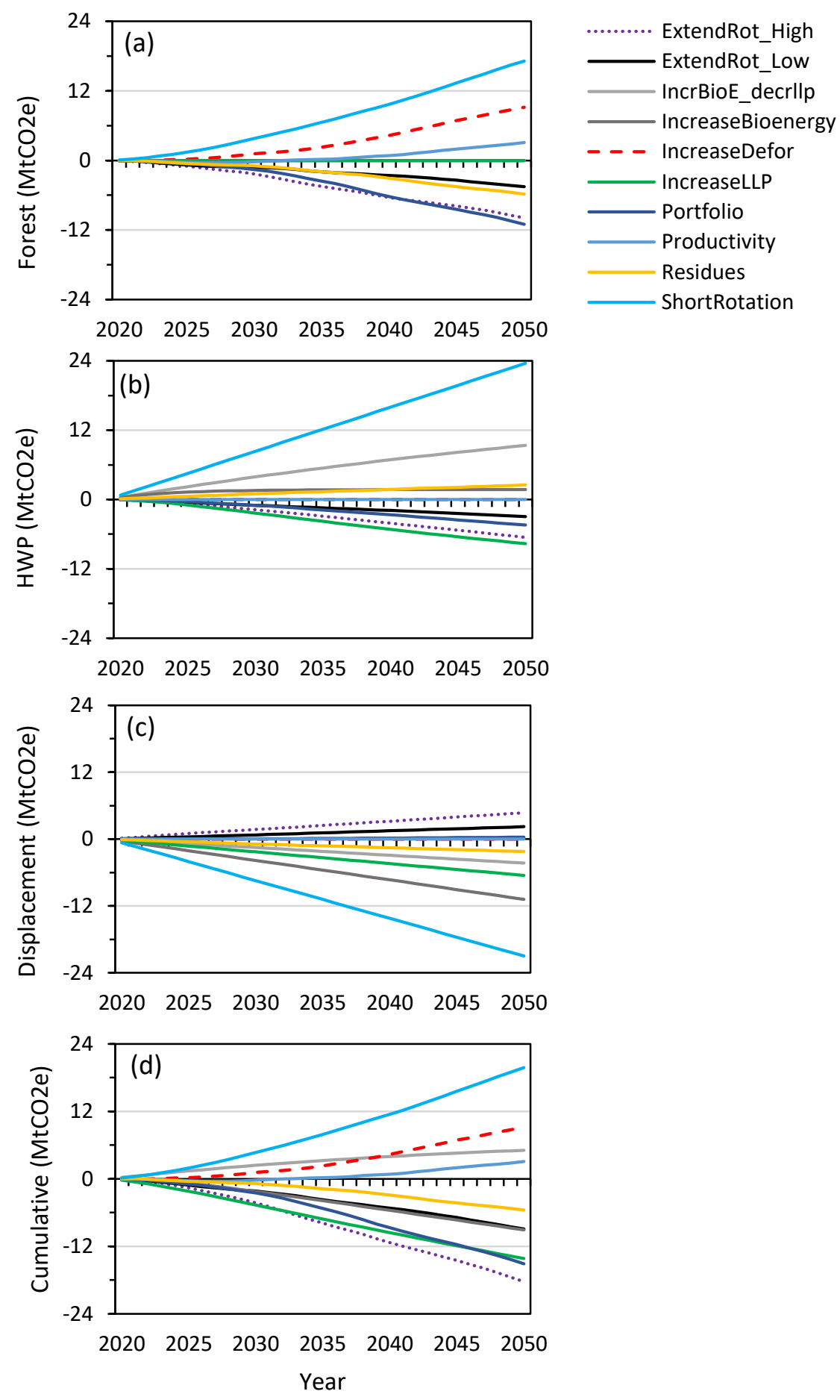

Figure A6i. Modeled cumulative mitigation for (a) forest ecosystem, (b) harvested wood products sector, (c) product and fossil fuel displacement, and (d) all components combined, from 2020 to 2050 for all ownership classes, Pennsy/vania. 


\section{ii. State Forest}
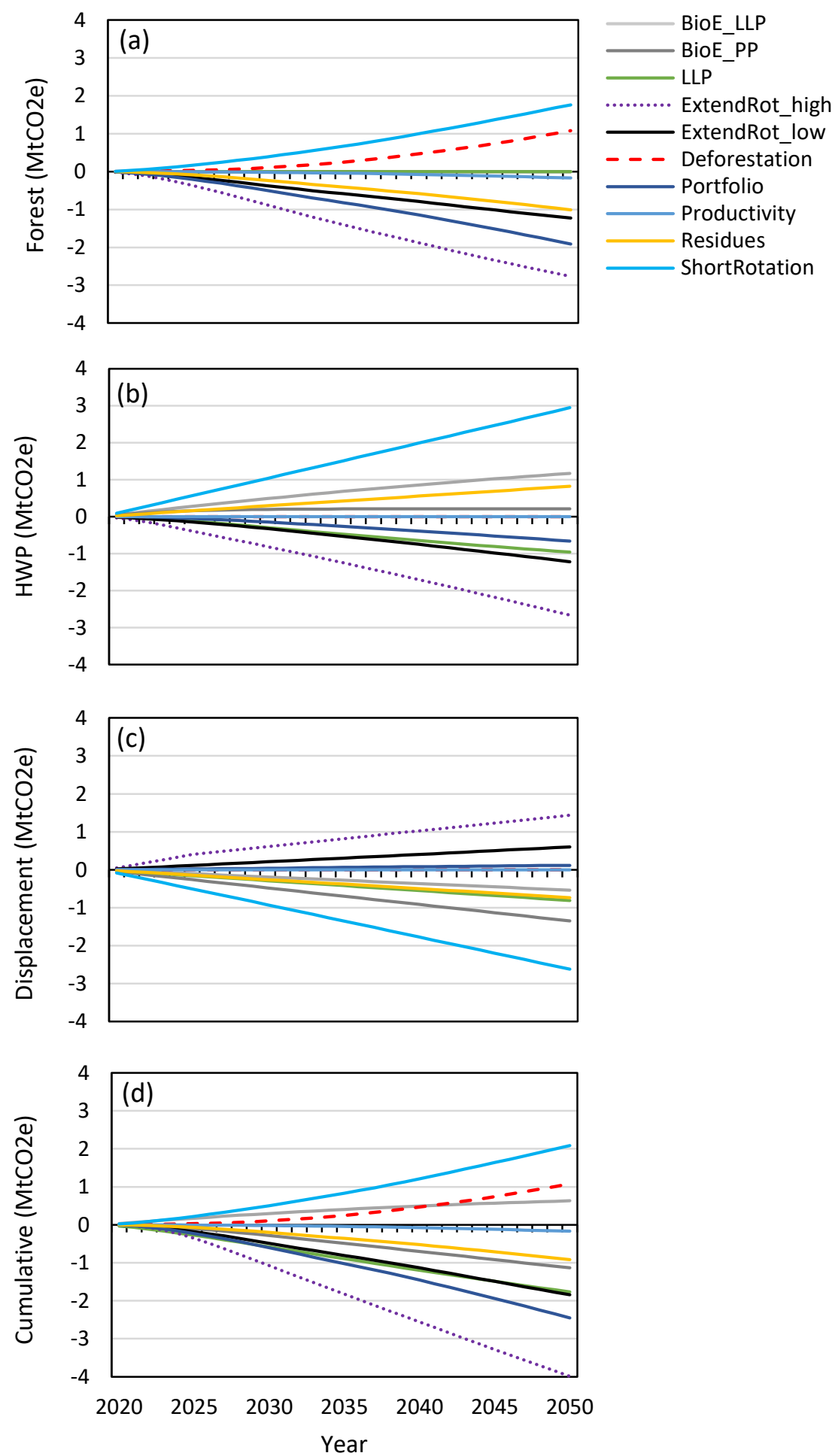

Figure A6ii. Modeled cumulative mitigation for (a) forest ecosystem, (b) harvested wood products sector, (c) product and fossil fuel displacement, and (d) all components combined, from 2020 to 2050 for State Forest lands, Pennsy/vania. 


\section{iii. Private Lands}
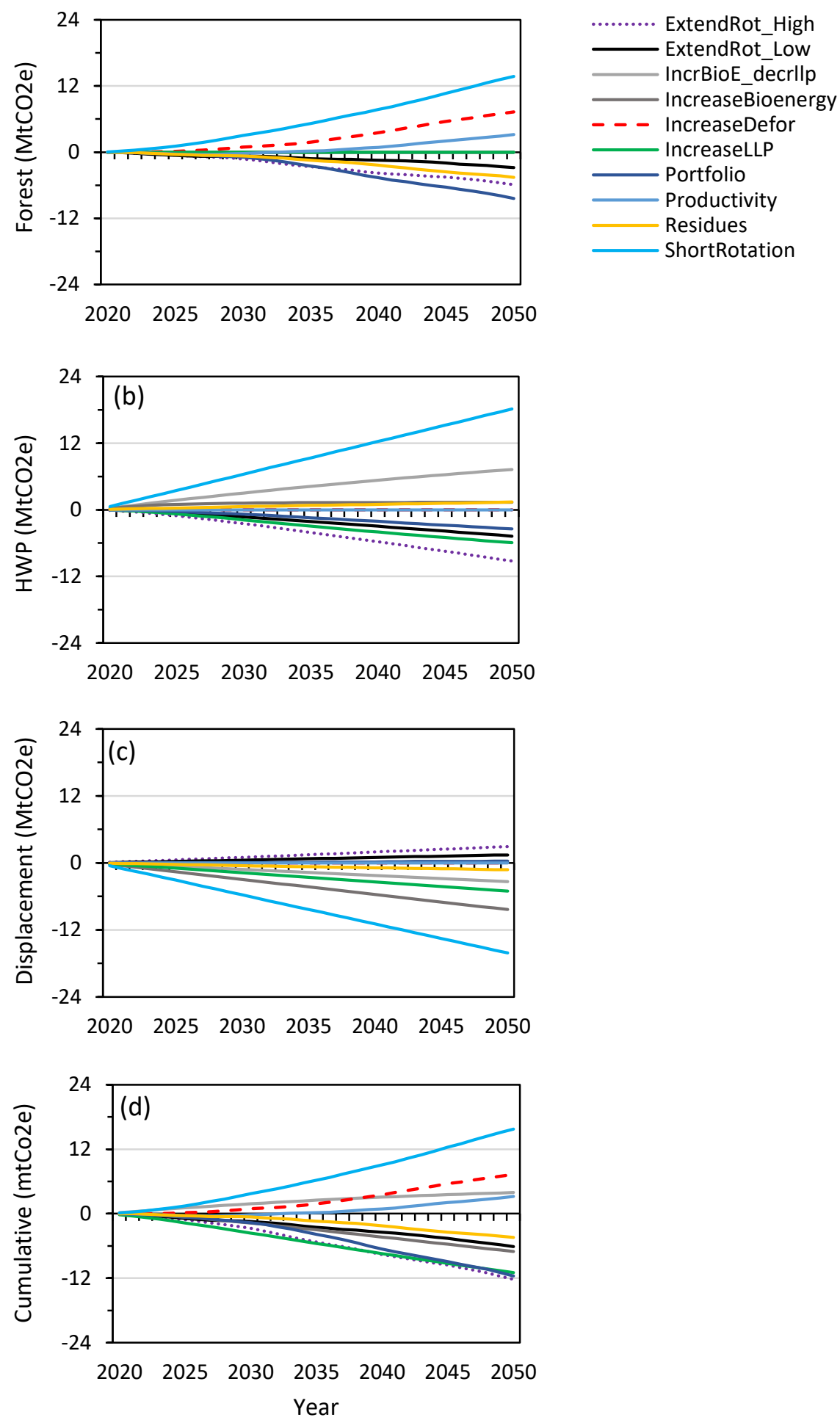

Figure A6iii. Modeled cumulative mitigation for (a) forest ecosystem, (b) harvested wood products sector, (c) product and fossil fuel displacement, and (d) all components combined, from 2020 to 2050 for Private lands, Pennsylvania. 


\section{iv. National Forest}
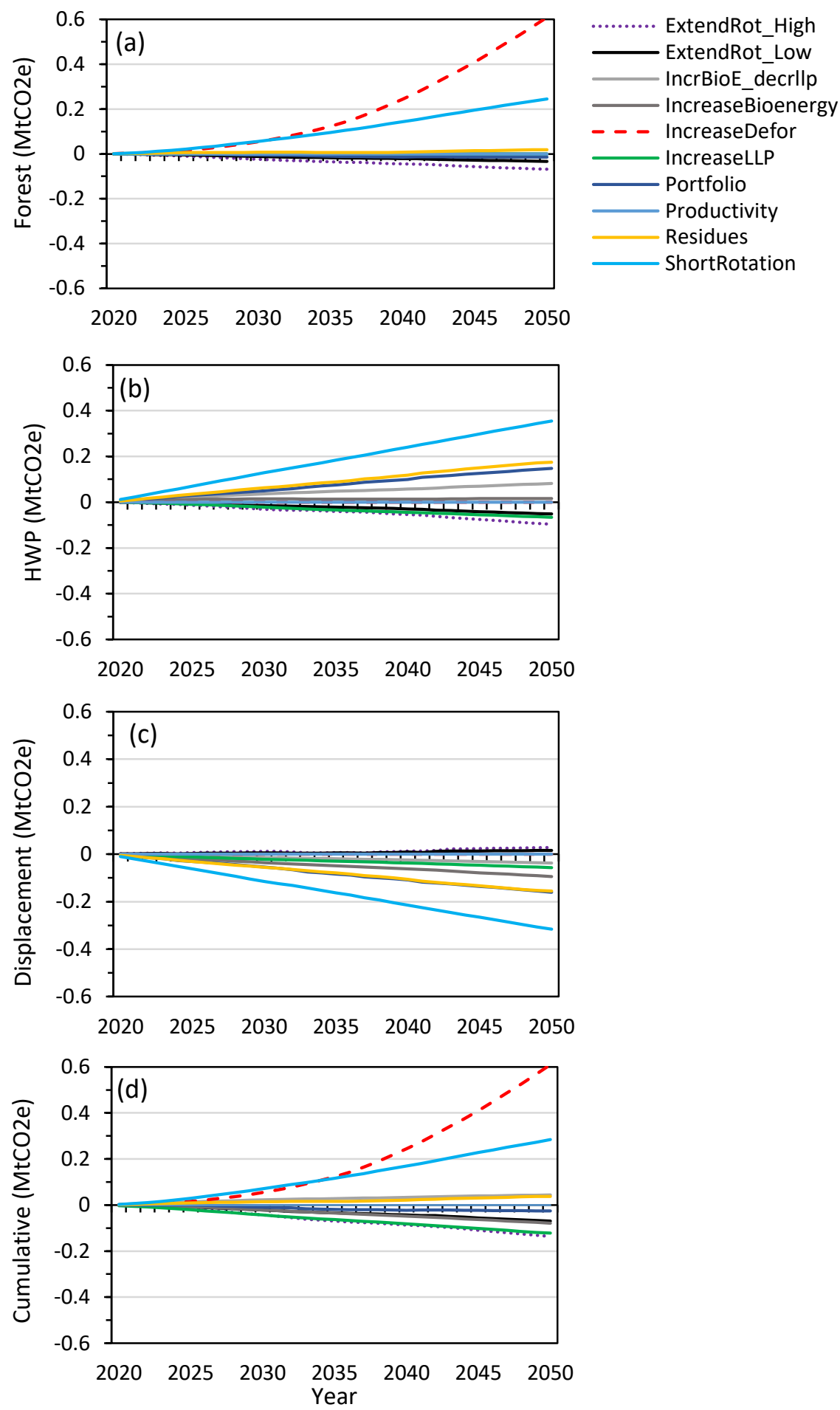

Figure A6iv. Modeled cumulative mitigation for (a) forest ecosystem, (b) harvested wood products sector, (c) product and fossil fuel displacement, and (d) all components combined, from 2020 to 2050 for Allegheny National Forest, Pennsylvania. 


\section{v. Other Public lands}
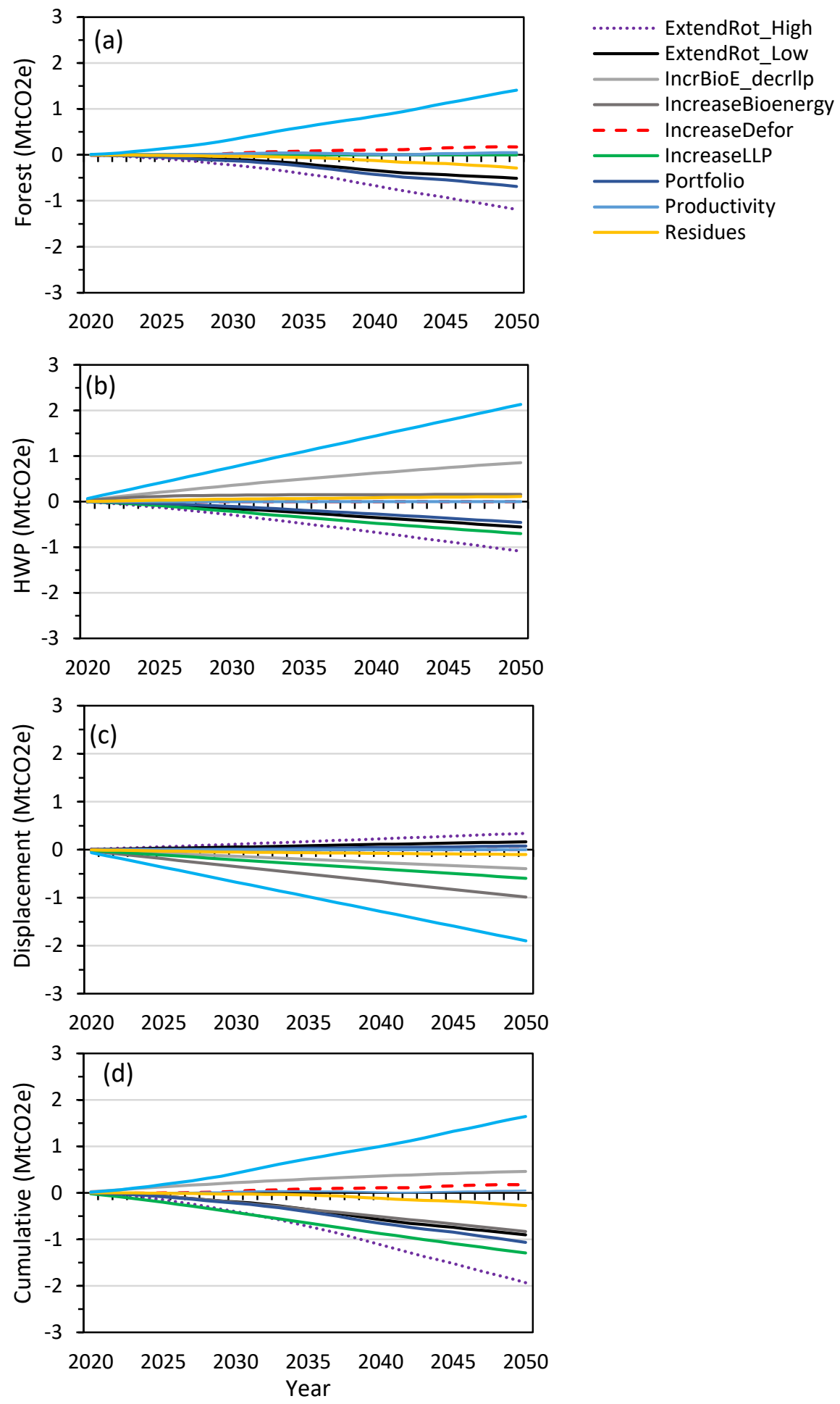

Figure A6v. Modeled cumulative mitigation for (a) forest ecosystem, (b) harvested wood products sector, (c) product and fossil fuel displacement, and (d) all components combined, from 2020 to 2050 for, Other Public lands, Pennsylvania. 


\subsection{Model Comparison: Forest Carbon Stocks}

There are many different modeling tools available for estimating forest ecosystem carbon stocks and trends. For this study, we selected the CBM-CFS3 model, which is a Canadian developed model that was parameterized with values and inventory data specific to Pennsylvania as has been done for applications in other countries (e.g. Pilli et al. 2013, Olguin et al. 2018, Dugan et al. in review). This model was selected because forest inventory data other than from the USFS Forest Inventory and Analysis (FIA) program can be easily integrated. This was an attractive quality given that we intended to utilize PA DCNR inventory data for State Forests. CBM also can incorporate high resolution and up to date disturbance data and is readily integrated with harvested wood products models making it a suitable model for this study.

To validate the use of the CBM model for PA, we compared model results to those of the Carbon Calculation Tool (CCT) (Smith et al. 2010; Woodall et al. 2011). CCT has been used by the U.S. for meeting national GHG inventory reporting required by the United Nation Framework Convention on Climate Change (UNFCCC). CCT is an empirical-based model that estimates total C stocks and C stock change by summarizing the available data using allometric equations and tree-level measurements). CCT estimates annual $\mathrm{C}$ stocks by linear interpolation between survey years and extrapolation to the past or present depending on the dates of the inventory data relative to the study period.

Unlike the CBM-CFS3 model, CCT applies a stock-change approach to C accounting, which estimates C stocks by linear interpolation between multiple inventory years (Smith et al. 2003, Woodall et al. 2011). We ran the CCT model for private lands, National Forest, and public lands. FIA data does not distinguish State Forest ownership from other state owned lands, thus State Forests were combined with the Other Public land ownership class. For the Allegheny National Forest in PA, we also compared results to those from the Integrated Terrestrial Ecosystem Carbon (InTEC) model, which is an ecosystem process model, that was run across the National Forest System as part of a related study (Dugan et al. 2017) and discussed in section 5.1.4. The FIA data only accounts for carbon in forested plots, thus we compared only the forest remaining forestland use class from CBM.

Results of the model comparison indicate that despite the different modeling approaches and datasets used CBM and CCT compare relatively well. Estimates for PA from both models show similar trends of increasing carbon stock density since 1990 (Fig. A7). Across all ownerships the CBM results are roughly 3-10\% higher than the CCT results. The largest discrepancies occur at the start of the simulation in 1990. For the Allegheny National Forest the InTEC process-based model produced reasonably similar $\mathrm{C}$ stock estimates, but shows a trend of decreasing $C$ stocks.

There are several factors causing these small discrepancies between model results. For example, FIA data used in the CCT model has a characteristic time lag as plots are only resampled every 5-7 years on eastern forests, causing more recent disturbances to be omitted from current $\mathrm{C}$ stock estimates. The CBM model also relies on the FIA data, which is used for the growth models, but incorporates high resolution, remotely-sensed maps of disturbances and land use change which are relatively current. Another source of differences between model estimates are the forested areas used by each model. Again because the CCT interpolates $\mathrm{C}$ stocks between available inventories, it incorporates inventory derived changes in forested area into these estimates. Due to changes in inventory design, parameters, and definitions, there may be some discrepancies between older estimates (pre-2000) and more recent $C$ estimates. Given these differences in modeling approaches and datasets utilized, discrepancies between carbon stock estimates between the two models are inevitable. Despite these differences, the results indicate reasonable comparable stock estimates and trends between models. 
(a) All owners

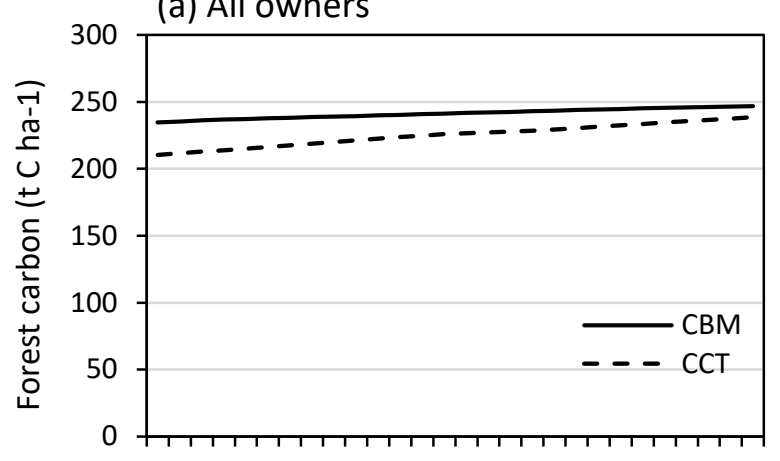

(c) Private

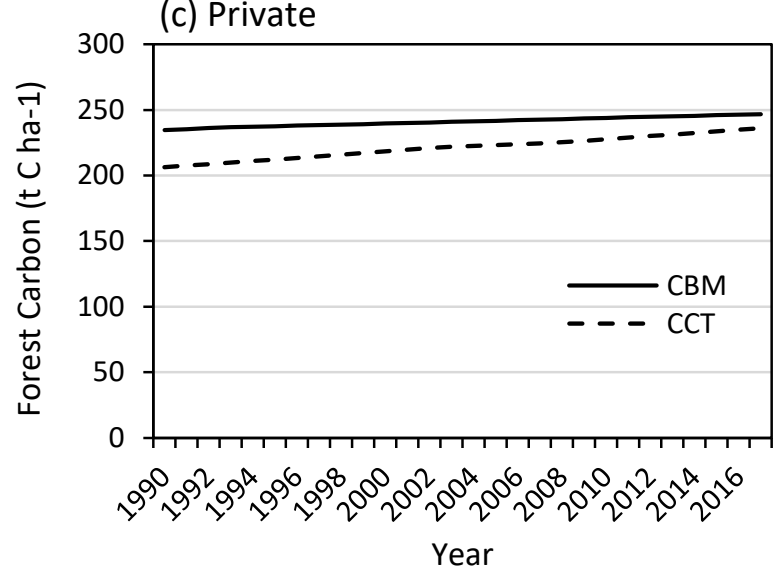

(b) State and Other Public

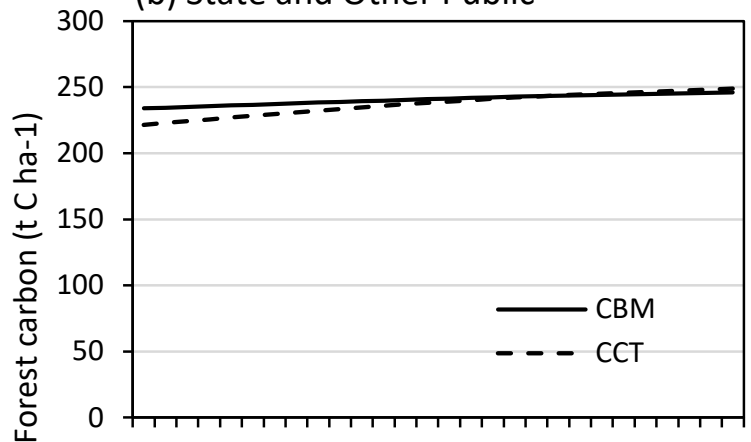

(d) National Forest

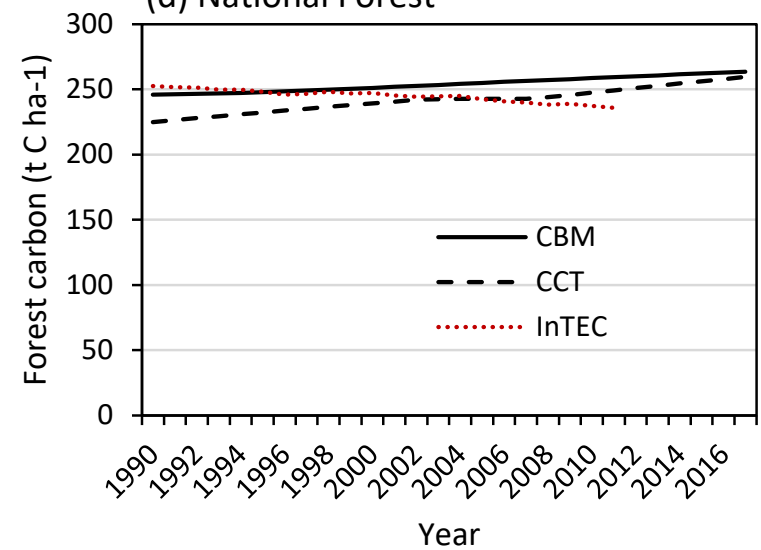

Figure A7. Comparison of total C stocks (Mg C ha-1) modeled using the Carbon Budget Model versus the Carbon Calculation Tool (Smith et al. 2010) for (a) all ownerships, (b) State Forests and Other Public lands, (c) private, and (d) National Forest (Allegheny) in Pennsylvania. For the Allegheny National Forest, we also compared results to those from the Integrated Terrestrial Ecosystem Carbon model (Dugan et al. 2017).

\subsection{Implementation mechanisms}

Financial incentives such as carbon offset credits, tax incentives, and direct subsidies may be effective means for achieving forest conservation and reductions in GHG emissions across the forest sector. For example, market-based approaches incentivize carbon stewardship through the sale of forest-based GHG offsets that counteract GHG emissions by compensating for equivalent emissions reductions. A carbon offset credit is equivalent to a metric tonne of $\mathrm{CO}_{2} \mathrm{e}$ of avoided emissions which are purchased by GHG emitters to compensate for emissions occurring elsewhere. Currently approved offset registries and standards award the following types of projects: avoided conversion of forest land (AC), afforestation or reforestation of nonforest land (A/R), and improved forest management (IFM) which may include increasing rotation ages, forest productivity, or stocking levels. 
One compliance market is governed under the California cap-and-trade program, the only economywide cap-and-trade program in the U.S., which requires the state's largest GHG emitters to meet the regulatory emission caps via emissions reductions or through the purchase of verified offset credits on the compliance market. The program which is overseen by the California Air Resources Board (ARB) has developed an emissions reductions target of $40 \%$ below 1990 levels by 2030 . Roughly $76 \%$ of offset projects approved under the ARB protocol are forestry projects and these projects may be conducted both across the U.S. and internationally. In addition to the California market, the Regional Greenhouse Gas Initiative (RGGI) which consists of 9 eastern states sets an overall multi-state-wide cap of the region's fossil fuel-fired power plant emissions via a similar cap-and trade system as California. Additionally, the voluntary market operates outside of these regulated markets and is driven by companies and individuals that value offsetting their own emissions.

Box 3 -To participate in the forest carbon offset market, projects must adhere to the following accounting criteria:

Additionality: The GHG emissions reductions are additional if they exceed those that would have occurred in the absence of the project and under a baseline "business-as-usual" scenario

Baselines: The expected sequestration or emissions that would occur without the project.

Leakage: An increase in GHG emissions or a decrease in sequestration outside the project boundaries.

Permanence: Refers to the longevity of the removal enhancement and that additional carbon sequestration may be reversed intentionally or unintentionally.

Although Pennsylvania does not currently take part in any mandatory cap-and-trade programs to reduce GHG emissions, landowners in the commonwealth may still participate in the compliance or voluntary carbon markets by contributing projects that generate offset credits. For instance, the Working Woodlands project organized by The Nature Conservancy rewards private landowners for forest conservation and sustainably harvested wood products in the form of offset revenue from the voluntary carbon market, which in turn is used to support improved carbon sequestration practices by participating landowners. However, the costs of preparing such offset projects for carbon trading are high given that they require extensive inventories and verification. Thus offset projects may be economically viable for larger land areas that are not typical of most of the private forest lands in PA. Furthermore, the compliance market typically does not yet include projects under public ownerships. Results here indicate that there exists substantial potential to reduce emissions using approved offset projects such as extending harvest rotations as a form of IFM. If mitigation activities like those evaluated here, which reduce emissions on the order of millions of tonnes $\mathrm{CO}_{2} \mathrm{e}$ are economically feasible and adhere to broader forest management objectives landowners in the Commonwealth have the potential to steer the state towards lower carbon emissions while generating revenue.

The product market can also incentivize climate change mitigation through the demand for wood. Research indicates that increasing the demand for wood increases investment in forestry in turn 
preventing the loss of forests or by promoting afforestation or reforestation (Lubowski et al. 2008; Nepal et al. 2014). Some studies suggest that the increasing wood demand for bioenergy could help expand forested area in the U.S. by 26.9 million acres by 2030 (Daigneault et al. 2012). However increased forest area does not always correlate to higher carbon stocks (USDA 2012). Policies mandating the shift to renewable energies such as the Renewable Energy Directive in Europe (EU 2009) and declaration of the carbon neutrality of biomass in the EU have increased the demand for woody biomass and is expected to continue over the next decade (Lamers et al. 2014; Dale et al. 2017). Officially, the U.S. federal government has declared that bioenergy is carbon neutral. This move could change the amount of wood used for bioenergy in the U.S., although this will depend on the relative prices of wood and other energy sources. It is important to consider that the carbon neutrality of bioenergy may also depend on the timeframe of desired emission reductions, as well as the bioenergy feedstock (residues, live trees) (Smyth et al. 2014, Ter Mikaelian et al. 2015, Birdsey et al. 2018, Schlesinger 2018, Dugan et al. in review).

In addition to market-based programs and policies, non-market policies can also influence landowner behavior and incentivize forest sector climate change mitigation. For instance to reduce deforestation or increase reforestation, Maryland's No-Net-Loss of Forest Policy (MD Nat Res Code $\S 5-104,2013$ ) which established new reforestation incentives to maintain the states $40 \%$ tree canopy, will help to offset $C$ losses associated with deforestation. Other state-level policies like Minnesota's Sustainable Forest Incentive Program (Minn. Stat. §§290C.01 et seq) provides incentive payments to private landowners who agree not to develop land and to follow sustainable forest management plans. Federal programs like the Forest Legacy Program and Community Forest Program, which support the acquisition of conservation easements on public and private lands, can also help to achieve GHG emission reduction. 